\title{
The Business Case for Systems Engineering: Comparison of Defense- Domain and Non-Defense Projects
}

\author{
Joseph P. Elm \\ Dennis R. Goldenson \\ June 2014 \\ SPECIAL REPORT \\ CMU/SEI-2014-SR-013 \\ Software Solutions Division
}

http://www.sei.cmu.edu

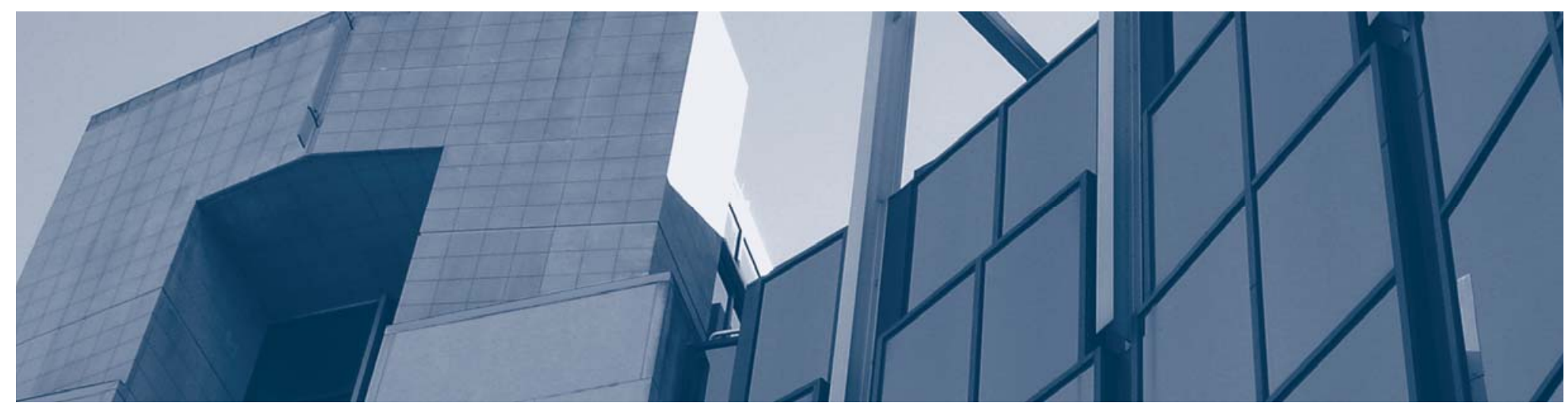

Carnegie Vellon University 
Copyright 2014 Carnegie Mellon University

This material is based upon work funded and supported by the Department of Defense under Contract No. FA8721-05-C-0003 with Carnegie Mellon University for the operation of the Software Engineering Institute, a federally funded research and development center.

This report was prepared for the

SEI Administrative Agent

AFLCMC/PZM

20 Schilling Circle, Bldg 1305, 3rd floor

Hanscom AFB, MA 01731-2125

NO WARRANTY. THIS CARNEGIE MELLON UNIVERSITY AND SOFTWARE

ENGINEERING INSTITUTE MATERIAL IS FURNISHED ON AN “AS-IS” BASIS.

CARNEGIE MELLON UNIVERSITY MAKES NO WARRANTIES OF ANY KIND, EITHER EXPRESSED OR IMPLIED, AS TO ANY MATTER INCLUDING, BUT NOT LIMITED TO, WARRANTY OF FITNESS FOR PURPOSE OR MERCHANTABILITY, EXCLUSIVITY, OR RESULTS OBTAINED FROM USE OF THE MATERIAL. CARNEGIE MELLON UNIVERSITY DOES NOT MAKE ANY WARRANTY OF ANY KIND WITH RESPECT TO FREEDOM FROM PATENT, TRADEMARK, OR COPYRIGHT INFRINGEMENT.

This material has been approved for public release and unlimited distribution except as restricted below.

Internal use:* Permission to reproduce this material and to prepare derivative works from this material for internal use is granted, provided the copyright and "No Warranty" statements are included with all reproductions and derivative works.

External use:* This material may be reproduced in its entirety, without modification, and freely distributed in written or electronic form without requesting formal permission. Permission is required for any other external and/or commercial use. Requests for permission should be directed to the Software Engineering Institute at permission@sei.cmu.edu.

* These restrictions do not apply to U.S. government entities.

$\mathrm{CMMI}^{\circledR}$ is registered in the U.S. Patent and Trademark Office by Carnegie Mellon University.

DM-0001238 


\section{Table of Contents}

Acknowledgments $\quad$ vii

$\begin{array}{ll}\text { Executive Summary } & \text { ix }\end{array}$

$\begin{array}{ll}\text { Abstract } & \text { xiii }\end{array}$

1 Introduction 1

$\begin{array}{lll}1.1 & \text { Purpose } & 1\end{array}$

1.2 Background 1

1.2.1 Developing the SE Effectiveness Survey 1

1.2.2 Executing the SE Effectiveness Survey 2

$\begin{array}{lll}1.2 .3 & \text { Survey Data Analysis } & 2\end{array}$

$\begin{array}{lll}\text { 1.2.3.1 Scoring } & 2\end{array}$

1.2.3.2 Identifying Relationships 3

1.2.4 Initial Results of the SE Effectiveness Survey Results 4

$\begin{array}{lll}1.3 & \text { Defense vs. Non-Defense Projects } & 7\end{array}$

2 Comparison of Projects in the Defense and Non-Defense Domains $\quad 8$

2.1 Project Characteristics $r$

2.2 Project Challenge $\quad 10$

2.2.1 Compensating for Differences in Project Challenge 12

$\begin{array}{lll}2.3 & \text { Project Performance } & 13\end{array}$

2.4 Systems Engineering Capabilities 16

2.4.1 Systems Engineering Process Areas 16

2.4.1.1 Project Planning 16

2.4.1.2 Verification 17

2.4.1.3 Project Monitoring and Control 18

2.4.1.4 Requirements Development and Management 19

2.4.1.5 Trade Studies $\quad 20$

2.4.1.6 Validation $\quad 21$

2.4.1.7 Product Integration 22

2.4.1.8 Configuration Management $\quad 24$

2.4.1.9 Product Architecture $\quad 25$

2.4.1.10 Integrated Product Teams 26

2.4.1.11 Risk Management $\quad 27$

2.4.2 Composite Systems Engineering Capabilities 28

2.4.2.1 Total Systems Engineering Capability 28

2.4.2.2 Early Systems Engineering $\quad 30$

$\begin{array}{lll}2.5 & \text { Experience } & 31\end{array}$

$3 \quad$ Summary and Conclusions $\quad 33$

$\begin{array}{lll}3.1 & \text { Summary } & 33\end{array}$

$\begin{array}{lll}3.2 & \text { Conclusions } & 37\end{array}$

$\begin{array}{llr}4 & \text { Next Steps } & 38\end{array}$

$\begin{array}{lll}\text { Appendix A Work Products Used to Assess SE Deployment } & 39\end{array}$

$\begin{array}{lll}\text { Appendix B } & \text { Acronyms and Abbreviations } & 40\end{array}$

$\begin{array}{lr}\text { References } & 41\end{array}$ 
CMU/SEI-2014-SR-013 | ii 


\section{List of Figures}

Figure 1: Project Performance Comparison $\quad$ ix

Figure 2: $\quad$ SE Deployment Comparison $\quad$ X

Figure 3: $\quad$ Perf vs. SEC Relationship Comparisons $\quad$ xi

Figure 4: $\quad$ Mosaic Chart Key $r$

Figure 5: Response Demographics $\quad 5$

Figure 6: $\quad$ Project Performance vs. Total SE Capability $\quad 5$

Figure 7: $\quad$ Project Performance vs. Total SE Capability Controlled by Project Challenge 6

Figure 8: $\quad$ Project Performance vs. SE Deployment $\quad 6$

$\begin{array}{lll}\text { Figure 9: } \quad \text { Industry and End User } & 7\end{array}$

Figure 10: Contract Value $\quad 8$

Figure 11: Contract Duration $\quad 8$

Figure 12: Current Completion Status $\quad 9$

Figure 13: Percentage of Customer Technical Requirements Marked “TBD” at Contract Award 9

Figure 14: Percentage of Customer Technical Requirements Currently Marked “TBD” 10

Figure 15: SE Percentage of Non-Recurring Engineering 10

Figure 16: PC Response Distribution 11

$\begin{array}{ll}\text { Figure 17: } P C \text { vs. Perf } & 11\end{array}$

Figure 18: $\quad$ Adjusted PC Response Distribution 12

$\begin{array}{ll}\text { Figure 19: } & \text { Adjusted PC vs. Perf }\end{array}$

Figure 20: Project Performance Response Distribution 13

\begin{tabular}{ll} 
Figure 21: & Performance Subfactor Distributions \\
\hline
\end{tabular}

$\begin{array}{ll}\text { Figure 22: } \quad \text { Project Performance Comparison } & 15\end{array}$

Figure 23: Perf Cumulative Response Distribution 15

Figure 24: SEC-PP Response Distribution 16

\begin{tabular}{ll} 
Figure 25: & SEC-PP vs. Perf \\
\hline
\end{tabular}

$\begin{array}{ll}\text { Figure 26: } & \text { SEC-VER Response Distribution } \\ \end{array}$

$\begin{array}{ll}\text { Figure 27: SEC-VER vs. Perf } & 18\end{array}$

$\begin{array}{ll}\text { Figure 28: } & 18\end{array}$

Figure 29: SEC-PMC vs. Perf 19

Figure 30: SEC-REQ Response Distribution 19

\begin{tabular}{ll} 
Figure 31: & SEC-REQ vs. Perf \\
\hline
\end{tabular}

\begin{tabular}{ll} 
Figure 32: & SEC-TRD Response Distribution \\
\hline
\end{tabular}

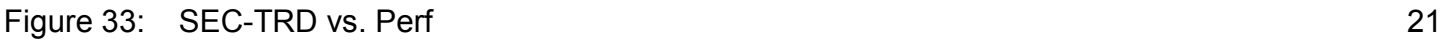


Figure 34: SEC-VAL Response Distribution $\quad 22$

\begin{tabular}{ll} 
Figure 35: & SEC-VAL vs. Perf \\
\hline
\end{tabular}

Figure 36: $\quad$ SEC-PI Response Distribution 23

\begin{tabular}{ll} 
Figure 37: & SEC-PI vs. Perf \\
\hline
\end{tabular}

Figure 38: SEC-CM Response Distribution $\quad 24$

\begin{tabular}{ll} 
Figure 39: & SEC-CM vs. Perf \\
\hline
\end{tabular}

Figure 40: $\quad$ SEC-ARCH Response Distribution $\quad 25$

$\begin{array}{ll}\text { Figure 41: SEC-ARCH vs. Perf } & 26\end{array}$

Figure 42: $\quad$ SEC-IPT Response Distribution $\quad 26$

\begin{tabular}{ll} 
Figure 43: & SEC-IPT vs. Perf \\
\hline
\end{tabular}

Figure 44: $\quad$ SEC-RSKM Response Distribution $\quad 27$

$\begin{array}{llr}\text { Figure 45: } & \text { SEC-RSKM vs. Perf } & 28\end{array}$

Figure 46: SEC-Total Response Distribution $\quad 29$

\begin{tabular}{ll} 
Figure 47: & SEC-Total vs. Perf \\
\hline
\end{tabular}

Figure 48: $\quad$ Early SE Response Distribution $\quad 30$

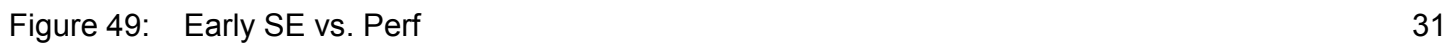

Figure 50: $\quad$ Experience Response Distribution 31

Figure 51: Performance vs. Experience $\quad 32$

Figure 52: Project Performance Comparison $\quad 34$

Figure 53: SE Deployment Comparison $\quad 35$

Figure 54: $\quad$ Perf vs. SEC Relationship Comparisons 36 


\section{List of Tables}

Table 1: Stronger SE Process Areas $\quad$ xi

Table 2: Project Performance Comparison $\quad 33$

Table 3: $\quad$ SE Deployment Comparison $\quad 34$

Table 4: $\quad$ Perf vs. SEC Relationship Comparisons 36

Table 5: $\quad$ Stronger SE Process Areas $\quad 37$

Table 6: $\quad$ Notably Stronger Non-Defense Relationships $\quad 37$ 
CMU/SEI-2014-SR-013 | vi 


\section{Acknowledgments}

We created this report based on the collaborative efforts of the National Defense Industrial Association (NDIA) Systems Engineering Division, the Institute of Electrical and Electronic Engineers (IEEE) Aerospace and Electronic Systems Society, the Carnegie Mellon Software Engineering Institute, and the Systems Engineering Effectiveness Working Group of the International Council on Systems Engineering (INCOSE).

We offer our sincere appreciation to the members of the NDIA-IEEE-SEI SE Effectiveness Committee and the members of the INCOSE SE Effectiveness Committee. 
CMU/SEI-2014-SR-013 | viii 


\section{Executive Summary}

In 2011 and 2012, the National Defense Industrial Association (NDIA) Systems Engineering Division collaborated with the Institute of Electrical and Electronic Engineers (IEEE) Aerospace and Electronic Systems Society and the Carnegie Mellon ${ }^{\circledR}$ Software Engineering Institute (SEI) to obtain quantitative evidence of the benefits of systems engineering (SE) best practices on project performance. The team developed and executed a survey of system developers to identify SE best practices used on projects, collect performance data on these projects, and identify relationships between the application of these SE best practices and project performance. Results of this study were published in 2012 and 2013 [Elm 2012b, 2013]. The study found clear and significant relationships between the application of SE best practices to projects and the performance of those projects.

The data collected for the survey was provided by projects operating in the defense domain as well as projects from non-defense domains. This distribution of data enabled us to compare and contrast both the deployment of SE activities in the two domains and the impact of those SE activities. Our intent is to identify similarities and differences between the domains that can be instructive in the effective application of SE.

We found that the performance (Perf) of the projects - as measured on a scale of 1 (poor performance) to 5 (good performance) based on satisfaction of budget (PerfC), schedule (PerfS), and technical requirements (PerfT) - was better for non-defense projects than for defense projects. Figure 1 shows the median values for these performance assessments.

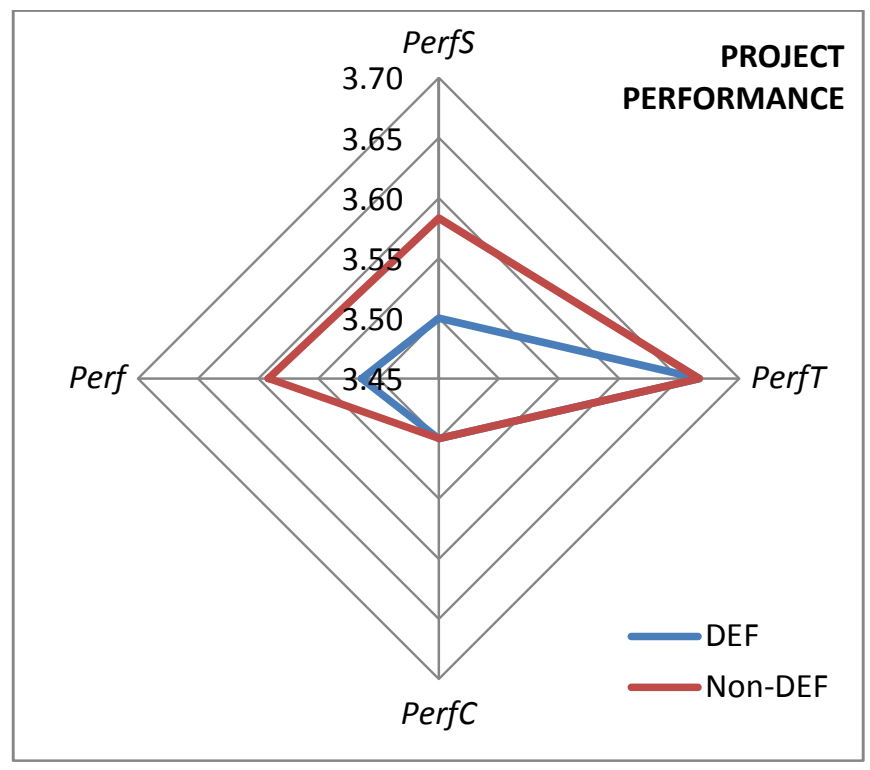

Figure 1: Project Performance Comparison

We also examined the degree of project challenge $(P C)$ posed by the projects, measured on a scale of 1 (low challenge) to 4 (high challenge). To temper the impact of $P C$ on project performance,

${ }^{\circledR} \quad$ Carnegie Mellon is registered in the U.S. Patent and Trademark Office by Carnegie Mellon University. 
we adjusted our sample to include only a subsample of defense projects that had the same median $P C($ median $=2.61)$ as the non-defense projects.

Finally, we examined the deployment of SE practices in a number of SE process areas. The deployment was measured on a scale of 1 (little SE deployment) to 4 (much SE deployment). Here, we found some differences between the defense and the non-defense domains, as shown in Figure 2 .

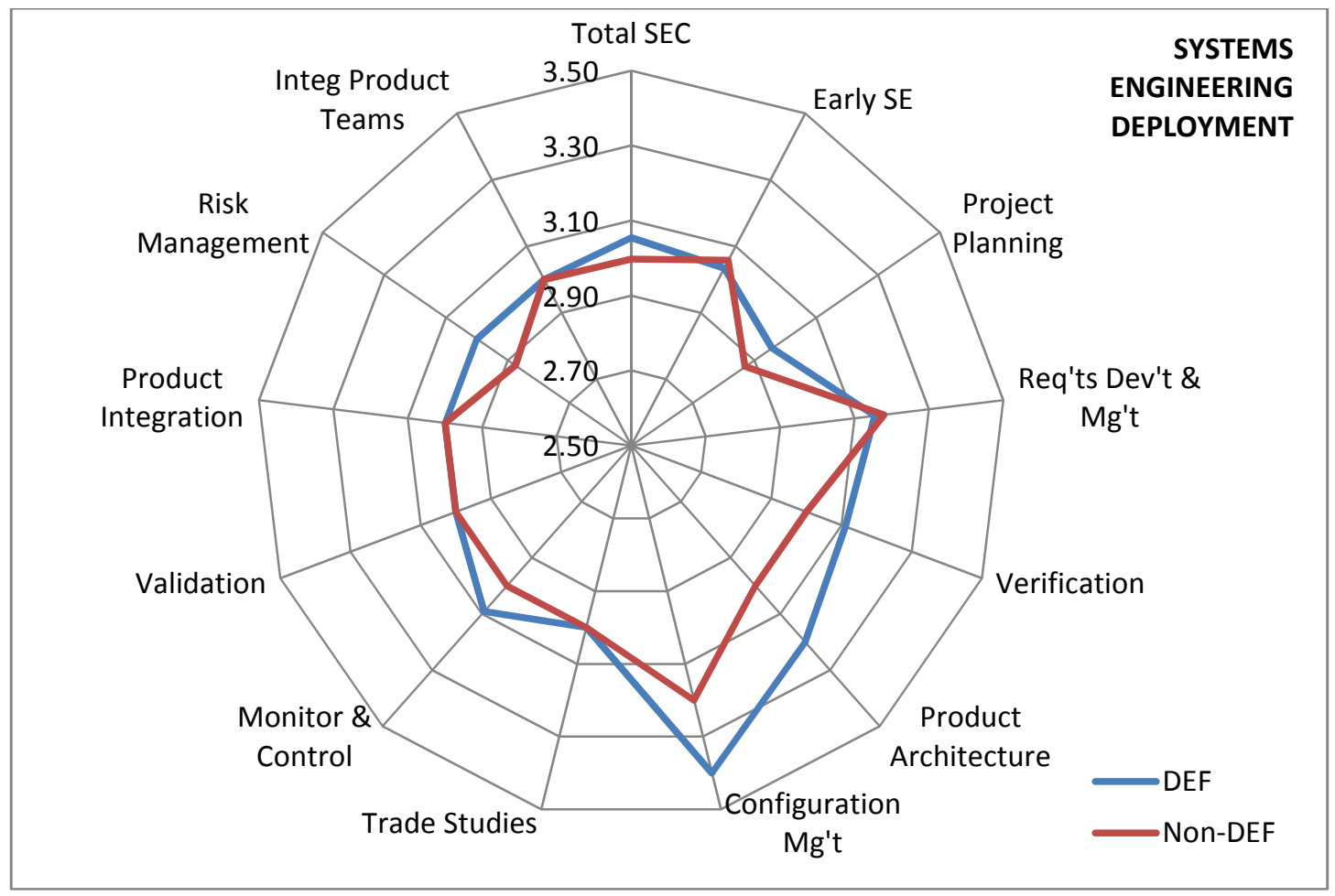

Figure 2: SE Deployment Comparison

Figure 2 shows that in nearly all SE process areas except (1) Early SE and (2) Requirements Development and Management, the SE capabilities (SEC) deployed by the defense projects were greater than or equal to those deployed by the non-defense projects. While most of the differences appear to be modest, the probability that 10 of the 13 would be better for the non-defense projects by chance alone is unlikely ( $p<0.02$ using a simple sign test).

We then examined the relationships between the deployed SE activities and project performance, using Goodman and Kruskal's gamma to quantify the strength of the relationships. A gamma value near -1 indicates a very strong opposing relationship; a value near 0 indicates a weak or nonexistent relationship; and a value near +1 indicates a very strong supporting relationship. These relationships are summarized in Figure 3. 


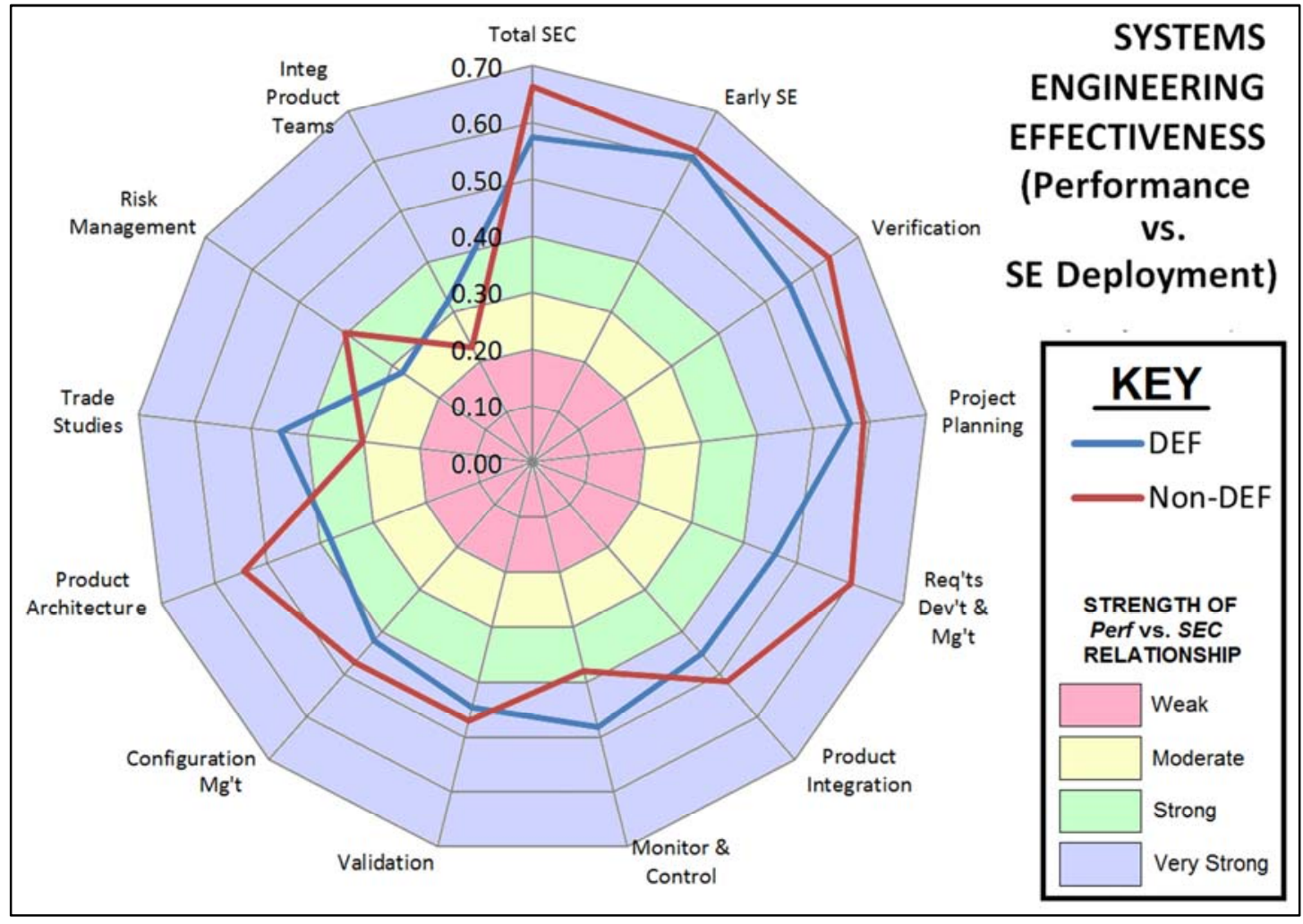

Figure 3: Perf vs. SEC Relationship Comparisons

In Figure 3 and Table 1, we see that 10 of the 13 relationships are stronger for non-defense projects than they are for defense projects. The probability that 10 of the 13 would be stronger for the defense projects by chance alone is, again, unlikely ( $p<0.02$ using a simple sign test).

Table 1: Stronger SE Process Areas

\begin{tabular}{|l|l|}
\hline $\begin{array}{l}\text { Stronger Perf vs. SEC Relationships } \\
\text { for Defense Projects }\end{array}$ & $\begin{array}{l}\text { Stronger Perf vs. SEC Relationships } \\
\text { for Non-Defense Projects }\end{array}$ \\
\hline - Project Monitoring and Control & - Total SE \\
- Trade Studies & - Early SE \\
- Integrated Product Teams & - Verification \\
& - Project Planning \\
& - Requirements Development and Management \\
& - Product Integration \\
& - Validation \\
& - Configuration Management \\
& - Rroduct Architecture \\
\hline
\end{tabular}

We also found a significant difference in the impact of prior experience on project performance, with a weak positive relationship (gamma $=0.09$ ) between prior experience $(E X P)$ and Perf for the defense-domain projects but a very strong positive relationship (gamma $=0.54$ ) for the nondefense projects. The difference in the magnitude of the relationship between defense and nondefense projects indicates that experience has a far greater impact on non-defense projects than it has on defense projects. 
In summary, our data shows that non-defense projects deploy less SE than defense projects, yet achieve better performance. We find that the relationships between SE deployment and project performance for most SE process areas are stronger for non-defense projects than they are for defense projects. Thus, even though the non-defense projects deploy less SE, they gain more benefit from it, contributing to better project performance.

Of particular consequence are the SE process areas of Product Architecture, Requirements Development and Management, and Risk Management. These process areas show notably stronger relationships for non-defense projects than for defense projects. Understanding the implementation of these SE activities in non-defense projects and adopting these practices for defense projects could produce significant improvements in the performance of defense-domain projects.

However, we also note several areas where activities in defense-domain projects show stronger relationships to project performance. Defense projects show a considerably stronger relationship between Trade Studies and project performance. Additionally, the performance of defense projects appears to be notably less influenced by project challenge than non-defense projects. Understanding the reasons behind these relationships in the defense domain and adopting them for nondefense projects could produce significant improvements in the performance of non-defense projects.

Our data clearly shows the differences in SE deployment and the impact of that SE deployment in the defense and non-defense domains. Unfortunately, since our data collection was focused only on quantifying deployment and relationships, it cannot explain why these differences exist.

We plan to perform additional research to further investigate the effectiveness of Product Architecture, Requirements Development and Management, and Risk Management activities in nondefense projects and Trade Study activities in defense-domain projects. We will also investigate factors that make defense-domain projects less sensitive than non-defense projects to project challenge.

The results of these investigations will benefit both domains by enabling them to share best practices. 


\section{Abstract}

This report summarizes analysis of data collected from the 2011 Systems Engineering (SE) Effectiveness Survey performed by the National Defense Industrial Association Systems Engineering Division, the Institute of Electrical and Electronics Engineers Aerospace and Electronic Systems Society, and the Software Engineering Institute. This analysis examined the differences in the deployment and impact of SE activities between defense-domain projects and non-defense projects. The analysis found significant differences in both the deployment of SE in the two domains and the effectiveness of the SE. The report identifies specific process areas where effectiveness in one domain is noticeably higher than in the other. Further research to understand these differences will benefit both domains by enabling them to share best practices. 
CMU/SEI-2014-SR-013 | xiv 


\section{Introduction}

\subsection{Purpose}

The purpose of this report is to compare and contrast the impact of systems engineering (SE) activities on projects in the defense domain with projects in other commercial domains.

\subsection{Background}

\subsubsection{Developing the SE Effectiveness Survey}

In 2011 and 2012, the National Defense Industrial Association (NDIA) Systems Engineering Division, the Institute of Electrical and Electronic Engineering (IEEE) Aerospace and Electronic Systems Society, and the Software Engineering Institute (SEI) collaborated to perform the Systems Engineering Effectiveness Study. The purpose of this study was to identify the relationship between the application of SE activities to projects and the performance of those projects. Such data would promote an understanding of the value of SE and build a business case for SE that would justify a project's investment in SE resources and activities.

The study was performed by surveying 148 individual projects to determine

- the SE activities applied to individual projects

- the performance of those projects as measured by satisfaction of budget, schedule, and technical requirements

- factors other than SE that could impact performance, such as

- the degree of challenge posed by the project

- the environment in which the project was executed

- prior experience of the organization and the team executing the project

To assess the SE activities applied to the project, we questioned the respondents about work products resulting from specific SE activities. The survey questionnaire assessed SE deployment via 82 questions addressing the presence and quality of 51 work products (see Appendix A).

We assessed project performance in terms of meeting schedule, meeting budget, and satisfying technical requirements. We collected multiple project performance measures and looked for the degree of agreement between these measures. An in-depth discussion of the collection and analysis of project performance information is found in the report The Business Case for Systems Engineering Study: Assessing Project Performance from Sparse Data [Elm 2012a].

We also collected information on several other factors that can impact project performance, including the degree of challenge posed by the project, the environment in which the project was executed, and prior experience of the organization and the team executing the project. 


\subsubsection{Executing the SE Effectiveness Survey}

To reach project members to participate in the survey, we relied on the resources of the NDIA, IEEE, and the International Council on Systems Engineering (INCOSE). The sample is not based on known probability of selection criteria, so the results related to the distributions of any single variable cannot be generalized to the entire population of system developers. However, there is sufficient variation in the sample to analyze relationships among those variables. It is those relationships that allow us to address the validity of assertions about the effects that SE activities can have on program performance under varying circumstances.

We made the process of responding to the survey simple and convenient by providing the survey online. To participate, a respondent merely had to obtain an online account from the survey server, $\log$ in, and complete the survey.

Some organizations were reluctant to respond due to the survey's request for competitionsensitive information identifying project performance. To mitigate these concerns, we collected all responses anonymously and did not solicit information to identify people, projects, or organizations. Additionally, we promised that data would be collected and handled by a trusted organization - the SEI, which is a federally funded research and development center (FFRDC) that does not compete with any of the responding organizations and is known for handling sensitive data.

Survey data collection occurred between October 2011 and March 2012. Valid survey responses were received from 148 projects.

\subsubsection{Survey Data Analysis}

The primary survey hypotheses were that the deployment of SE best practices, the degree of challenge imposed by the project, and the environment in which the project was executed all have a quantifiable impact on project performance. This can be stated mathematically as

$$
\text { Perf }=f(P C, E X P, S E C) \text {, }
$$

$$
\begin{array}{lll}
\text { where } & P C=\text { project challenge } & E X P=\text { prior experience } \\
& S E C=\text { systems engineering capability } & P e r f=\text { project performance }
\end{array}
$$

Our goal was to identify the impact of PC, EXP, and SEC on Perf. We did this by first scoring each parameter based on the survey responses and then by identifying the relationships among these scores.

\subsubsection{Scoring}

Project performance (Perf) was measured based on three subfactors: cost performance (PerfC), schedule performance (PerfS), and technical performance (PerfT). These subfactors were combined to create a measure of overall performance (Perf) that ranged in value from 1 (very poor performance) to 5 (very good performance).

Systems Engineering Capability (SEC) is a measure of the SE activities applied to each project and was assessed based on the presence and quality of the 51 SE work products listed in Appendix A. Because these work products could be categorized within specific areas of SE, we could 
assess not only the total SE activities (SEC-Total) applied to the project but also the SE capabilities in the following SE process groups:

- Project Planning

(SEC-PP)

- Verification

(SEC-VER)

- Project Monitoring and Control

(SEC-PMC)

- Requirements Development and Management

(SEC-REQ)

- Trade Studies

- Validation

- Product Integration

- Configuration Management

(SEC-CM)

- Product Architecture

- Integrated Product Teams (IPT)-based capability

- Risk Management

Each of these factors, as well as SEC-Total, was assessed over the range of 1 (low capability) to 4 (high capability).

Project challenge $(P C)$ was assessed via questions probing a number of diverse issues such as project size, project complexity, and technology precedents. All of these factors are combined into a single $P C$ measure scaled from 1 (not very challenging) to 4 (very challenging).

Other factors with the potential to impact project performance were also assessed, including prior experience, contract type, SE organization, percentage of project completion, and project SE content.

\subsubsection{Identifying Relationships}

Once the scores of all parameters were calculated, we identified relationships between the scores. Relationships were evaluated and presented in two ways:

1. via mosaic charts

2. via nonparametric statistical analysis

Mosaic charts provide an intuitive and visual means of examining the relationship between a dependent variable (e.g., Perf depicted on the vertical axis) and an independent variable (e.g., SECTotal or SEC-PP depicted on the horizontal axis). Development of a mosaic chart starts with the scores of the independent and dependent variable (i.e., SEC-Total and Perf). For each project, the scores are categorized as lower, middle, or higher, based on the establishment of breakpoints that distribute the projects evenly between these categories. The categorized scores are then tallied and displayed on the mosaic chart to show the relationship between the variables, as illustrated in Figure 4. In this case, it is visually evident that those programs with higher SE deployment tend to deliver higher project performance. 


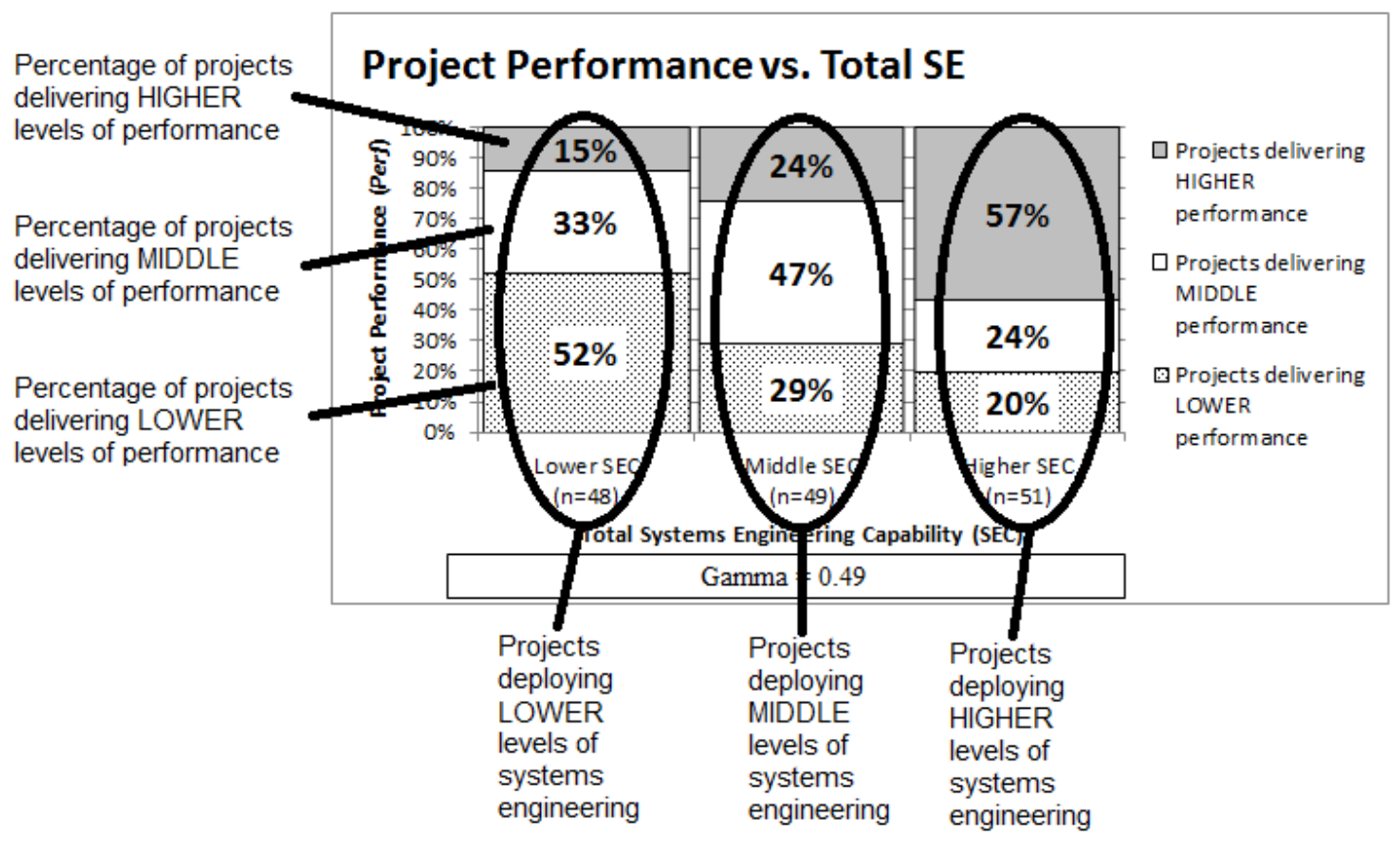

Figure 4: Mosaic Chart Key

Figure 4 also contains a nonparametric statistical measure of the relationship between SEC-Total and Perf. Goodman and Kruskal's gamma is a measure of association that expresses the strength of relationship between two ordinal variables. Gamma varies from +1 to -1 , with values near -1 indicating a strong opposing relationship, values near 0 indicating a weak or no relationship (statistical independence), and values near +1 indicating a strong supporting relationship.

\subsubsection{Initial Results of the SE Effectiveness Survey Results}

We received 148 valid survey responses, with response demographics as shown in Figure 5. Both the distributions for SE deployment (SEC-Total) and project performance (Perf) are skewed to the right, indicating that the surveyed sample consisted of projects deploying larger amounts of SE and producing higher levels of performance. Some of this bias may be due to the inherent optimism of self-reporting. Fortunately, the analysis techniques utilized to identify the relationships between the independent and dependent variables are not affected by this bias. 


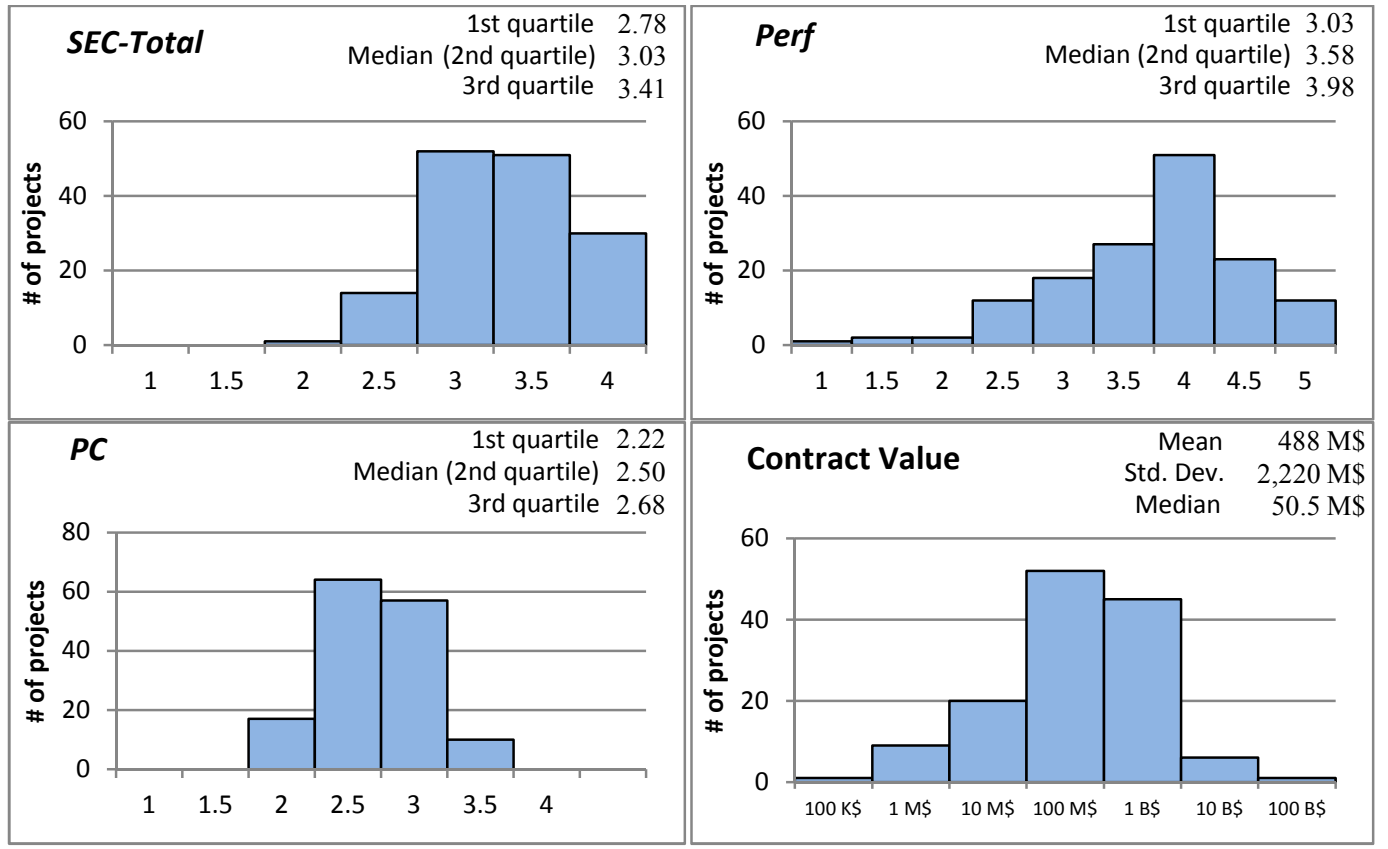

Figure 5: Response Demographics

The study found strong relationships between the deployment of SE and project performance, as shown in Figure 6.

\section{Project Performance vs. Total-SEC}

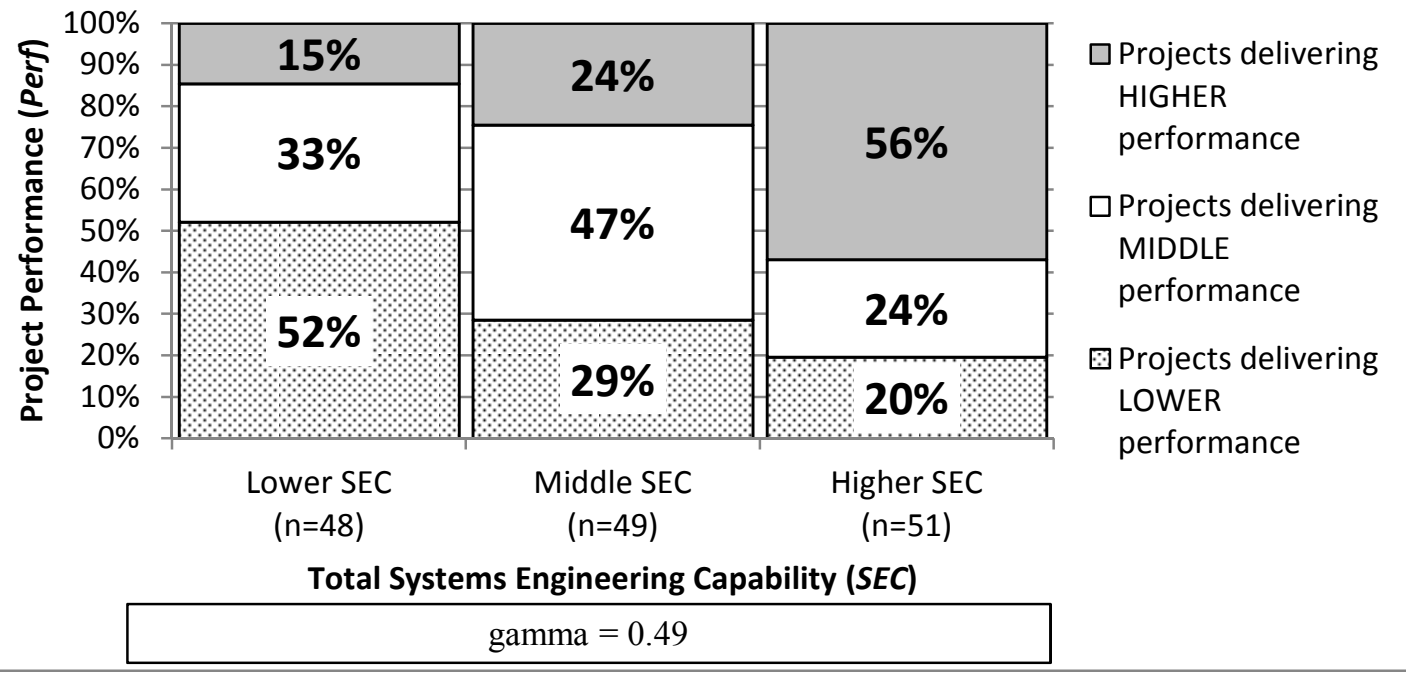

Figure 6: Project Performance vs. Total SE Capability

This figure clearly shows that projects that deploy more SE deliver better performance. This relationship is amplified for projects posing more challenge, as shown in Figure 7. 


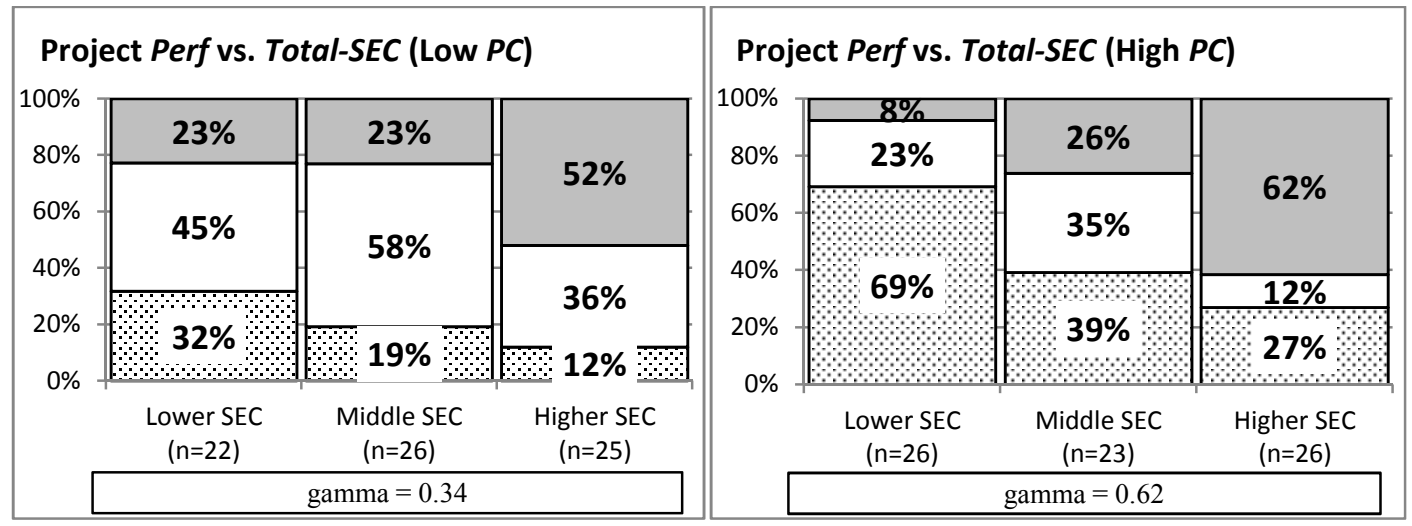

Figure 7: Project Performance vs. Total SE Capability Controlled by Project Challenge

The individual process areas of SE and project performance display similarly strong relationships. Figure 8 shows the strength of the relationships between each of the factors and project performance, as measured by gamma.

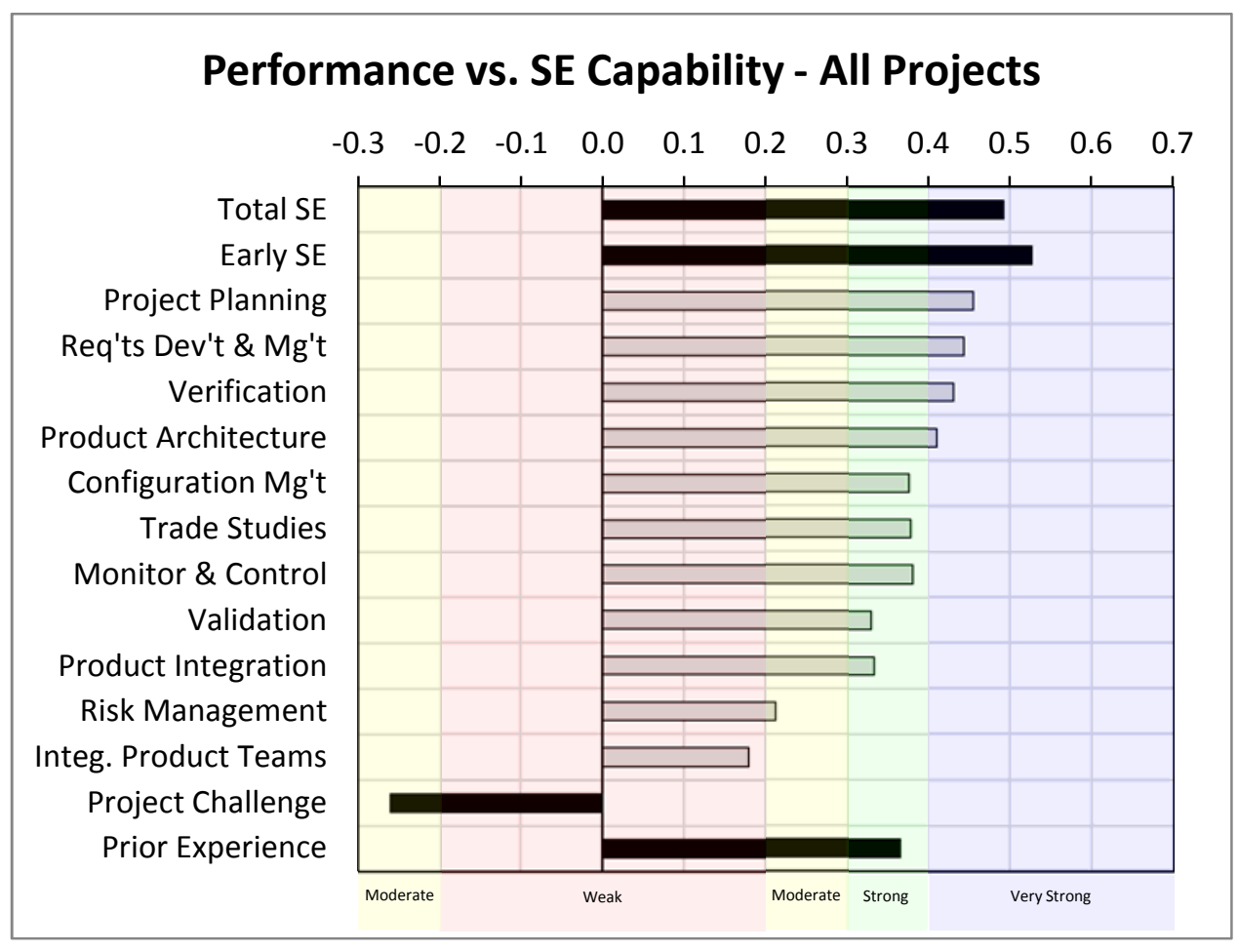

Figure 8: Project Performance vs. SE Deployment

Significantly, all of the SE factors have a positive relationship with project performance, and for most of them that relationship is either strong or very strong.

The results of this study are presented in considerable detail in

- $\quad$ The Business Case for Systems Engineering Study: Results of the Systems Engineering Effectiveness Survey [Elm 2012b]

- The Business Case for Systems Engineering Study: Detailed Response Data [Elm 2013] 


\subsection{Defense vs. Non-Defense Projects}

In conducting the SE Effectiveness Survey in 2011 and 2012, we solicited project members through the resources of NDIA, IEEE, and INCOSE. While many of those who participated in the survey were associated with the U.S. defense domain, a nontrivial number were not associated with defense-related activities. This division is shown in Figure 9.

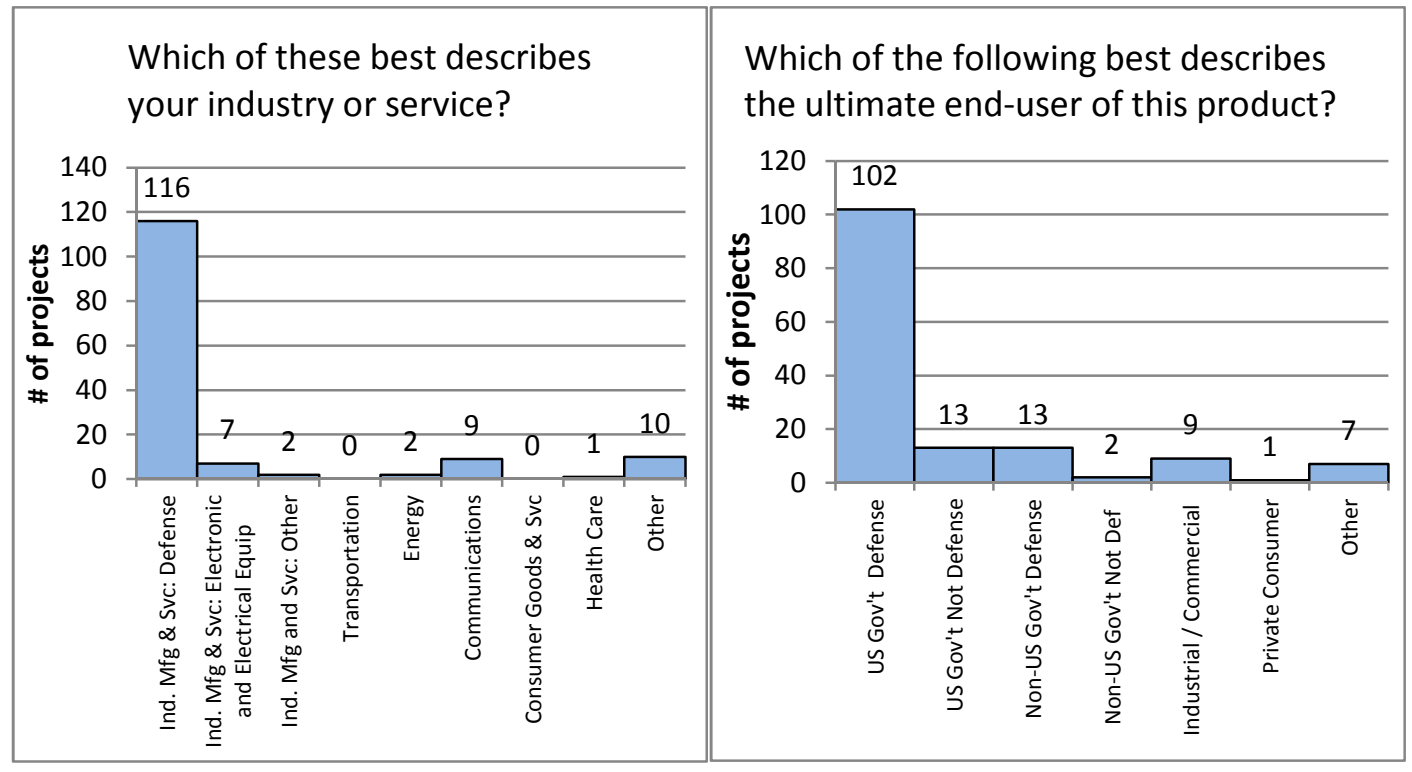

Figure 9: Industry and End User

Figure 9 shows that 116 respondents declared their primary industry as defense related, while 31 respondents declared their primary industry as non-defense related. These non-defense projects supported industrial domains including energy, communications, and health care. The figure also shows that 115 respondents declared that the end user for their products was a defense organization, while 32 declared that the end user was not a defense organization. ${ }^{1}$

Since we could categorize the responding projects as either defense related or non-defense related, we could analyze each group independently to identify relationships between SE deployment, project challenge, experience, and project performance. Independent analysis enabled us to compare and contrast these groups to identify similarities and differences that can be instructive in the effective application of SE.

In total, 148 responses were received. The numbers cited here may not add to 148 because some respondents chose not to answer the questions identifying their primary industry and end users. 


\section{Comparison of Projects in the Defense and Non-Defense Domains}

\subsection{Project Characteristics}

Before comparing and contrasting the SE and performance characteristics of the two project groups, we must first understand the demographics of the groups.

Figure 10 shows the distribution of project contract values for the projects in the defense domain and those not in the defense domain. The median contract value for the group of defense projects was $\$ 60$ million, while the median contract value for the group of non-defense projects was $\$ 40$ million. While this represents a $33 \%$ difference, the two sets of projects are within the same order of magnitude.

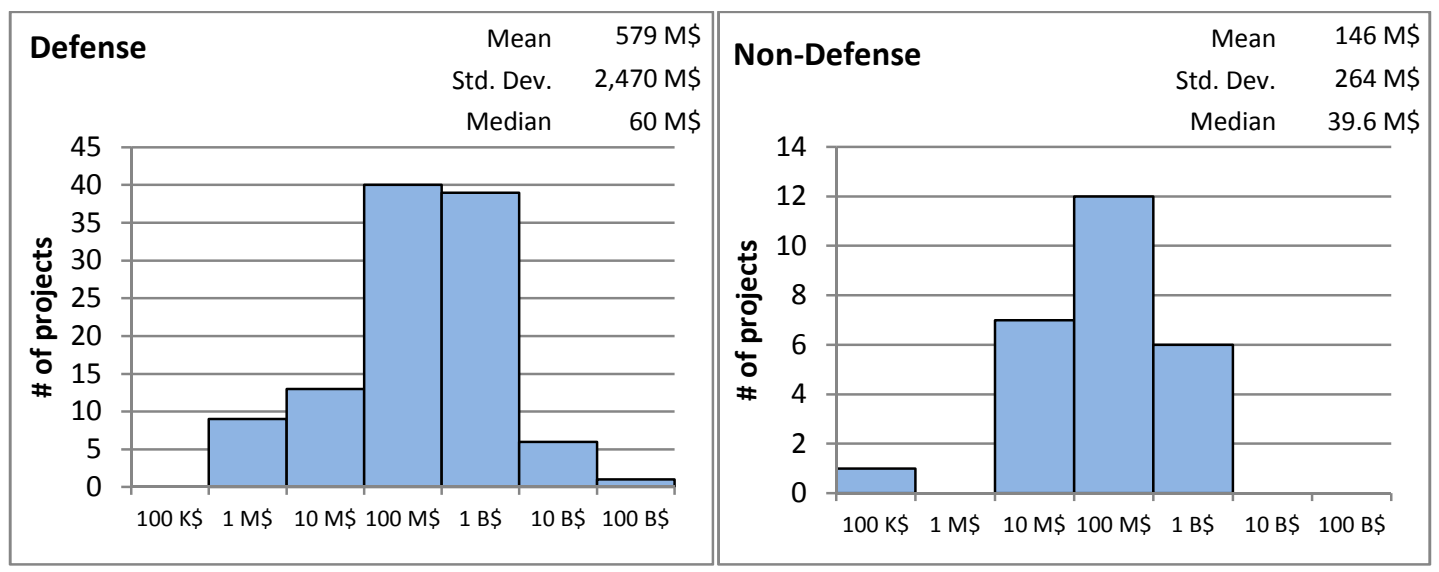

Figure 10: Contract Value

Figure 11 shows the distribution of project duration for the groups of projects in the defense and non-defense domains. The median project duration for the group of defense projects was 48 months, while the median project duration of the non-defense projects was only $10 \%$ less at 44 months.

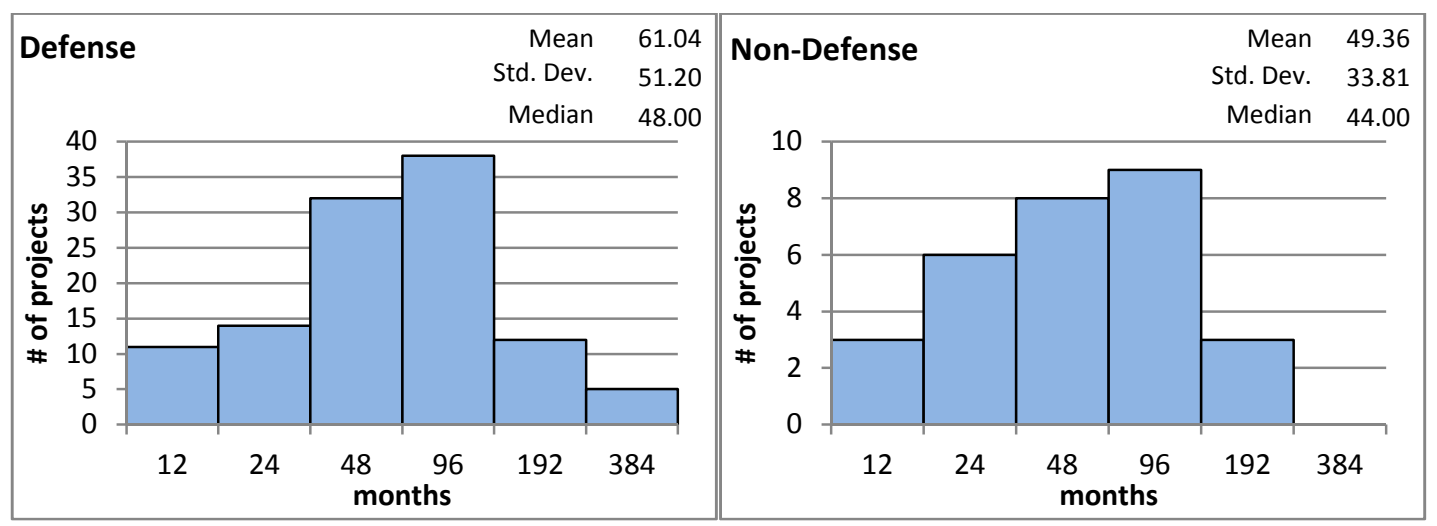

Figure 11: Contract Duration 
We did not restrict our surveys to completed projects; thus our survey responses included projects at various stages of completion. Figure 12 shows the distribution of the completion status of the groups of projects in the defense and non-defense domains. Within the defense domains, the mean completion status of the projects is $71 \%$, and in the non-defense domain, the mean is nearly the same at $72 \%$.

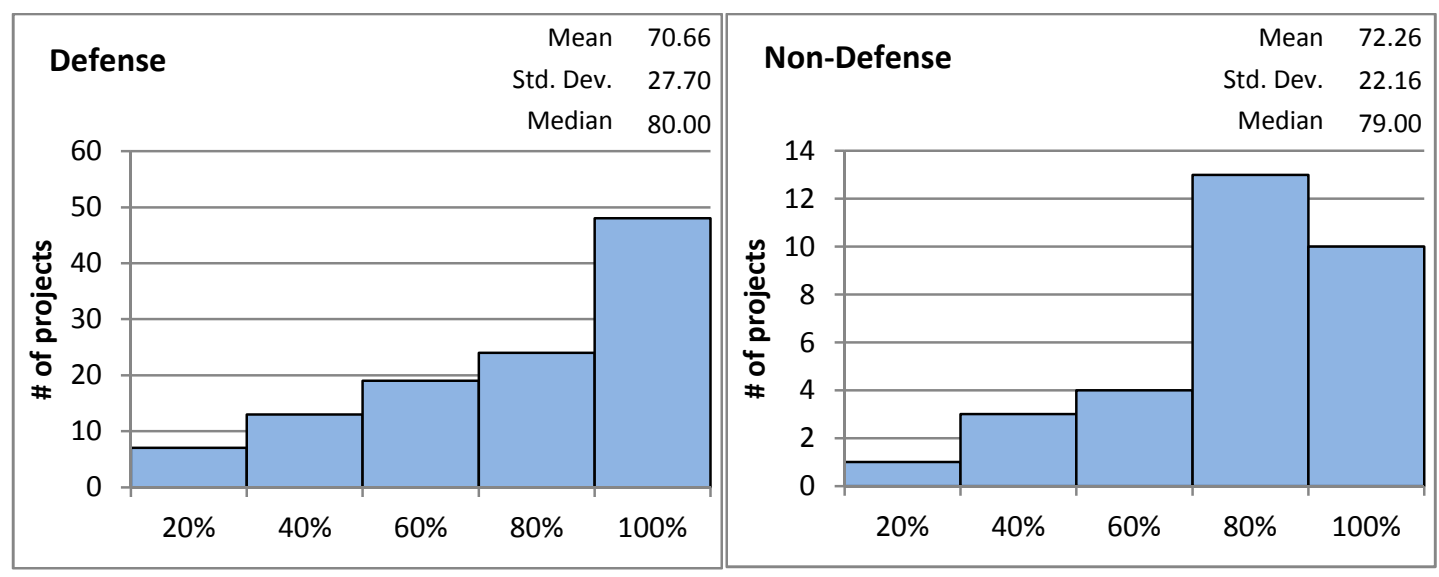

Figure 12: Current Completion Status

Starting projects before they are sufficiently defined can impact project performance. One measure of the quality of the project definition is the completeness of the customer requirements. Figure 13 shows the percentage of undefined customer requirements at the time of contract award.

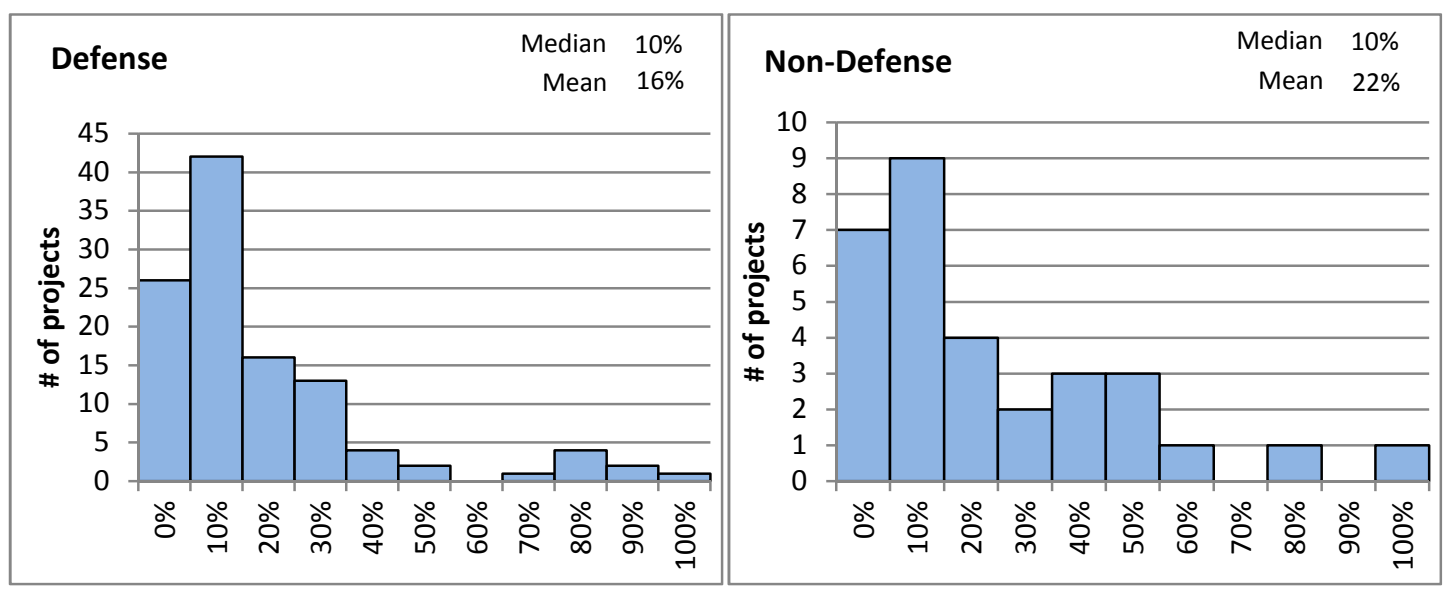

Figure 13: Percentage of Customer Technical Requirements Marked "TBD" at Contract Award

For the group of defense-domain projects, half of the projects have $\leq 10 \%$ undefined requirements at the time of award. The group of non-defense projects has the same median. The mean value for the percentage of undefined requirements in the defense domain is $16 \%$, compared to a mean value for the non-defense domain of $22 \%$. This indicates that initial project definition in the nondefense domain may be less complete than that within the defense domain.

As the project progresses, many of the customer requirements that were initially undefined become known. Figure 14 shows the percentage of undefined technical requirements within the projects at the time of the survey. 


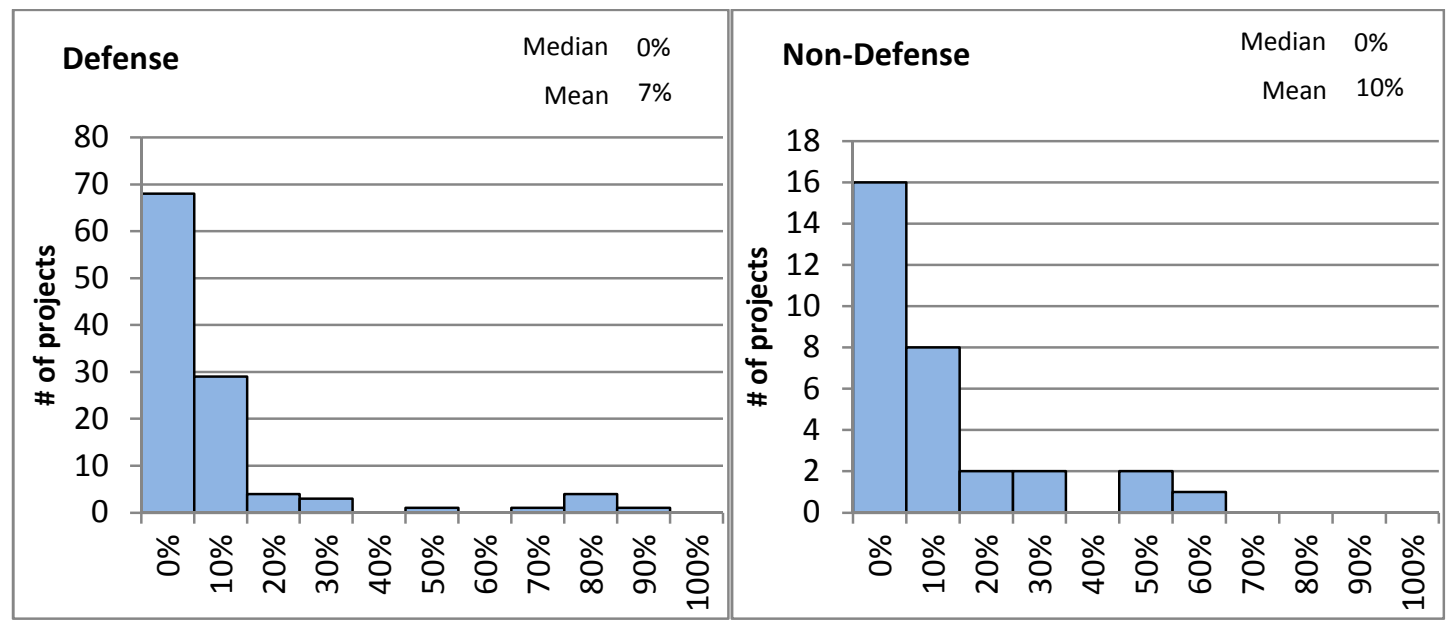

Figure 14: Percentage of Customer Technical Requirements Currently Marked "TBD"

Within the groups of defense and non-defense projects, over half of the projects in each group had no undefined customer requirements at the time of the survey, as evidenced by the median values of $0 \%$. The $10 \%$ mean percentage of undefined requirements for the non-defense projects is only slightly higher than the mean of $7 \%$ for the defense projects, indicating no significant difference in project definition between the two groups.

In most cases, SE is only a part of the total non-recurring engineering (NRE) applied to a project. Figure 15 shows the amount of SE applied to a project as a percentage of the total NRE of the project. The defense-domain projects and the non-defense projects show little difference between the median ( $15 \%$ vs. $13 \%)$ and mean ( $21 \%$ vs. $26 \%$ ) values for the SE percentage.

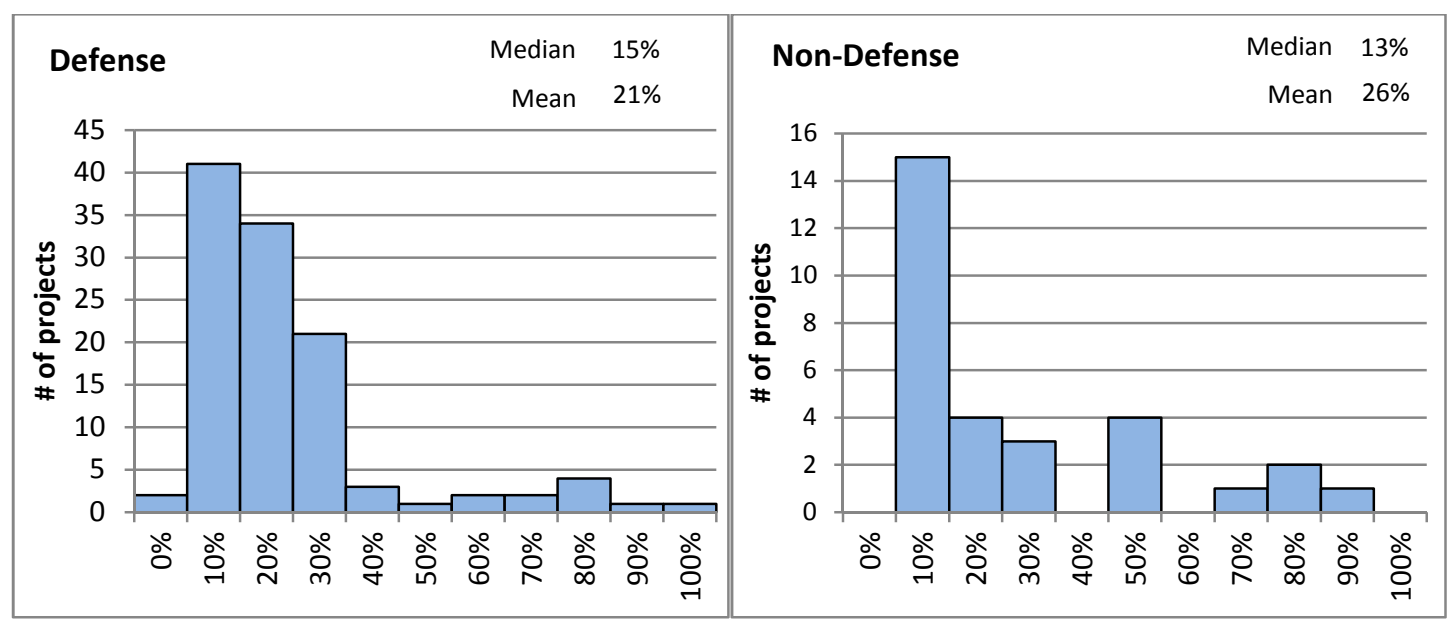

Figure 15: SE Percentage of Non-Recurring Engineering

\subsection{Project Challenge}

As discussed previously, we assessed the degree of challenge posed by each project by evaluating factors such as project size, project complexity, and technology precedents. The distribution of project challenge $(P C)$ is shown in Figure 16, with the value of 1 representing very low challenge and 4 representing very high challenge. 


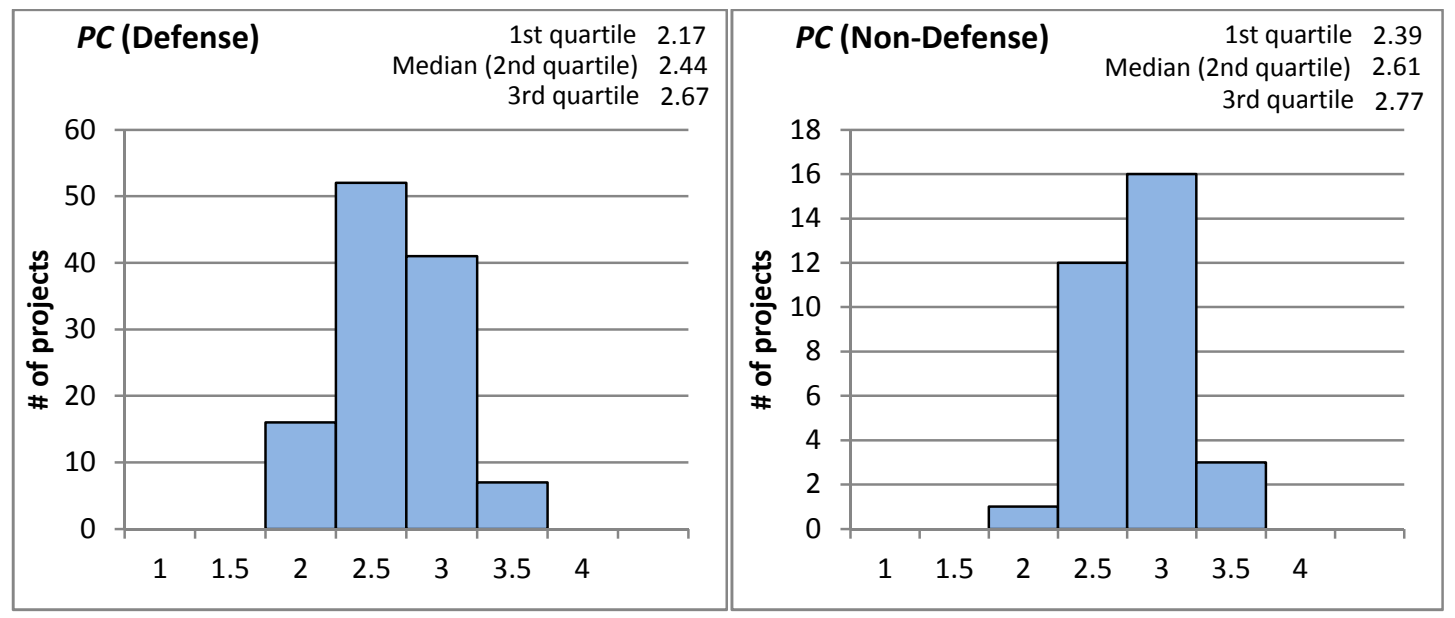

Figure 16: PC Response Distribution

For the defense-domain projects, the median of 2.44 indicates that the sampled projects were nearly in the middle of the continuum of project challenge. Similar conclusions may be drawn for the non-defense projects, with a median of 2.61 , which appeared to be a bit more challenging than the defense projects.

As part of preparing the mosaic chart showing the relationship between $P C$ and Perf, three groups for $P C$ were established with breakpoints at 2.33 and 2.65. These breakpoints resulted in a nearly even distribution of projects across the three categories of lower challenge, middle challenge, and higher challenge. The resulting mosaic charts are shown in Figure 17.

Perf vs. PC (Defense)

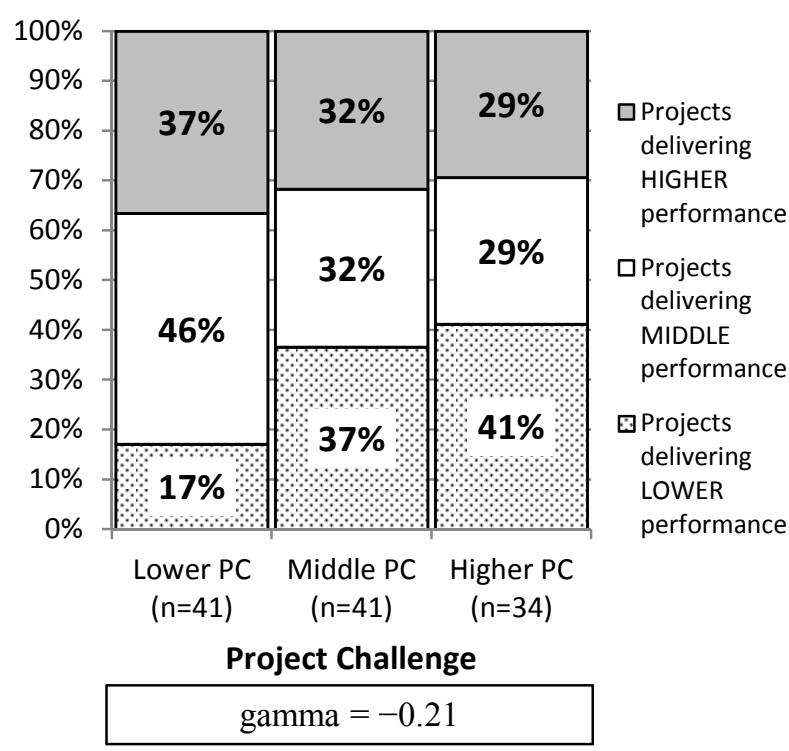

Perf vs. PC (Non-Defense)

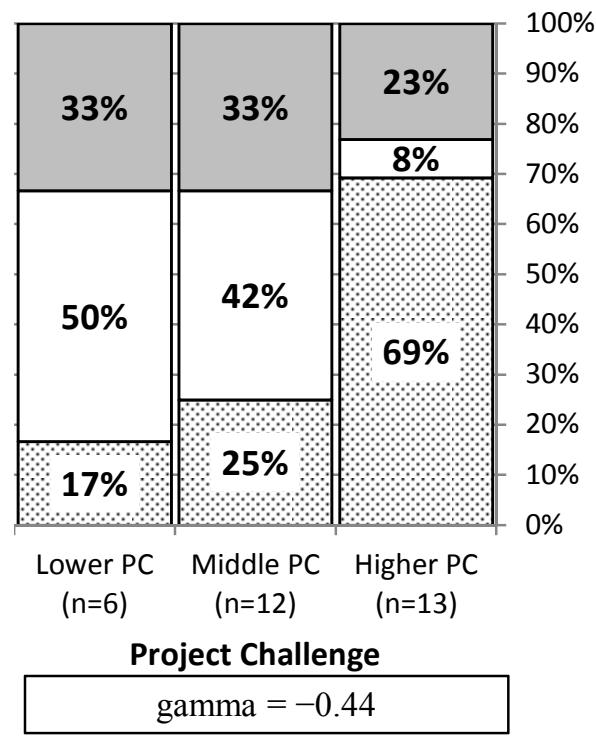

Figure 17: PC vs. Perf

These charts reveal a moderately negative relationship (gamma $=-0.21$ ) between PC and Perf for the defense-domain projects, but a very strong negative relationship (gamma $=-0.44$ ) for the non- 
defense projects. The negative polarity of these relationships is consistent with intuition-one would expect more challenging projects to have greater difficulty achieving performance expectations. The difference in the magnitude of the relationship between defense and non-defense projects is interesting and will be discussed later in this report.

\subsubsection{Compensating for Differences in Project Challenge}

To achieve the best comparison between defense and non-defense projects, to the greatest extent possible, we endeavored to eliminate variations in other factors affecting project performance. $P C$ is one of those factors. The 116 projects in the defense domain sample had a median $P C$ value of 2.44 , while the 32 non-defense projects had a median $P C$ value of 2.66 , representing a higher degree of challenge.

To temper the impact of this variation in $P C$, we identified a subset of the defense projects that also had a median $P C$ value of 2.66. This subset consisted of the 75 most challenging defense projects. As shown in Figure 18, the PC distributions for the defense and non-defense projects are remarkably similar.

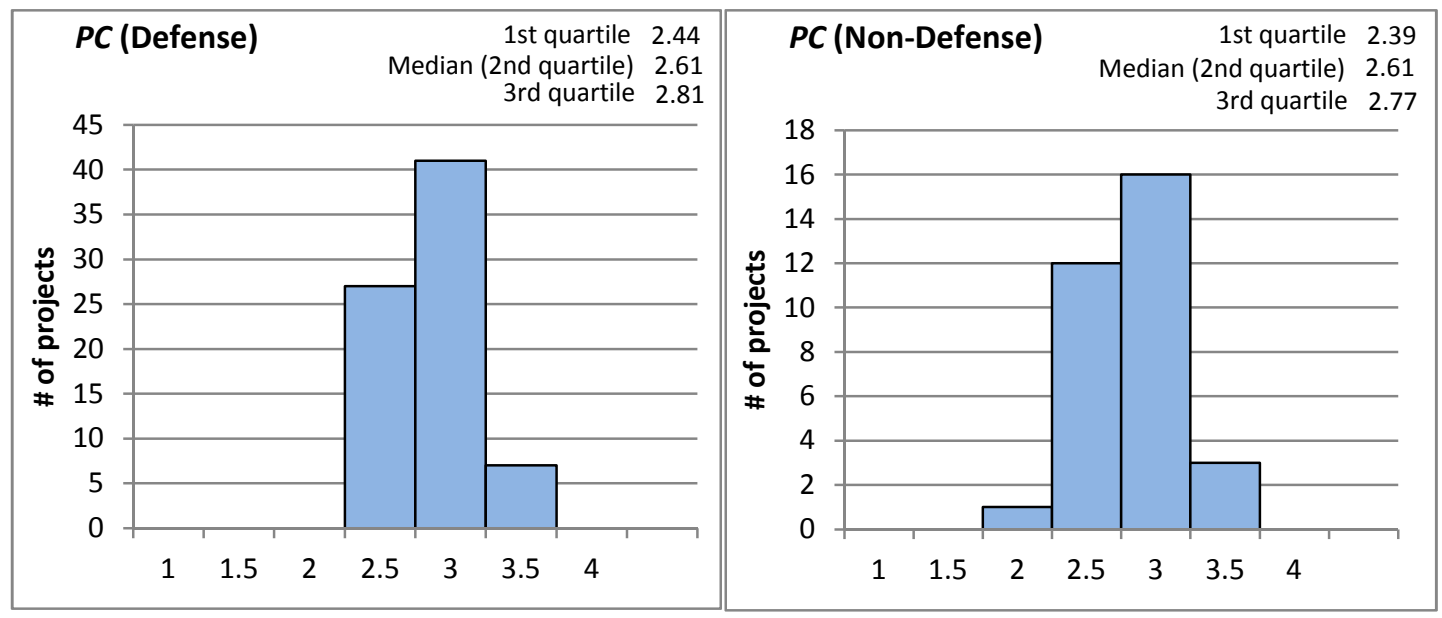

Figure 18: Adjusted PC Response Distribution

For the remainder of this report, we will perform all analyses using this 75-project subset of the defense-domain projects.

The resulting mosaic charts of Figure 19 show the relationship between the PC subset and Perf. We established three groups for $P C$ with breakpoints at 2.45 and 2.70 to obtain a nearly even distribution of projects across the three categories of lower challenge, middle challenge, and higher challenge. These charts reveal a weak negative relationship (gamma $=-0.08$ ) between $P C$ and Perf for the defense-domain projects, but a moderate negative relationship (gamma $=-0.24$ ) for the non-defense projects. 
Perf vs. PC (Defense)

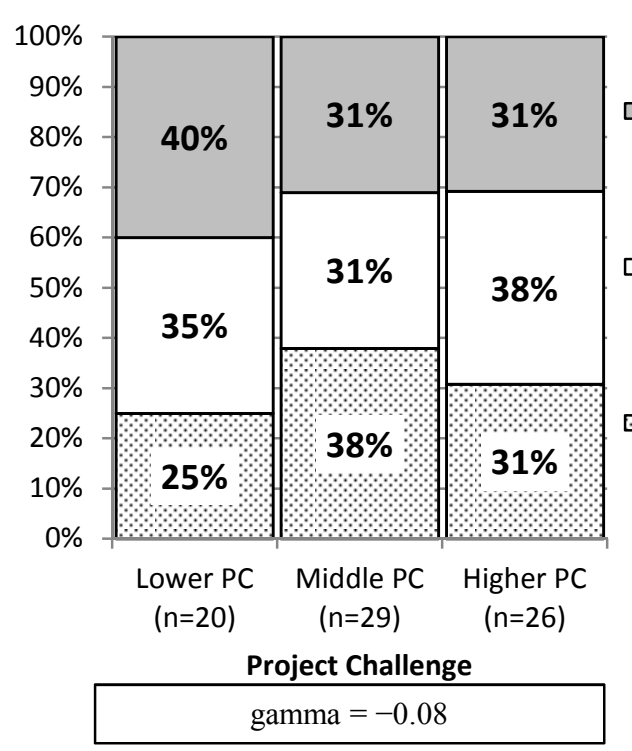

Perf vs. PC (Non-Defense)

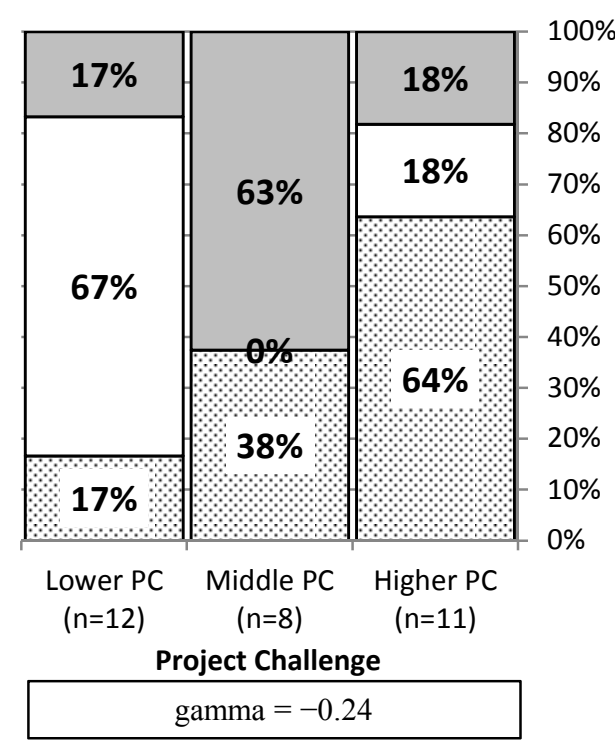

Figure 19: Adjusted PC vs. Perf

\subsection{Project Performance}

As discussed previously, the performance (Perf) of each project was assessed by evaluating its conformance to budget (PerfC), schedule (PerfS), and technical (PerfT) requirements. These three factors were combined additively to create a measure of overall project performance. Distribution of Perf for defense and non-defense projects is shown in Figure 20.

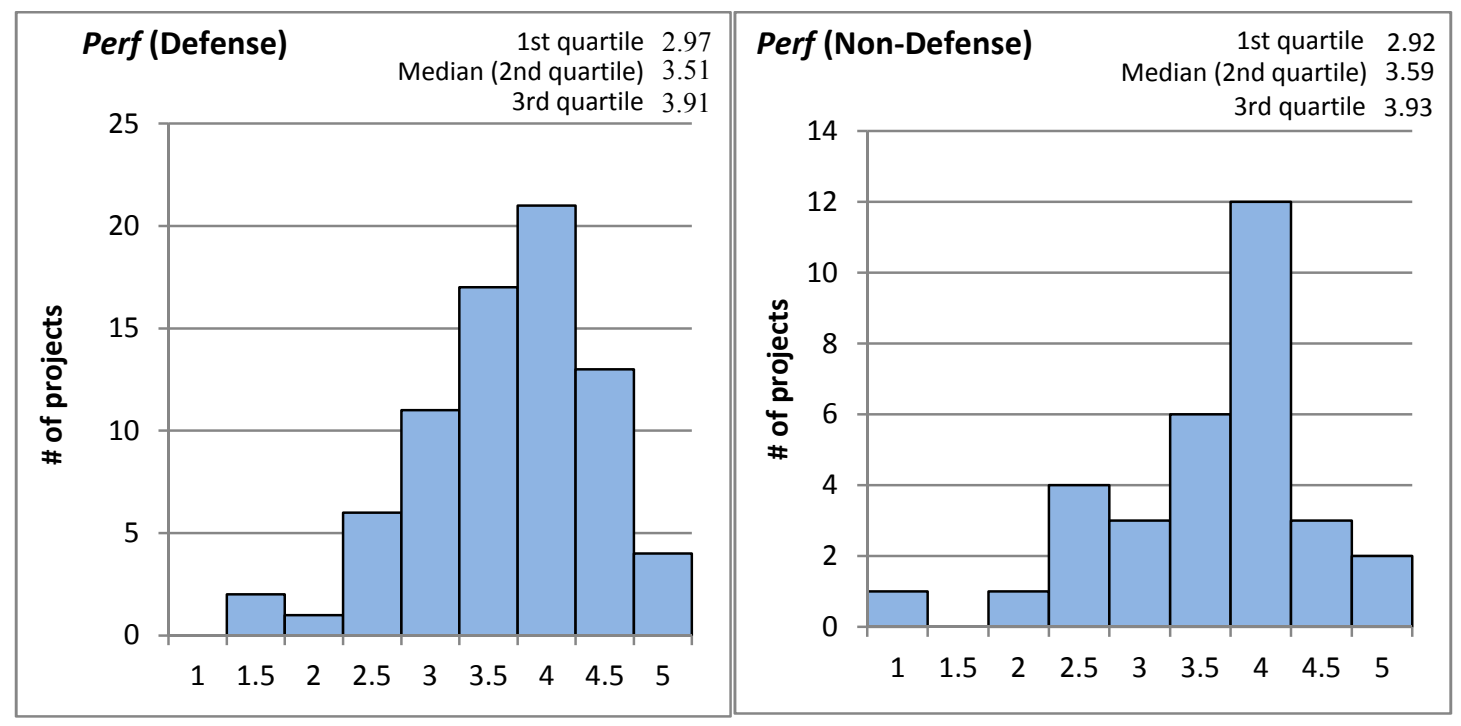

Figure 20: Project Performance Response Distribution

A Perf value of 3.00 may be interpreted as a project that is on schedule, on budget, and satisfying technical requirements. Values greater than 3 indicate superior performance (e.g., under budget, ahead of schedule, and/or exceeding technical requirements), while values less than 3 represent inferior performance. The median values of 3.51 for the defense projects and 3.59 for the non- 
defense projects indicate that the projects surveyed, in the aggregate, exceeded performance expectations in terms of cost, schedule, and/or technical performance.

Figure 21 shows the distributions of the performance subfactors of cost performance, schedule performance, and technical performance.

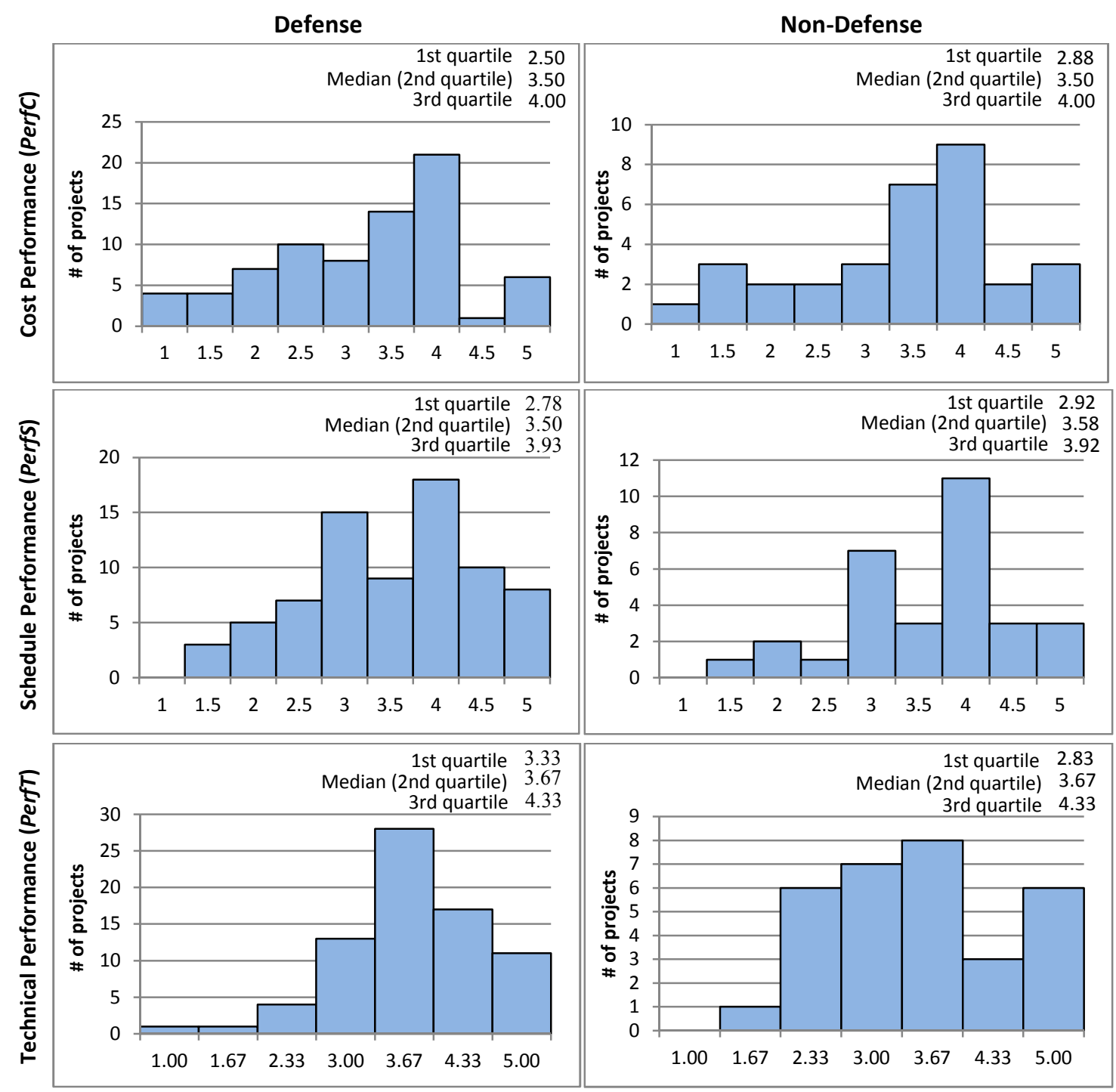

Figure 21: Performance Subfactor Distributions

Only the distribution of the schedule subfactor (PerfS) shows a noticeable difference between the defense projects (median $=3.50)$ and the non-defense projects (median =3.58). All of these performance measures are shown graphically in Figure 22. 


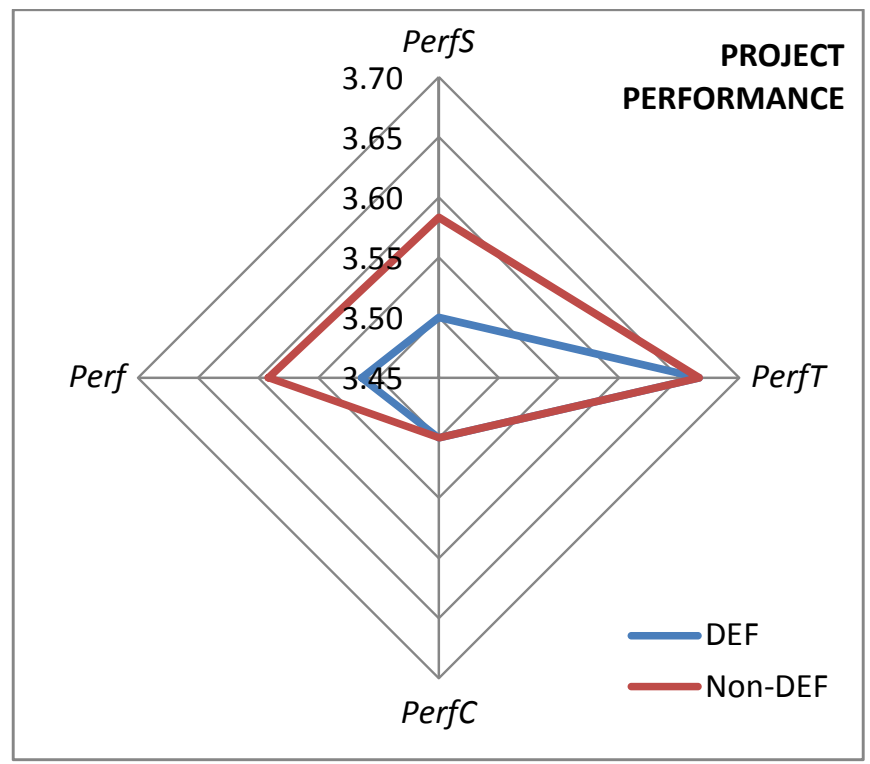

Figure 22: Project Performance Comparison

Perf is used as the primary variable for comparison with SEC variables. As discussed previously, the first step in preparing the mosaic charts showing these relationships is to divide the projects into three groups based on Perf - those delivering lower, middle, and higher performance. We do this by examining the cumulative distribution function of Perf (Figure 23) to identify two breakpoints that distribute the projects evenly into three bins. ${ }^{2}$

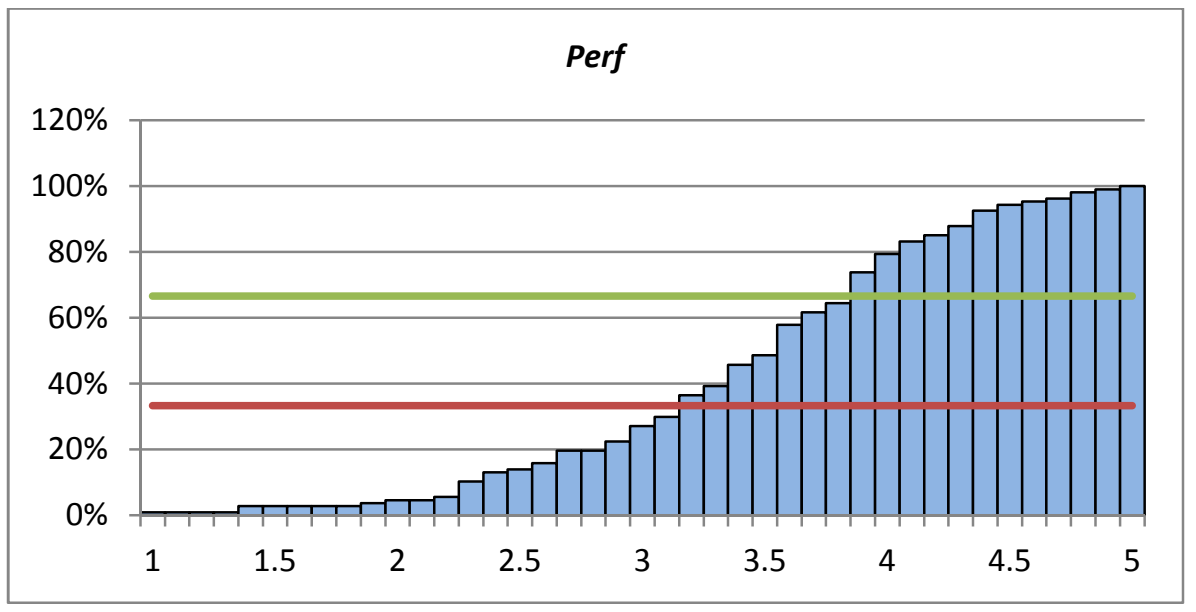

Figure 23: Perf Cumulative Response Distribution

Examining the data, we can identify these breakpoints at 3.18 and 3.83. Thus, for all future analysis, we categorize projects as follows:

$$
\begin{array}{llll}
1 & \leq \text { Perf } \leq 3.18 & \Rightarrow & \text { Lower project performance } \\
3.18<\text { Perf } \leq 3.83 & \Rightarrow & \text { Middle project performance } \\
3.83<\text { Perf } & & \Rightarrow & \text { Higher project performance }
\end{array}
$$

2 More detail about establishing the cutting points can be found in The Business Case for Systems Engineering Study: Assessing Project Performance from Sparse Data [Elm 2012a]. 


\subsection{Systems Engineering Capabilities}

The following sections discuss the results of the survey for SE capabilities.

\subsubsection{Systems Engineering Process Areas}

\subsubsection{Project Planning}

The distributions of the responses assessing Project Planning activities (SEC-PP) are shown in Figure 24, with a value of 1 representing very poor Project Planning and 4 representing very good Project Planning. The respective median values of 2.96 and 2.87 for the defense and non-defense projects indicate that defense projects deploy somewhat more Project Planning activities than non-defense projects.

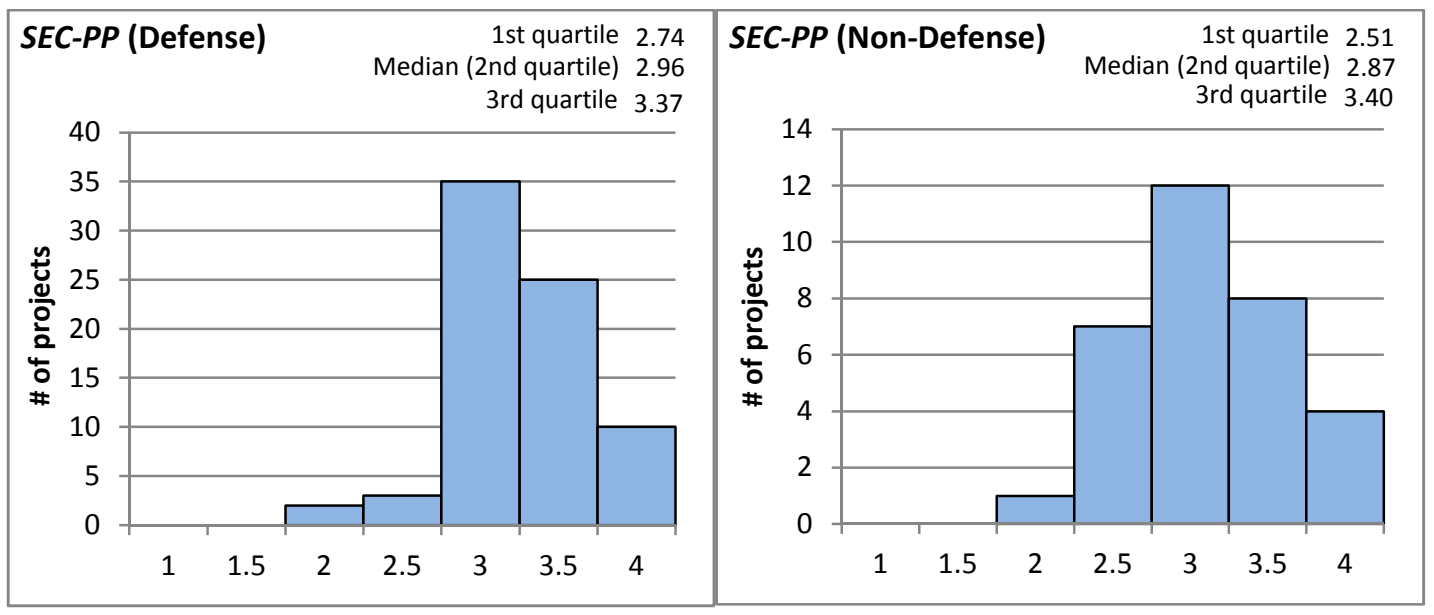

Figure 24: SEC-PP Response Distribution

The mosaic charts of Figure 25 show the relationship between SEC-PP and Perf for the defense and non-defense projects. We established three categories-lower SEC, middle SEC, and higher SEC-for SEC-PP with breakpoints at 2.82 and 3.25 to create a nearly even distribution of projects across the three categories. Examination of these charts reveals a very strong supporting relationship (gamma $=0.57$ ) between $S E C-P P$ and Perf for the defense projects and a very strong supporting relationship $($ gamma $=0.59)$ for the non-defense projects. 
Perf vs. SEC-PP (Defense)

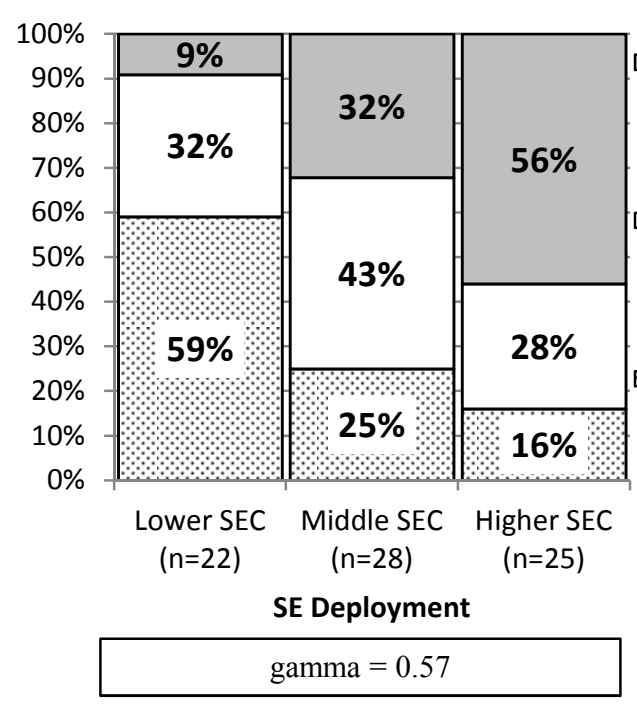

Perf vs. SEC-PP (Non-Defense)

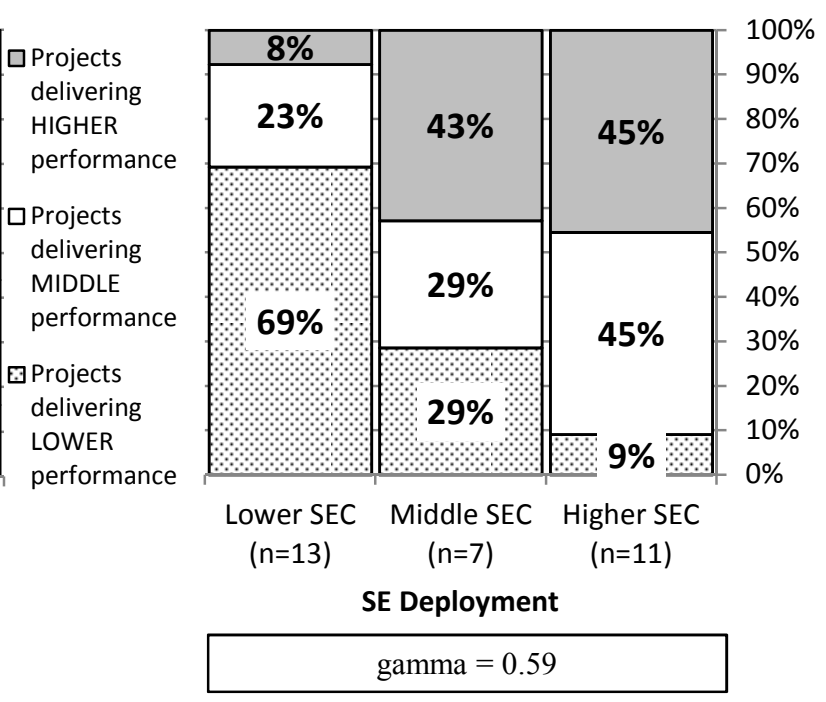

Figure 25: SEC-PP vs. Perf

\subsubsection{Verification}

The distributions of the responses assessing Verification activities (SEC-VER) of the projects are shown in Figure 26, with a value of 1 representing very poor Verification work and 4 representing very good Verification work. The respective median values of 3.11 and 3.00 for the defense and non-defense projects indicate that defense projects deploy somewhat more Verification activities than non-defense projects.

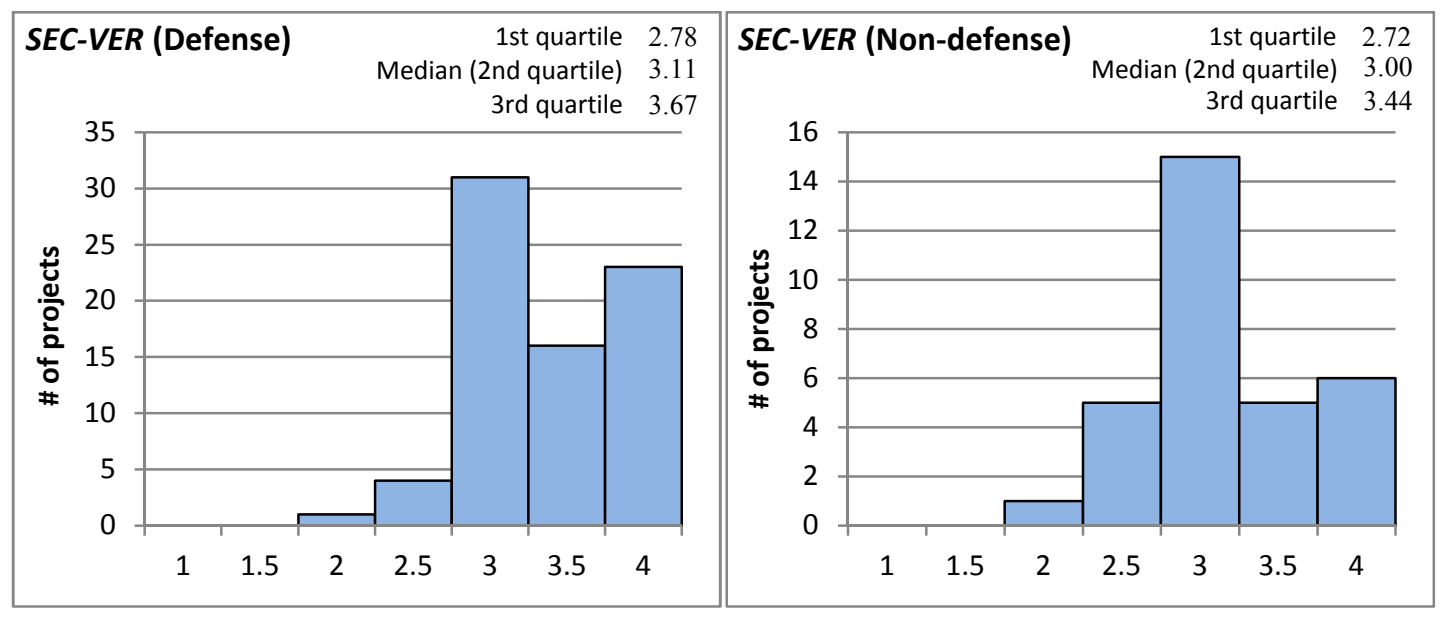

Figure 26: SEC-VER Response Distribution

The mosaic charts of Figure 27 show the relationship between SEC-VER and Perf for the defense and non-defense projects. We established three categories - lower SEC, middle SEC, and higher SEC - for SEC-VER with breakpoints at 2.88 and 3.40 to create a nearly even distribution of projects across the three categories. Examination of these charts reveals a very strong supporting rela- 
tionship (gamma $=0.55$ ) between SEC-VER and Perf for the defense projects and a very strong supporting relationship $($ gamma $=0.64)$ for the non-defense projects.

Perf vs. SEC-VER (Defense)

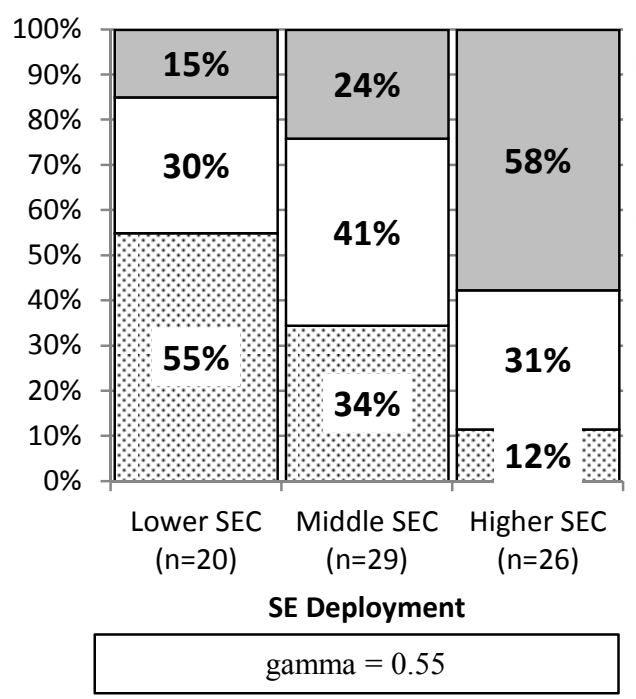

Perf vs. SEC-VER (Non-Defense)

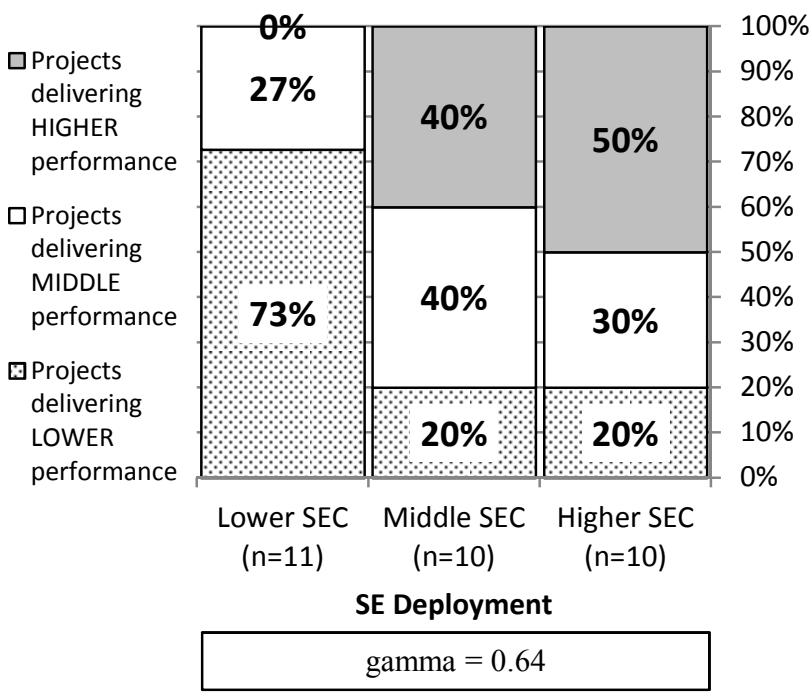

Figure 27: SEC-VER vs. Perf

\subsubsection{Project Monitoring and Control}

The distributions of the responses assessing Project Monitoring and Control activities (SEC-PMC) of the projects are shown in Figure 28, with a value of 1 representing very poor Project Monitoring and Control and 4 representing very good Project Monitoring and Control. The respective median values of 3.09 and 3.00 for the defense and non-defense projects indicate that defense projects deploy somewhat more Project Monitoring and Control activities than non-defense projects.

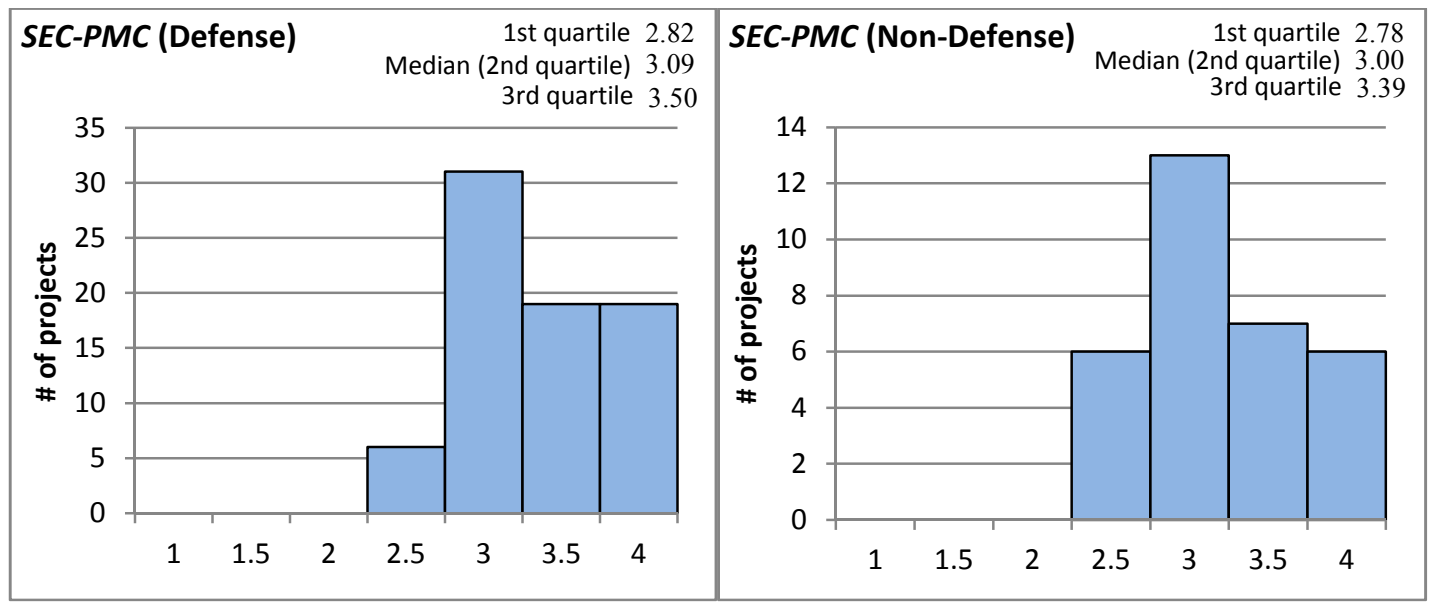

Figure 28: SEC-PMC Response Distribution

The mosaic charts of Figure 29 show the relationship between SEC-PMC and Perf for the defense and non-defense projects. We established three categories - lower SEC, middle SEC, and higher 
SEC - for SEC-PMC with breakpoints at 2.90 and 3.30 to create a nearly even distribution of projects across the three categories. Examination of these charts reveals a very strong supporting relationship (gamma $=0.48$ ) between SEC-PMC and Perf for the defense projects and a strong supporting relationship $($ gamma $=0.38)$ for the non-defense projects.

Perf vs. SEC-PMC (Defense)

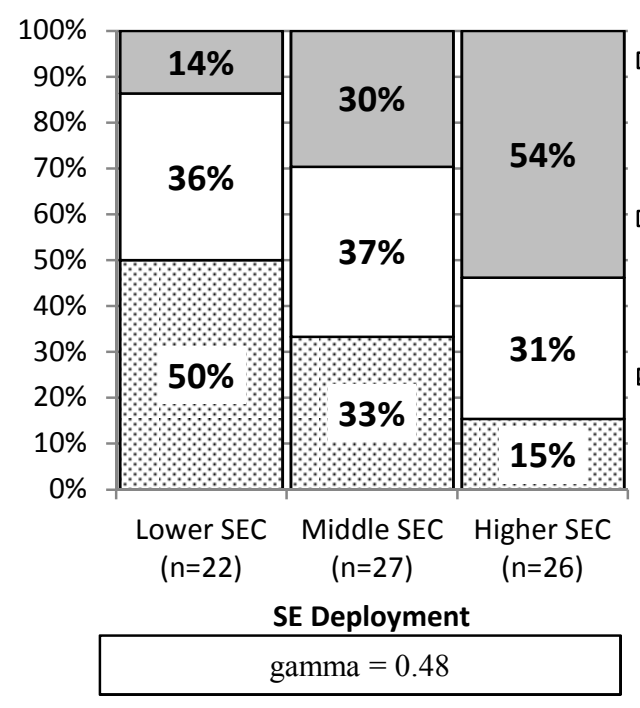

Perf vs. SEC-PMC (Non-Defense)

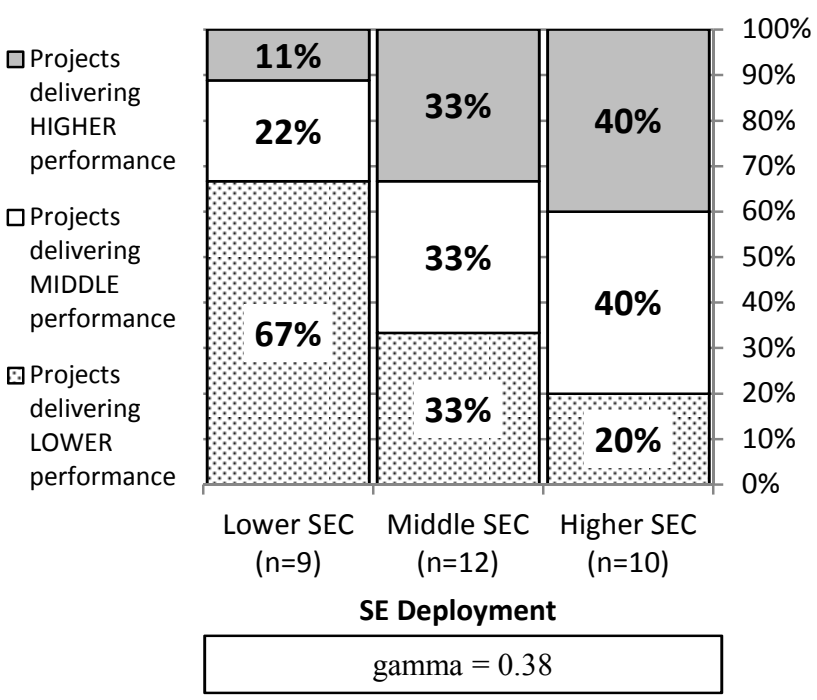

Figure 29: SEC-PMC vs. Perf

\subsubsection{Requirements Development and Management}

The distributions of the responses assessing the Requirements Development and Management activities (SEC-REQ) of the projects are shown in Figure 30, with a value of 1 representing very poor Requirements Development and Management and 4 representing very good Requirements Development and Management. The respective median values of 3.15 and 3.18 for the defense and non-defense projects indicate no significant difference in the deployment of Requirements Development and Management activities between the two project groups.

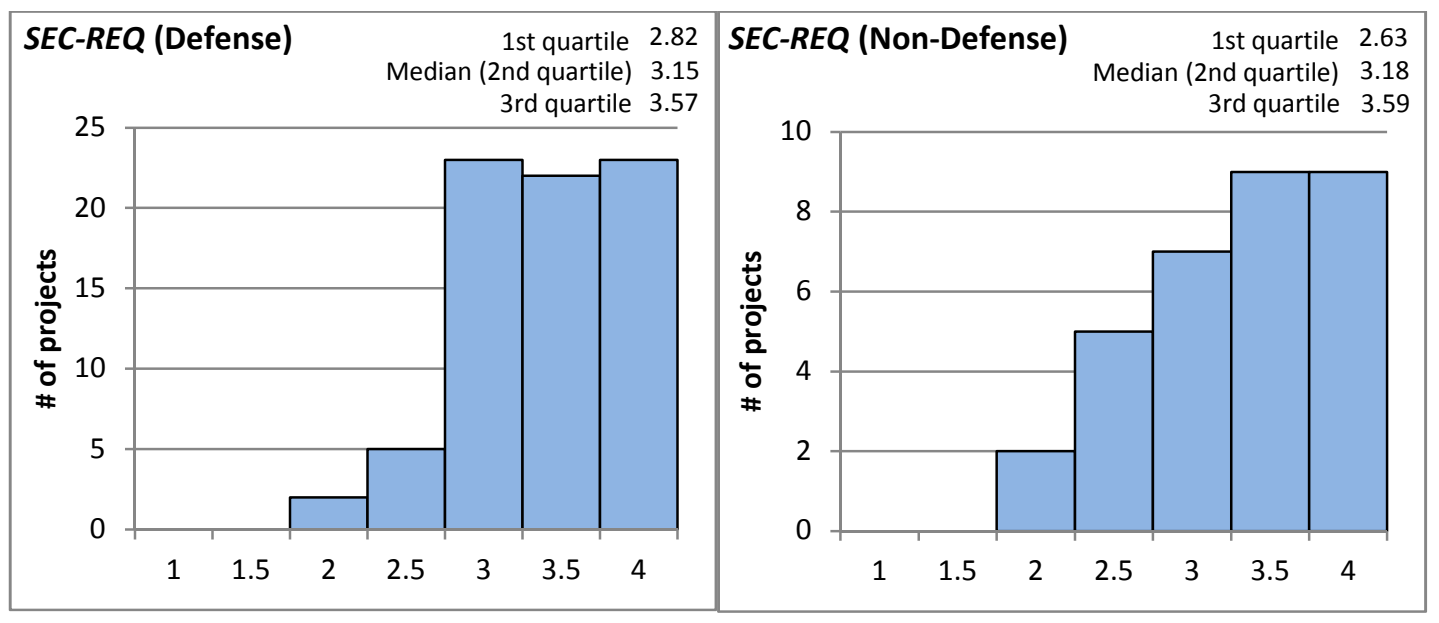

Figure 30: SEC-REQ Response Distribution 
The mosaic charts of Figure 31 show the relationship between SEC-REQ and Perf for the defense and non-defense projects. We established three categories - lower SEC, middle SEC, and higher SEC - for SEC-REQ with breakpoints at 2.90 and 3.45 to create a nearly even distribution of projects across the three categories. Examination of this chart reveals a very strong supporting relationship (gamma $=0.46$ ) between SEC-REQ and Perf for the defense projects, and a very strong supporting relationship $($ gamma $=0.60)$ for the non-defense projects.

Perf vs. SEC-REQ (Defense)

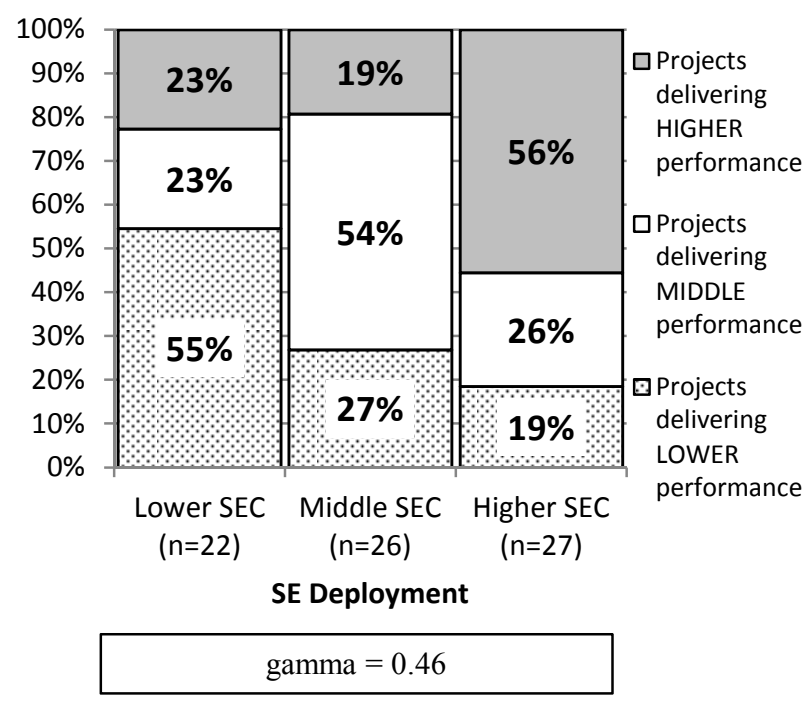

Perf vs. SEC-REQ (Non-Defense)

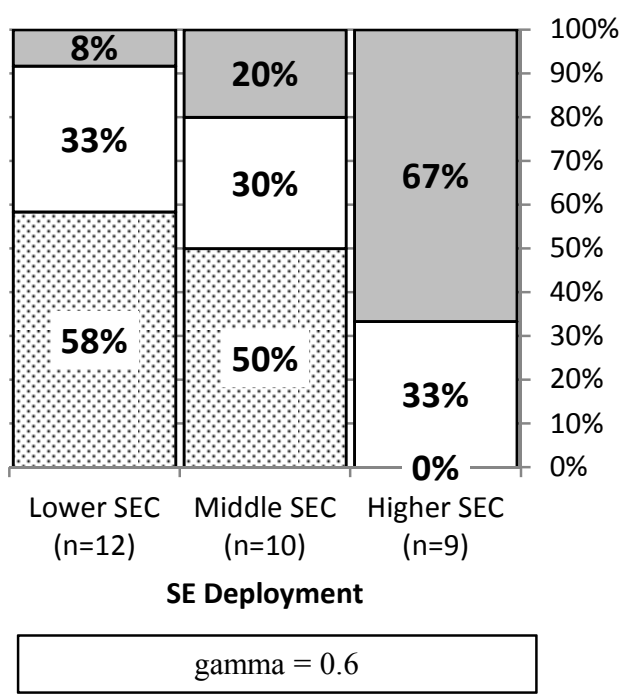

Figure 31: SEC-REQ vs. Perf

\subsubsection{Trade Studies}

The distributions of the responses assessing Trade Study activities (SEC-TRD) of the projects are shown in Figure 32, with a value of 1 representing very poor Trade Study work and 4 representing very good Trade Study work. The respective median values of 3.00 and 3.00 for the defense and non-defense projects indicate no difference in the deployment of Trade Study activities between the two project groups.

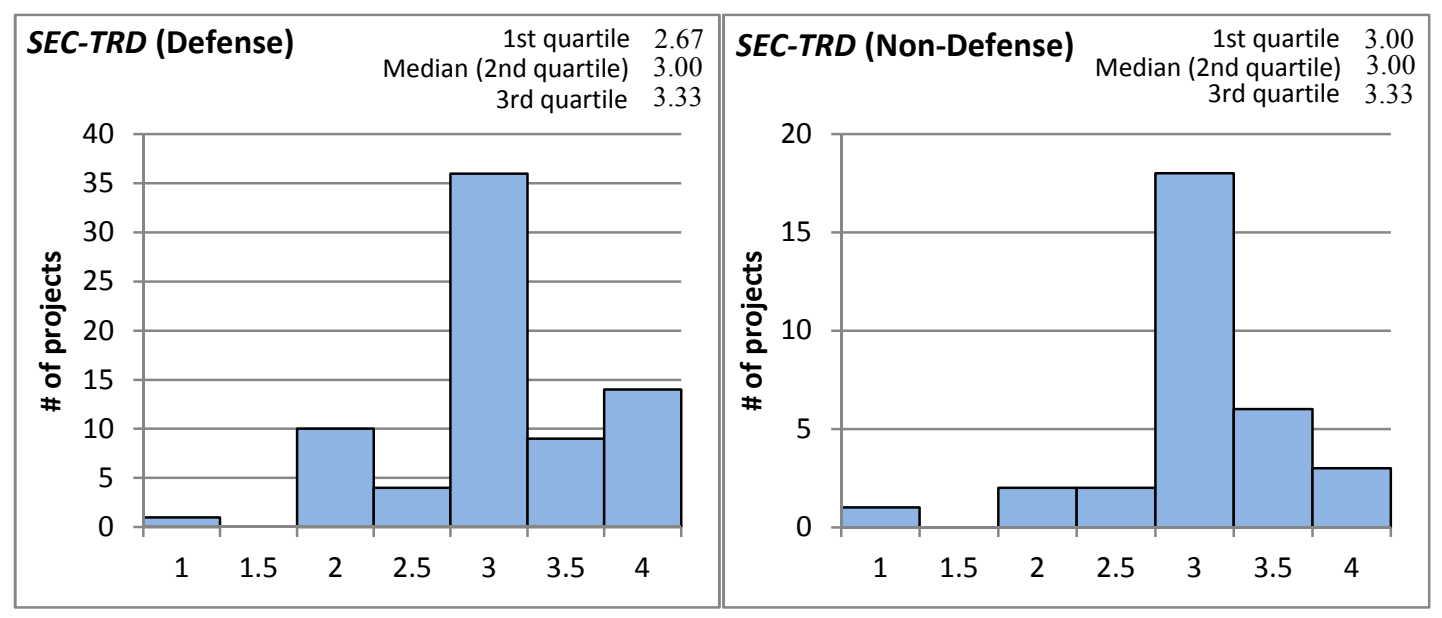

Figure 32: SEC-TRD Response Distribution 
The mosaic charts of Figure 33 show the relationship between SEC-TRD and Perf for the defense and non-defense projects. We established three categories - lower SEC, middle SEC, and higher SEC - for SEC-TRD with breakpoints at 2.70 and 3.00 to create a nearly even distribution of projects across the three categories. Examination of these charts reveals a very strong supporting relationship (gamma $=0.45$ ) between SEC-TRD and Perf for the defense projects but only a strong supporting relationship $($ gamma $=0.30)$ for the non-defense projects.

Perf vs. SEC-TRD (Defense)

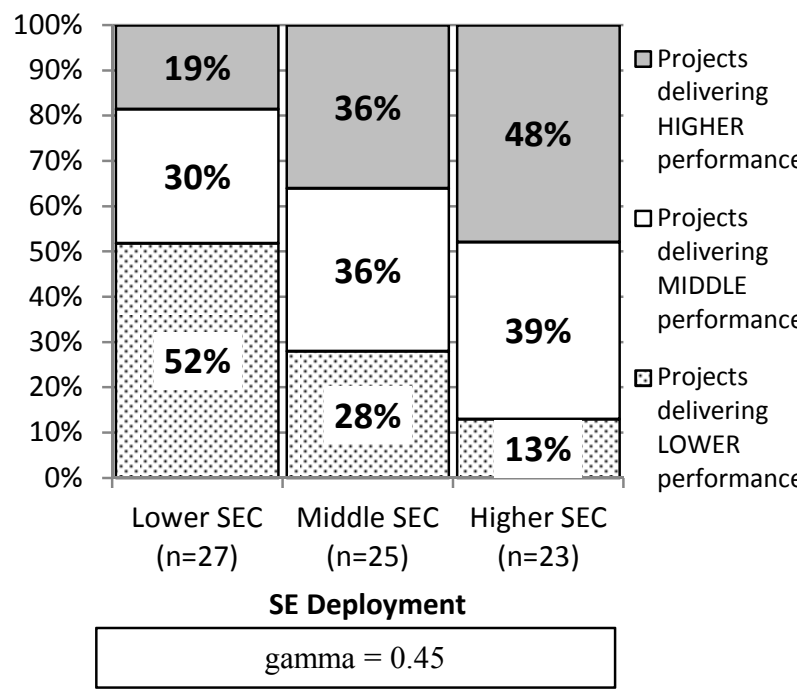

Perf vs. SEC-TRD (Non-Defense)

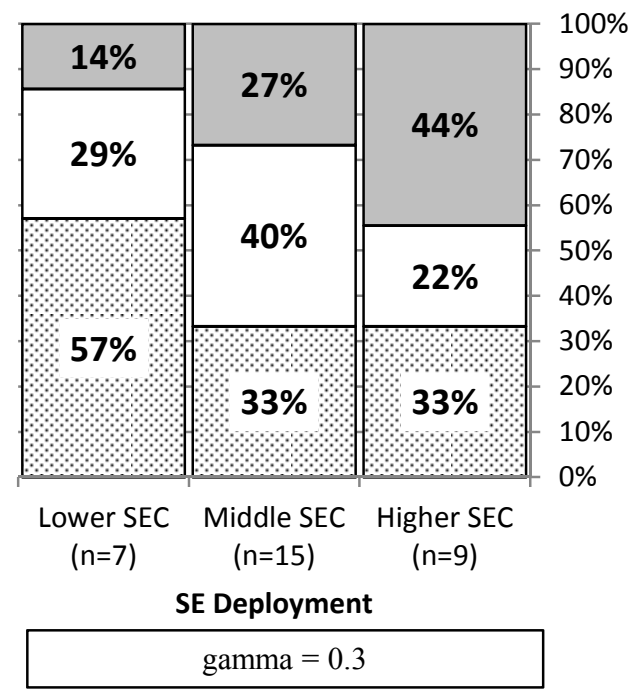

Figure 33: SEC-TRD vs. Perf

\subsubsection{Validation}

The distributions of the responses assessing Validation activities (SEC-VAL) of the projects are shown in Figure 34, with a value of 1 representing very poor Validation work and 4 representing very good Validation work. The respective median values of 3.00 and 3.00 for the defense and non-defense projects indicate no apparent difference in the deployment of Validation activities between defense and non-defense projects. 


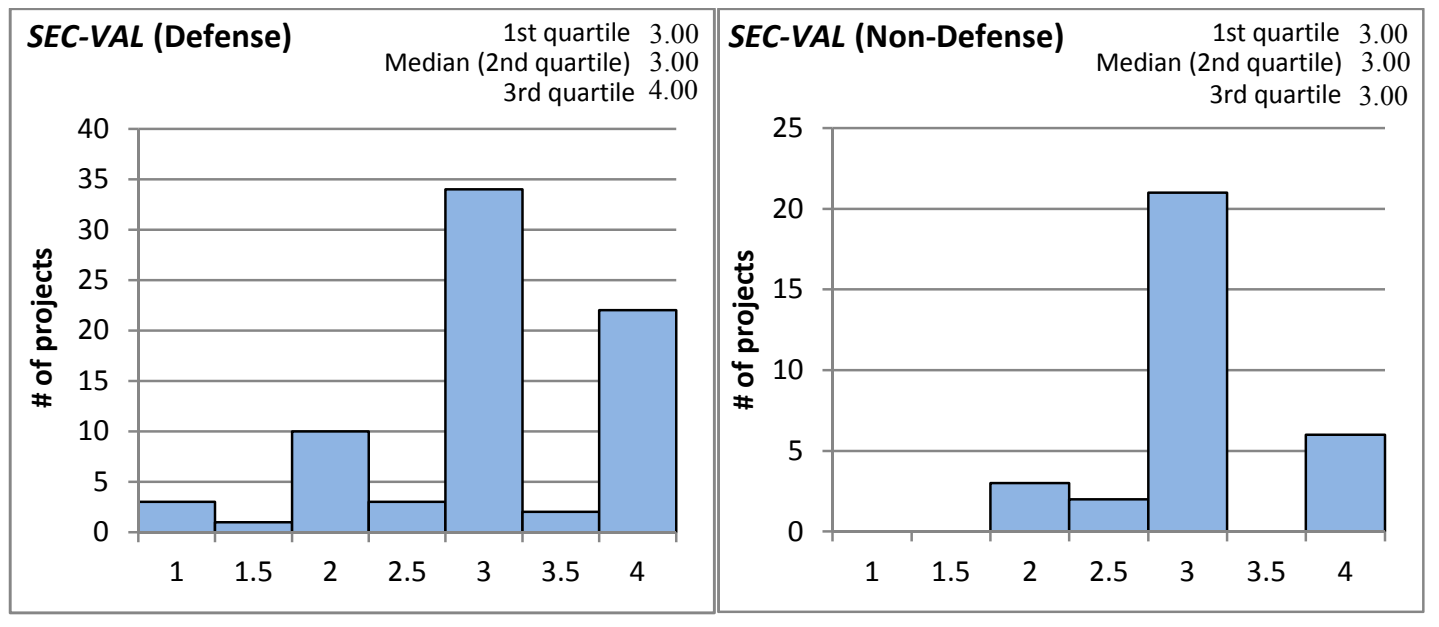

Figure 34: SEC-VAL Response Distribution

The mosaic charts of Figure 35 show the relationship between SEC-VAL and Perf for the defense and non-defense projects. We established three categories - lower SEC, middle SEC, and higher SEC - for SEC-VAL with breakpoints at 2.50 and 3.00 to create a nearly even distribution of projects across the three categories. Examination of these charts reveals a very strong supporting relationship (gamma $=0.45$ ) between $S E C$-VAL and Perf for the defense projects and a very strong supporting relationship $($ gamma $=0.47)$ for the non-defense projects.

Perf vs. SEC-VAL (Defense)

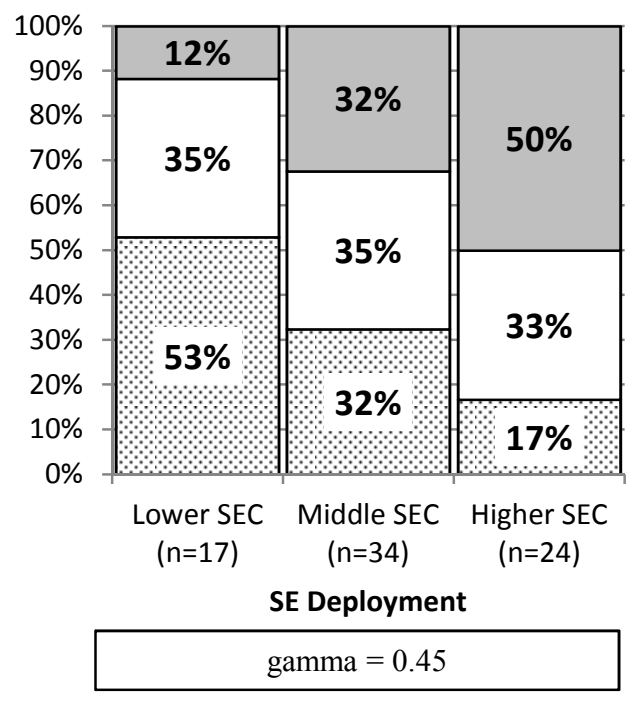

Perf vs. SEC-VAL (Non-Defense)

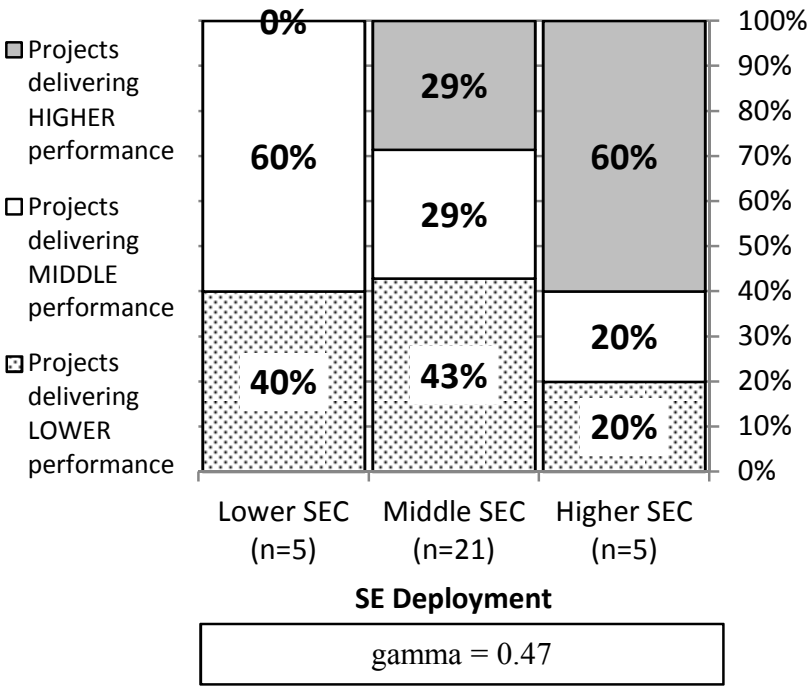

Figure 35: SEC-VAL vs. Perf

\subsubsection{Product Integration}

The distributions of the responses assessing Product Integration activities (SEC-PI) of the projects are shown in Figure 36, with a value of 1 representing very poor Product Integration and 4 representing very good Product Integration. The respective median values of 3.00 and 3.00 for the de- 
fense and non-defense projects indicate no difference in the deployment of Product Integration activities between the two project groups.

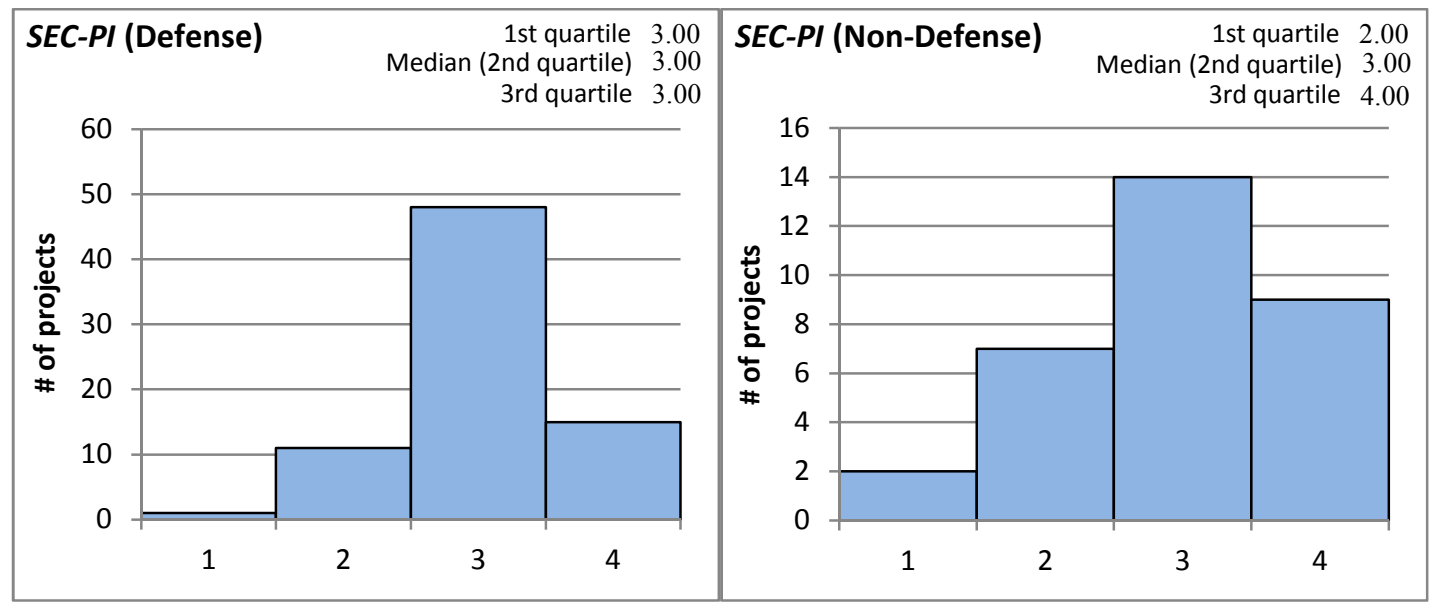

Figure 36: SEC-PI Response Distribution

The mosaic charts of Figure 37 show the relationship between SEC-PI and Perf for the defense and non-defense projects. We established three categories-lower SEC, middle SEC, and higher SEC - for SEC-PI with breakpoints at 2.50 and 3.50 to create a nearly even distribution of projects across the three categories. Examination of these charts reveals a very strong supporting relationship (gamma $=0.45$ ) between SEC-PI and Perf for the defense projects and a very strong supporting relationship $($ gamma $=0.52)$ for the non-defense projects.

Perf vs. SEC-PI (Defense)

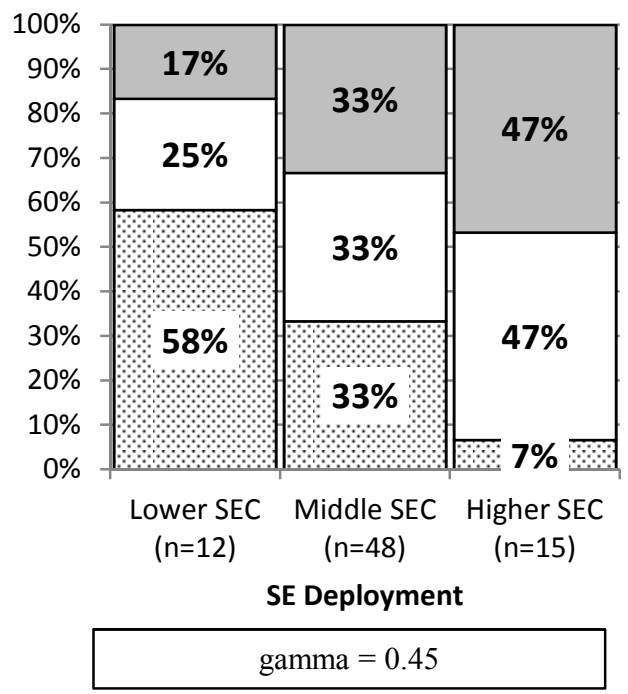

Perf vs. SEC-PI (Non-Defense)

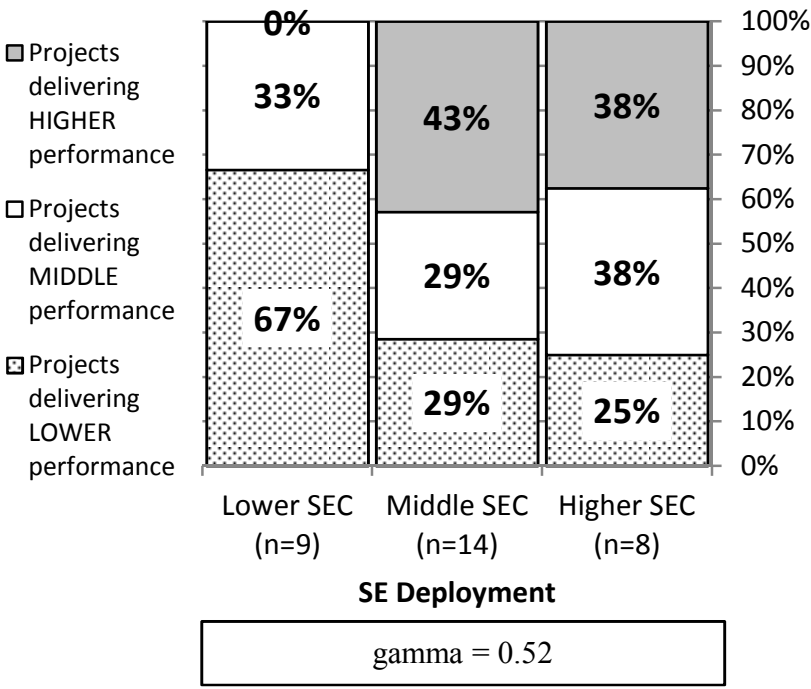

Figure 37: SEC-PI vs. Perf 


\subsubsection{Configuration Management}

The distributions of the responses assessing Configuration Management activities (SEC-CM) of the projects are shown in Figure 38, with a value of 1 representing very poor Configuration Management and 4 representing very good Configuration Management. The respective median values of 3.40 and 3.20 for the defense and non-defense projects indicate that defense projects deploy more Configuration Management activities than non-defense projects.

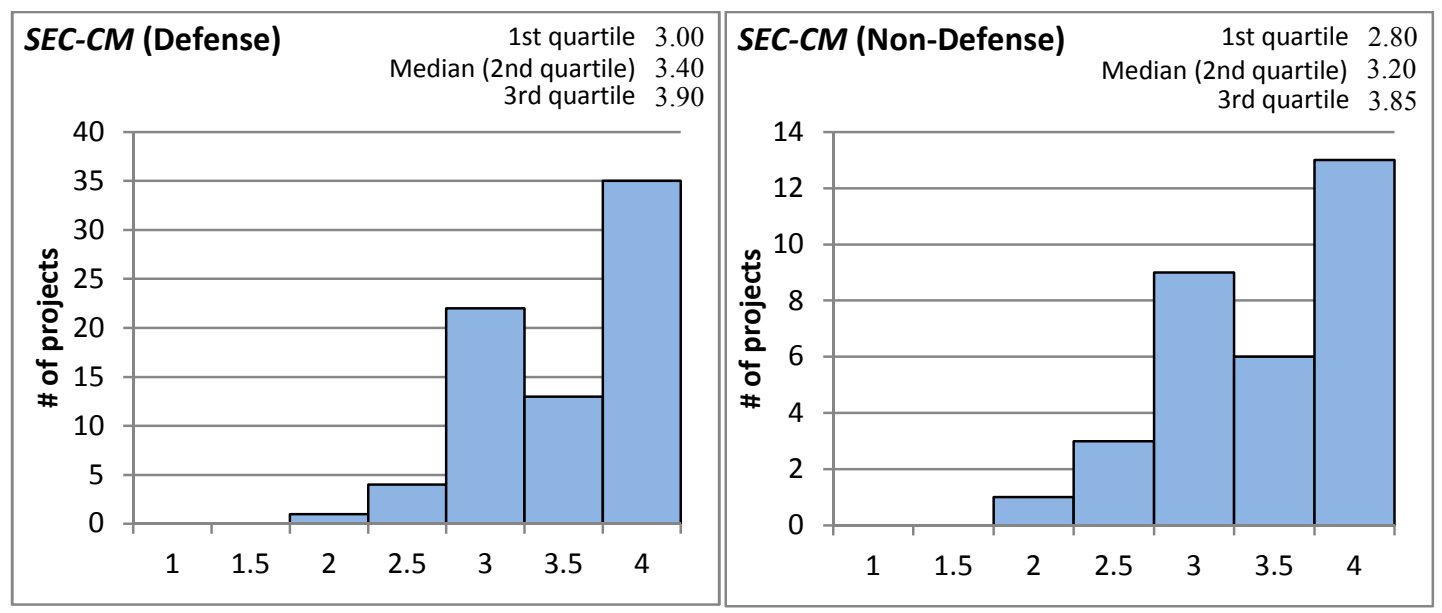

Figure 38: SEC-CM Response Distribution

The mosaic charts of Figure 39 show the relationship between SEC-CM and Perf for the defense and non-defense projects. We established three categories - lower SEC, middle SEC, and higher SEC - for SEC-CM with breakpoints at 3.10 and 3.80 to create a nearly even distribution of projects across the three categories. Examination of these charts reveals a very strong supporting relationship (gamma $=0.42$ ) between SEC-CM and Perf for the defense projects and a very strong supporting relationship $($ gamma $=0.47)$ for the non-defense projects. 
Perf vs. SEC-CM (Defense)

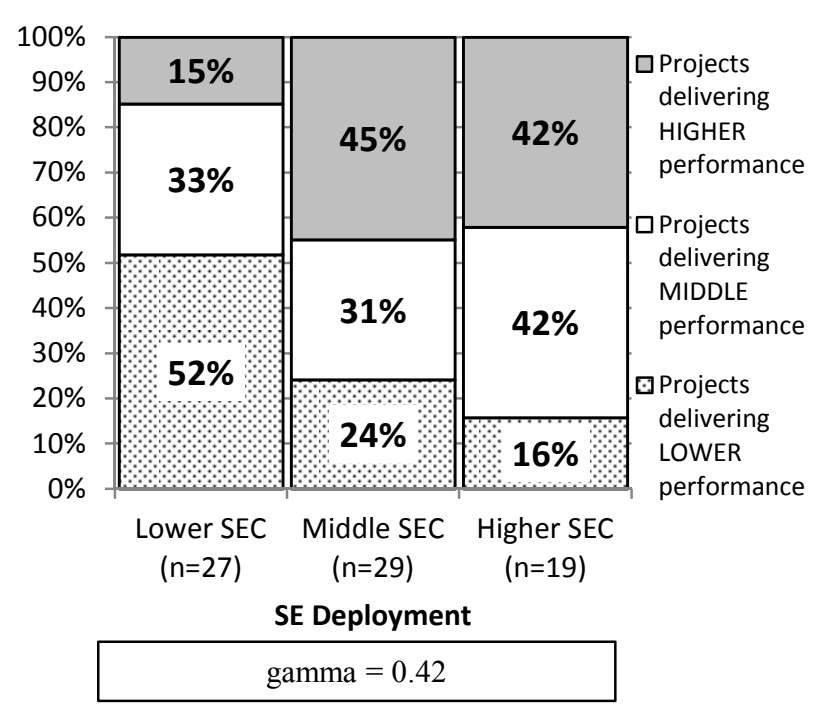

Perf vs. SEC-CM (Non-Defense)

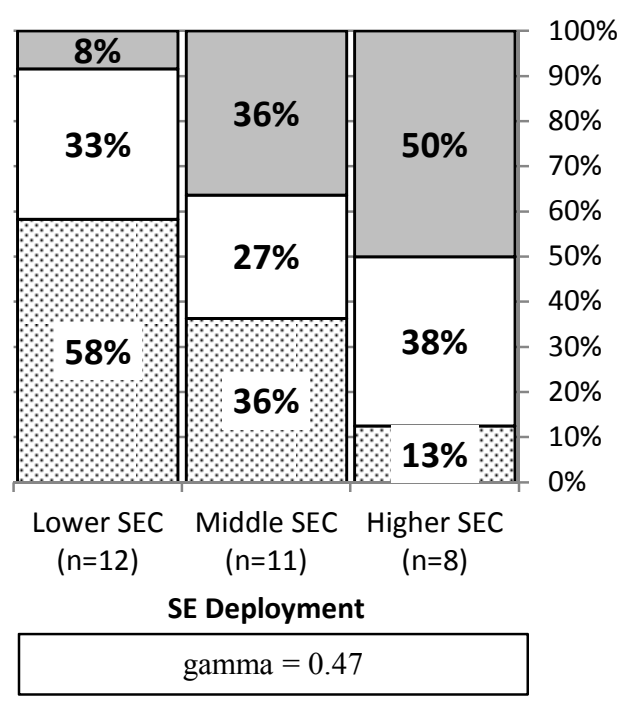

Figure 39: SEC-CM vs. Perf

\subsubsection{Product Architecture}

The distributions of the responses assessing Product Architecture activities (SEC-ARCH) of the projects are shown in Figure 40, with a value of 1 representing very poor Product Architecture work and 4 representing very good Product Architecture work. The respective median values of 3.20 and 3.00 for the defense and non-defense projects indicate that the defense projects deploy more Product Architecture activities than the non-defense projects.

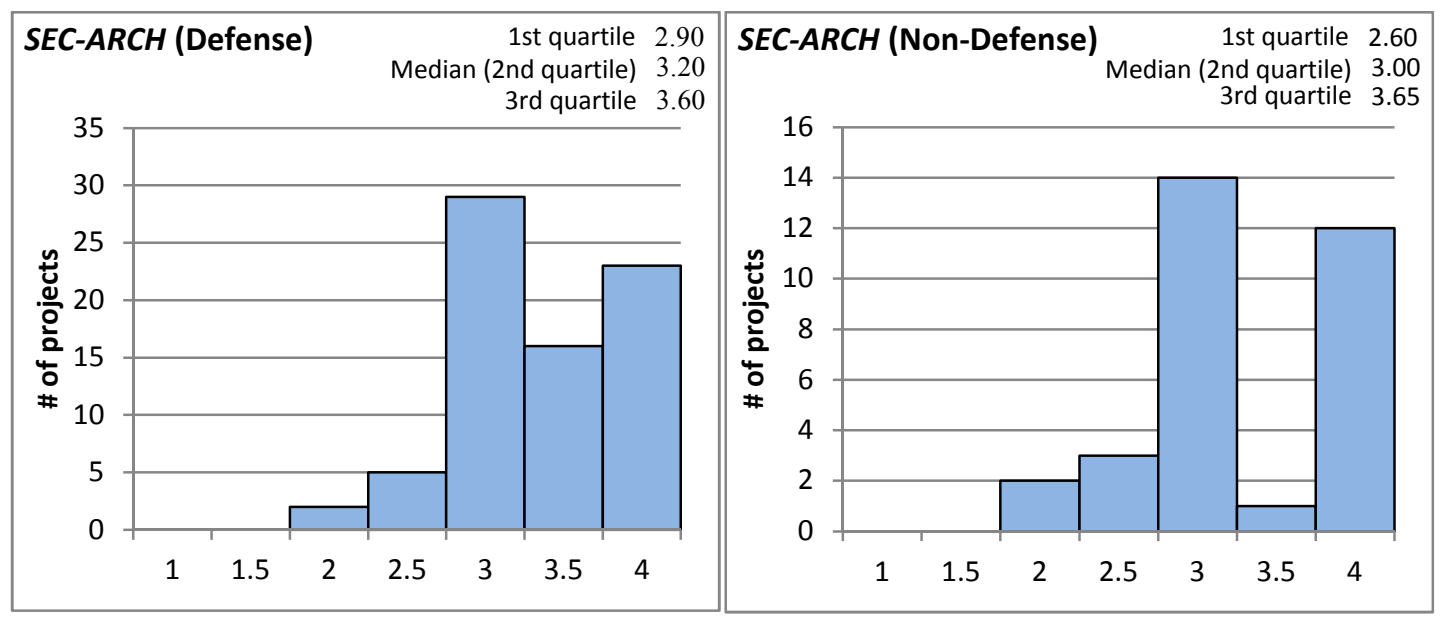

Figure 40: SEC-ARCH Response Distribution

The mosaic charts of Figure 41 show the relationship between SEC-ARCH and Perf for the defense and non-defense projects. We established three categories - lower SEC, middle SEC, and higher SEC - for SEC-ARCH with breakpoints at 2.95 and 3.40 to create a nearly even distribution of projects across the three categories. Examination of these charts reveals a strong support- 
ing relationship (gamma $=0.38$ ) between $S E C-A R C H$ and Perf for the defense projects and a very strong supporting relationship $($ gamma $=0.54)$ for the non-defense projects.

\section{Perf vs. SEC-ARCH \\ (Defense)}

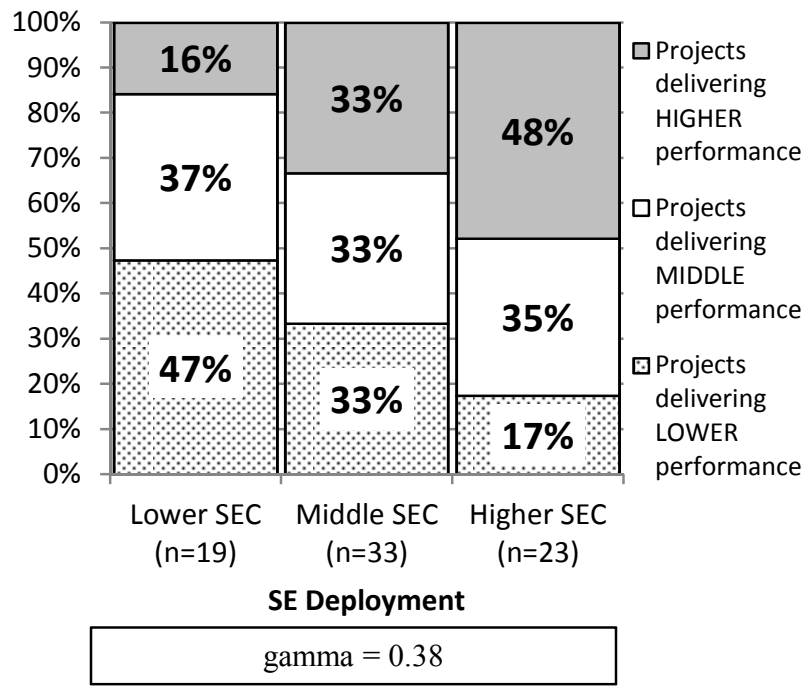

\section{Perf vs. SEC-ARCH \\ (Non-Defense)}

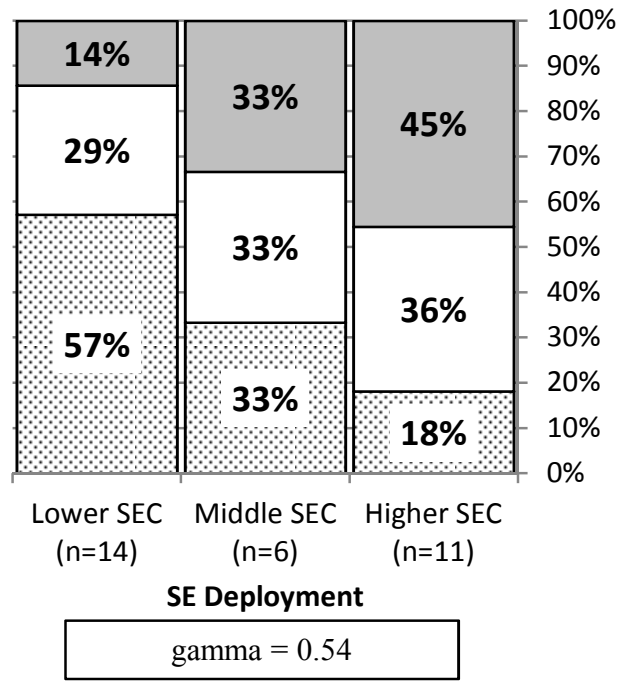

Figure 41: SEC-ARCH vs. Perf

\subsubsection{Integrated Product Teams}

The distributions of the responses assessing the use of Integrated Product Teams (SEC-IPT) are shown in Figure 42, with a value of 1 representing very poor use and 4 representing very good use. The respective median values of 3.00 and 3.00 for the defense and non-defense projects indicate no apparent differences in the deployment of Integrated Product Teams activities between the two project groups.

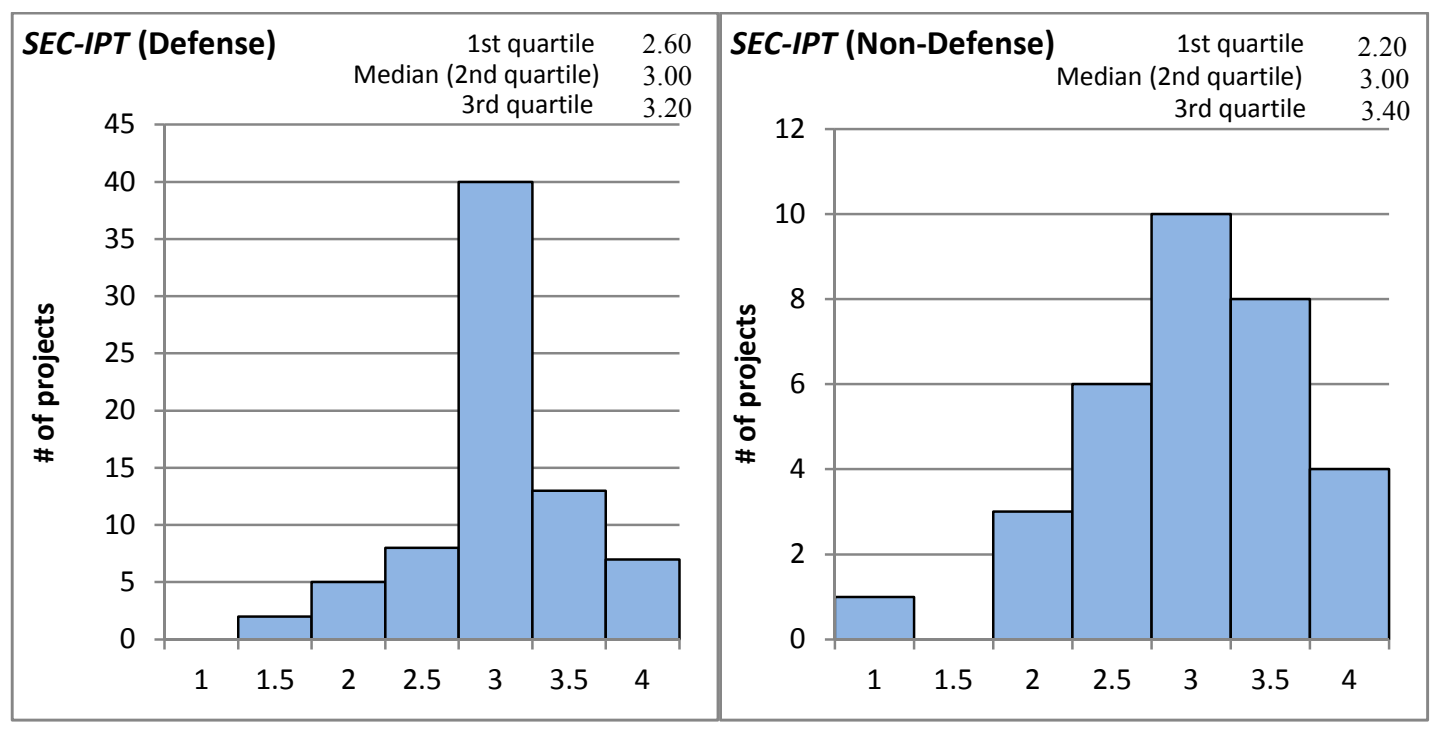

Figure 42: SEC-IPT Response Distribution 
The mosaic charts of Figure 43 show the relationship between SEC-IPT and Perf for the defense and non-defense projects. We established three categories-lower SEC, middle SEC, and higher SEC - for SEC-IPT with breakpoints at 2.6 and 3.00 to create a nearly even distribution of projects across the three categories. Examination of these charts reveals a strong supporting relationship (gamma $=0.32$ ) between SEC-IPT and Perf for the defense projects and a moderate supporting relationship $($ gamma $=0.23$ ) for the non-defense projects.

Perf vs. SEC-IPT

(Defense)

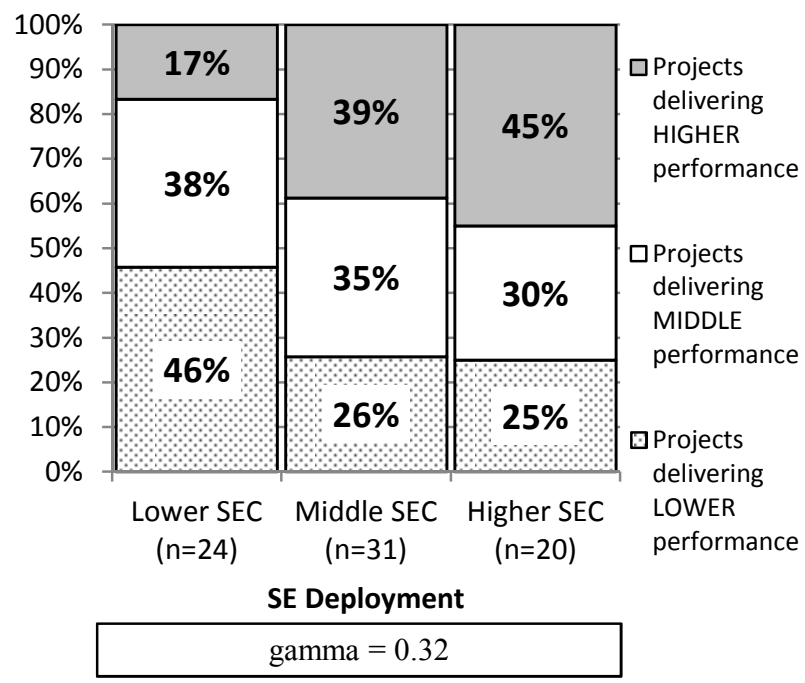

Perf vs. SEC-IPT

(Non-Defense)

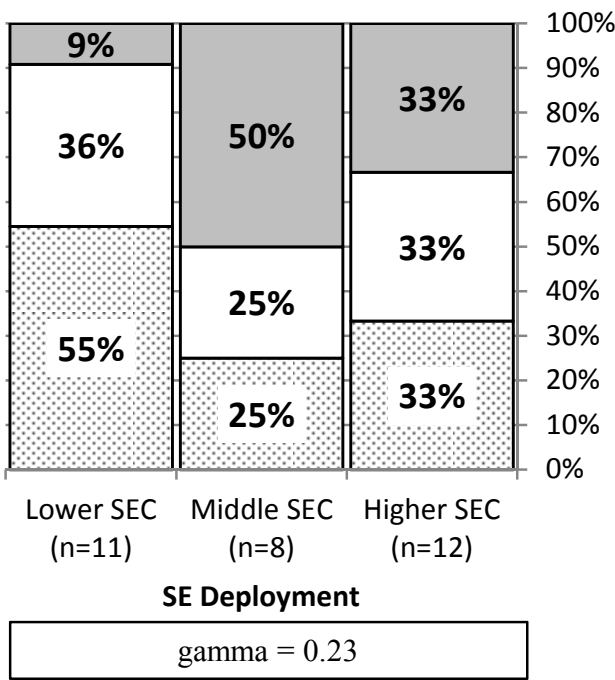

Figure 43: SEC-IPT vs. Perf

\subsubsection{Risk Management}

The distributions of the responses assessing Risk Management activities (SEC-RSKM) of the projects are shown in Figure 44, with a value of 1 representing very poor Risk Management and 4 representing very good Risk Management. The respective median values of 3.00 and 2.88 for the defense and non-defense projects indicate that defense projects deploy somewhat more Risk Management activities than non-defense projects.

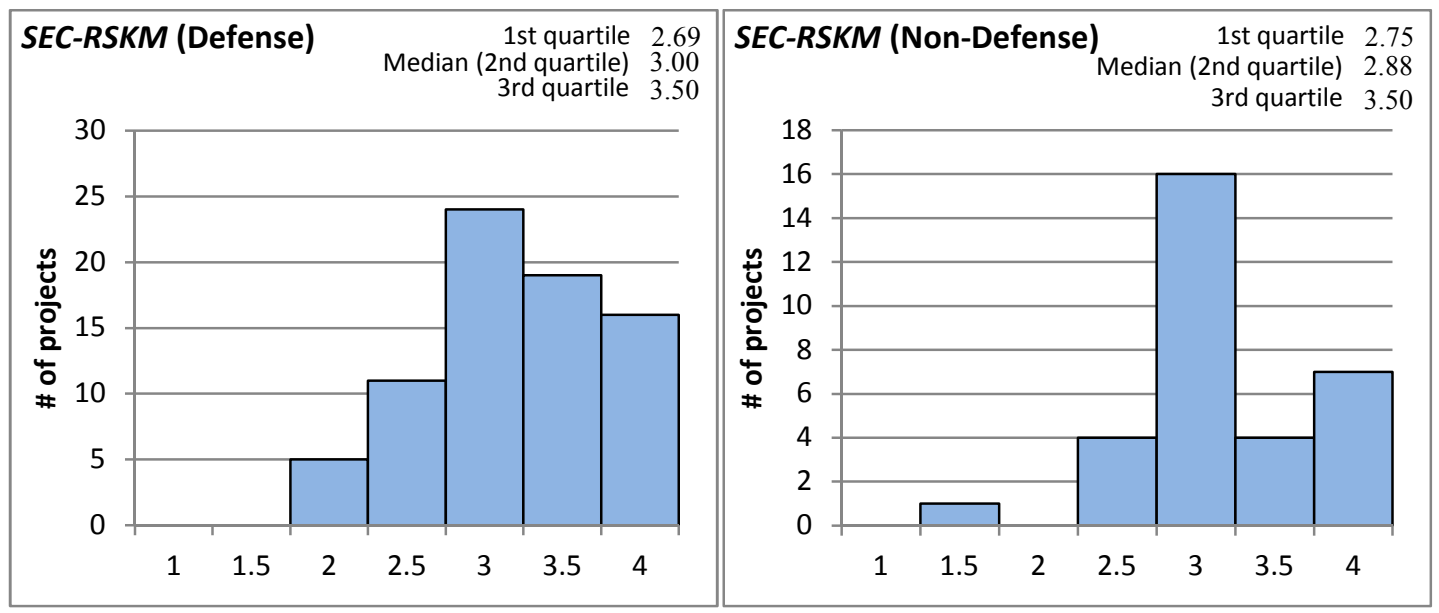

Figure 44: SEC-RSKM Response Distribution 
The mosaic charts of Figure 45 show the relationship between SEC-RSKM and Perf for the defense and non-defense projects. We established three categories-lower SEC, middle SEC, and higher SEC - for SEC-RSKM with breakpoints at 2.75 and 3.40 to create a nearly even distribution of projects across the three categories. Examination of these charts reveals a moderate supporting relationship (gamma $=0.28$ ) between SEC-RSKM and Perf for the defense projects and a very strong supporting relationship $($ gamma $=0.40)$ for the non-defense projects.

\section{Perf vs. SEC-RSKM}

(Defense)

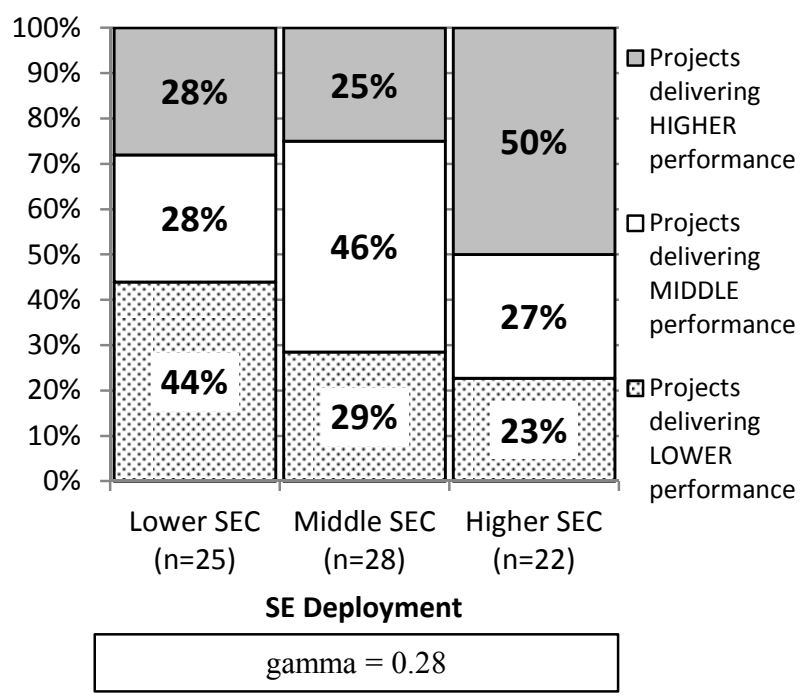

Perf vs. SEC-RSKM

(Non-Defense)

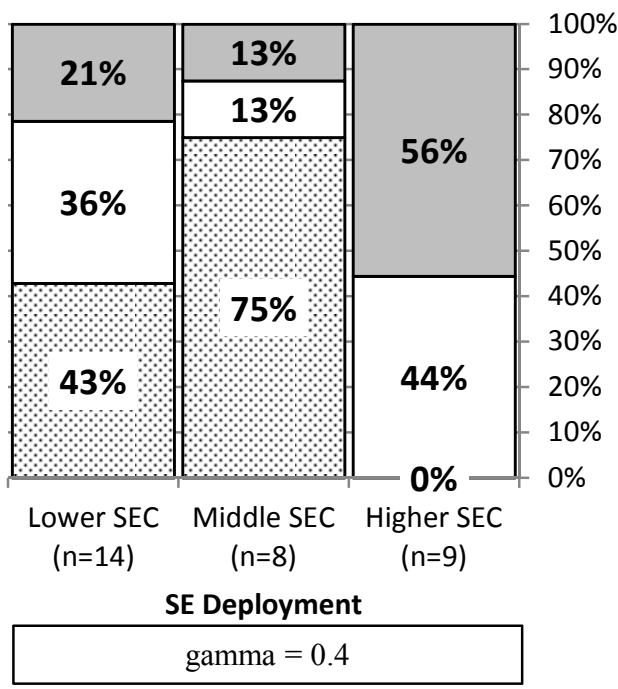

Figure 45: SEC-RSKM vs. Perf

\subsubsection{Composite Systems Engineering Capabilities}

\subsubsection{Total Systems Engineering Capability}

As discussed previously, the total SE capability (SEC-Total) applied to a project is assessed as the amalgam of SE capabilities applied in the following process groups:

- Project Planning (SEC-PP)

- Verification (SEC-VER)

- Project Monitoring and Control (SEC-PMC)

- Requirements Development and Management (SEC-REQ)

- $\quad$ Trade Studies (SEC-TRD)

- Validation $(S E C-V A L)$

- Product Integration (SEC-PI)

- Configuration Management (SEC-CM)

- Product Architecture (SEC-ARCH)

- Integrated Product Teams (SEC-IPT)

- Risk Management (SEC-RSKM) 
The distributions of SEC-Total are shown in Figure 46, with a value of 1 representing very poor SE deployment and 4 representing very good SE deployment. The median values of 3.05 and 3.00 for the defense and non-defense projects, respectively, show that defense-domain projects deploy slightly more SE than non-defense projects.

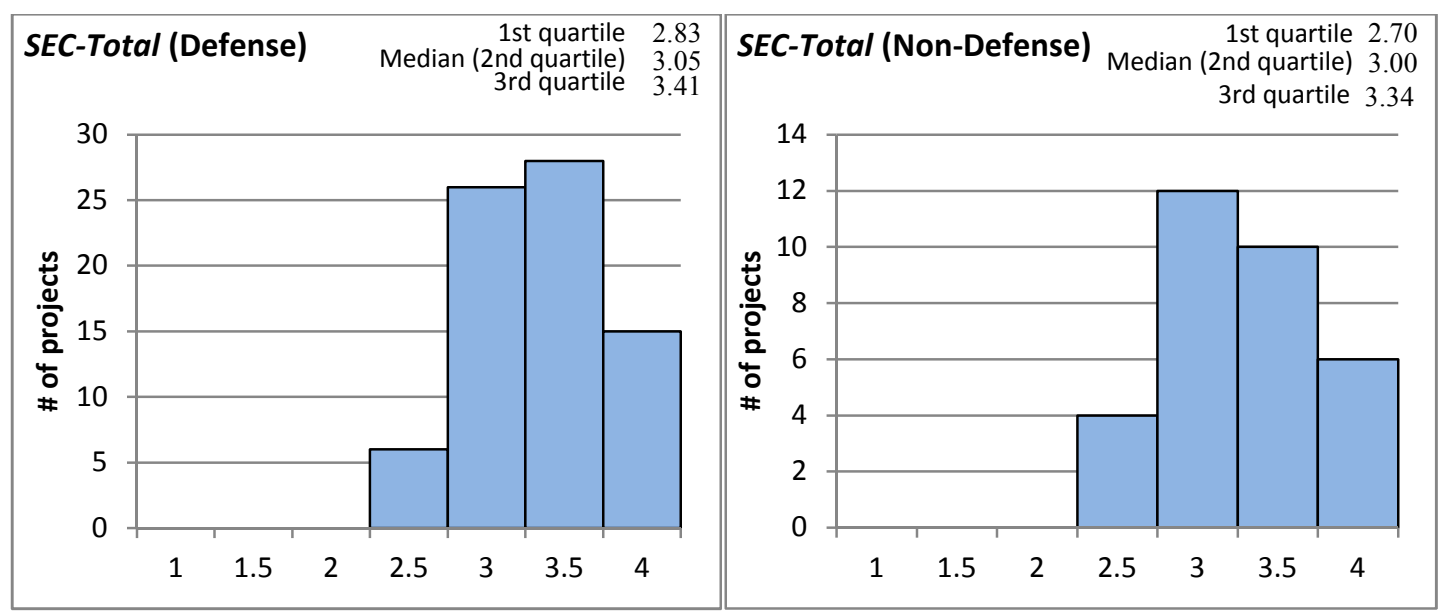

Figure 46: SEC-Total Response Distribution

The mosaic charts of Figure 47 show the relationship between SEC-Total and Perf for the defense and non-defense projects. We established three categories - lower SEC, middle SEC, and higher SEC - for SEC-Total with breakpoints at 2.87 and 3.27 to create a nearly even distribution of projects across the three categories. Examination of these charts reveals a very strong supporting relationship (gamma $=0.57$ ) between SEC-Total and Perf for the defense projects. But the relationship between SEC-Total and Perf for the non-defense projects is even stronger, with a gamma value of 0.66 .

Project Performance vs. SEC-Total (Defense)

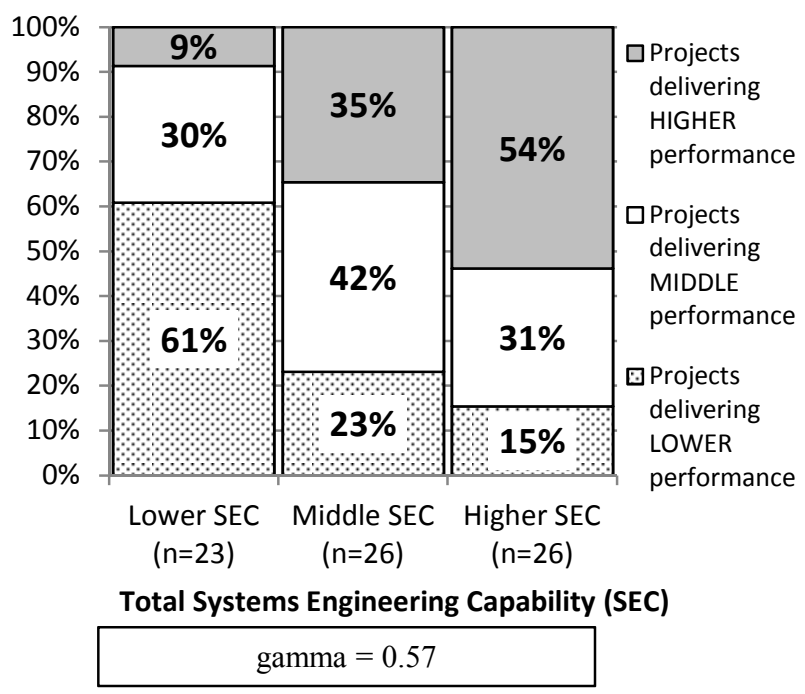

Project Performance vs. SECTotal (Non-Defense)

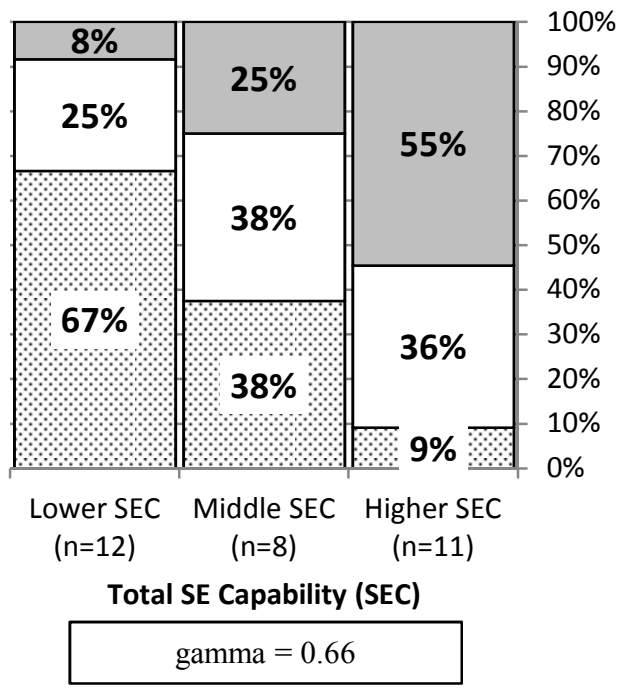

Figure 47: SEC-Total vs. Perf 


\subsubsection{Early Systems Engineering}

One of our hypotheses was that SE activities performed early in the program life cycle have the greatest impact on project performance. If this hypothesis is true, then we would expect to find the strongest relationships between these early SE activities and project performance. SE activities that are predominantly performed early in the system life cycle include

- Project Planning

- Requirements Development and Management

- Trade Study performance

- Product Architecture development

We formed an amalgam of these SE process areas, labeled it Early SE, and analyzed its relationship to project performance.

The distributions of the responses assessing Early SE are shown in Figure 48, with a value of 1 representing very poor use and 4 representing very good use. The respective median values of 3.03 and 3.06 for the defense and non-defense projects show that defense-domain projects deploy slightly less Early SE than non-defense projects.

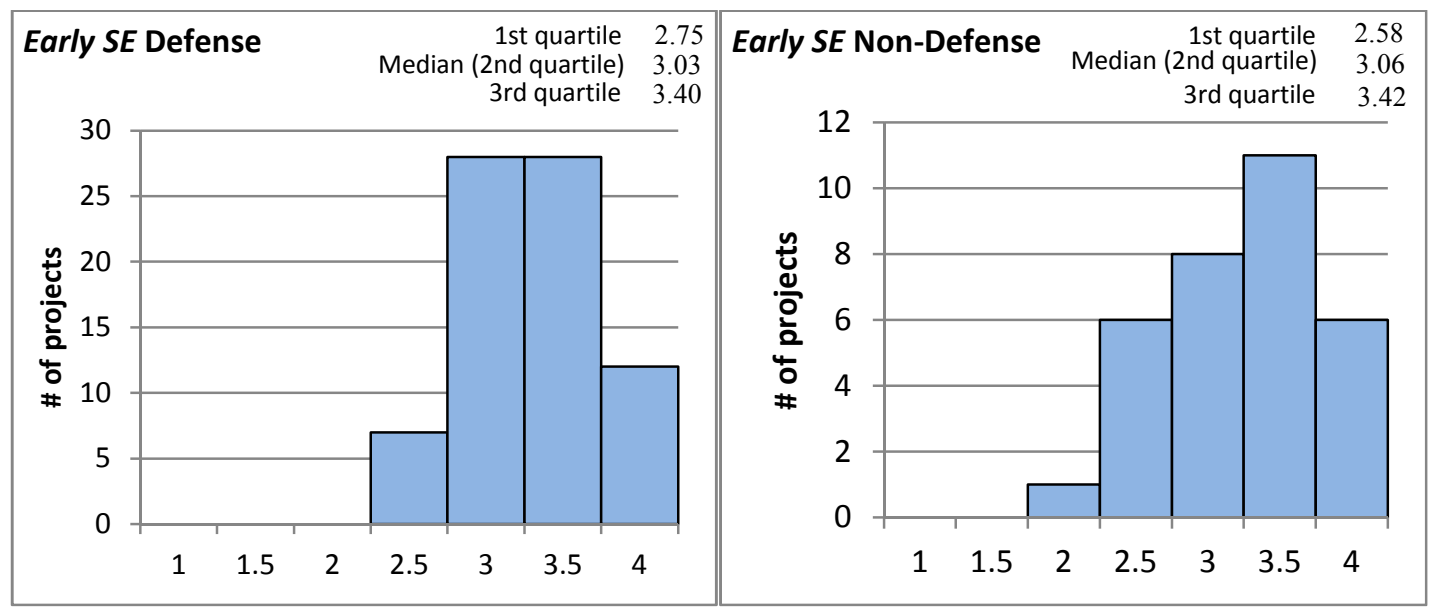

Figure 48: Early SE Response Distribution

The mosaic charts of Figure 49 show the relationship between Early SE and Perf for the defense and non-defense projects. We established three categories - lower SEC, middle SEC, and higher SEC - for Early SE with breakpoints at 2.85 and 3.375 to create a nearly even distribution of projects across the three categories. Examination of these charts reveals a very strong supporting relationship (gamma $=0.61$ ) between Early SE and Perf for the defense projects and a very strong supporting relationship $($ gamma $=0.62)$ for the non-defense projects. 
Perf vs. Early SE (Defense)

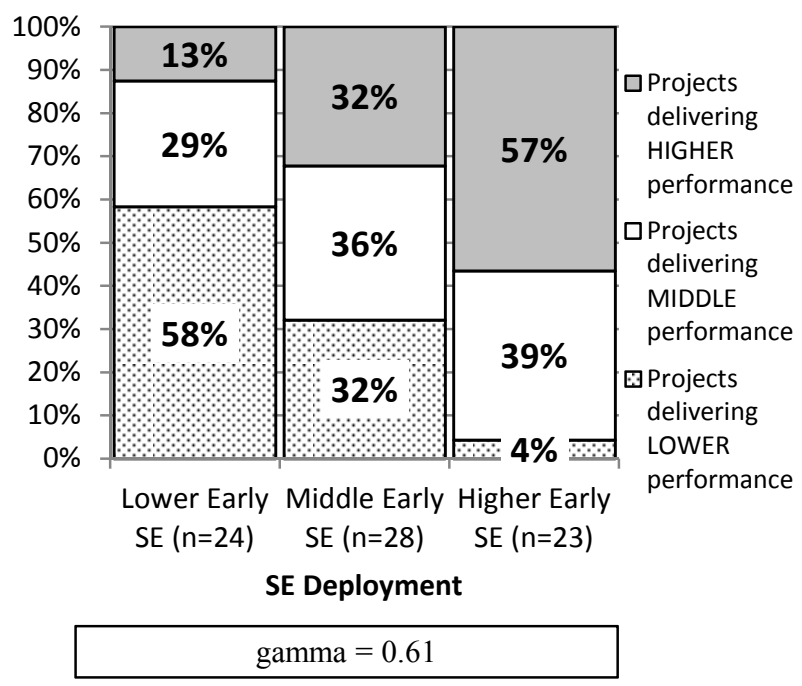

Perf vs. Early SE (Non-Defense)

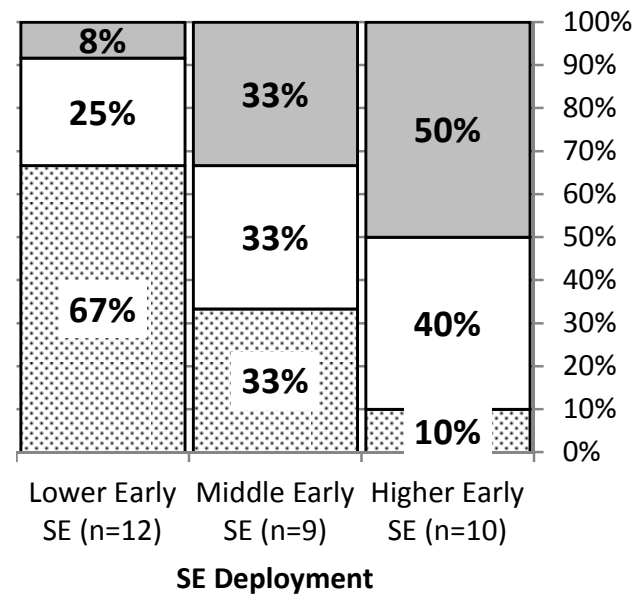

gamma $=0.62$

Figure 49: Early SE vs. Perf

\subsection{Experience}

The prior experience of the project team and the organization can have an impact on project performance. Figure 50 shows the distributions of survey responses assessing the prior experience metric $(E X P)$ for the defense and the non-defense projects. The two groups of projects show little difference in experience.

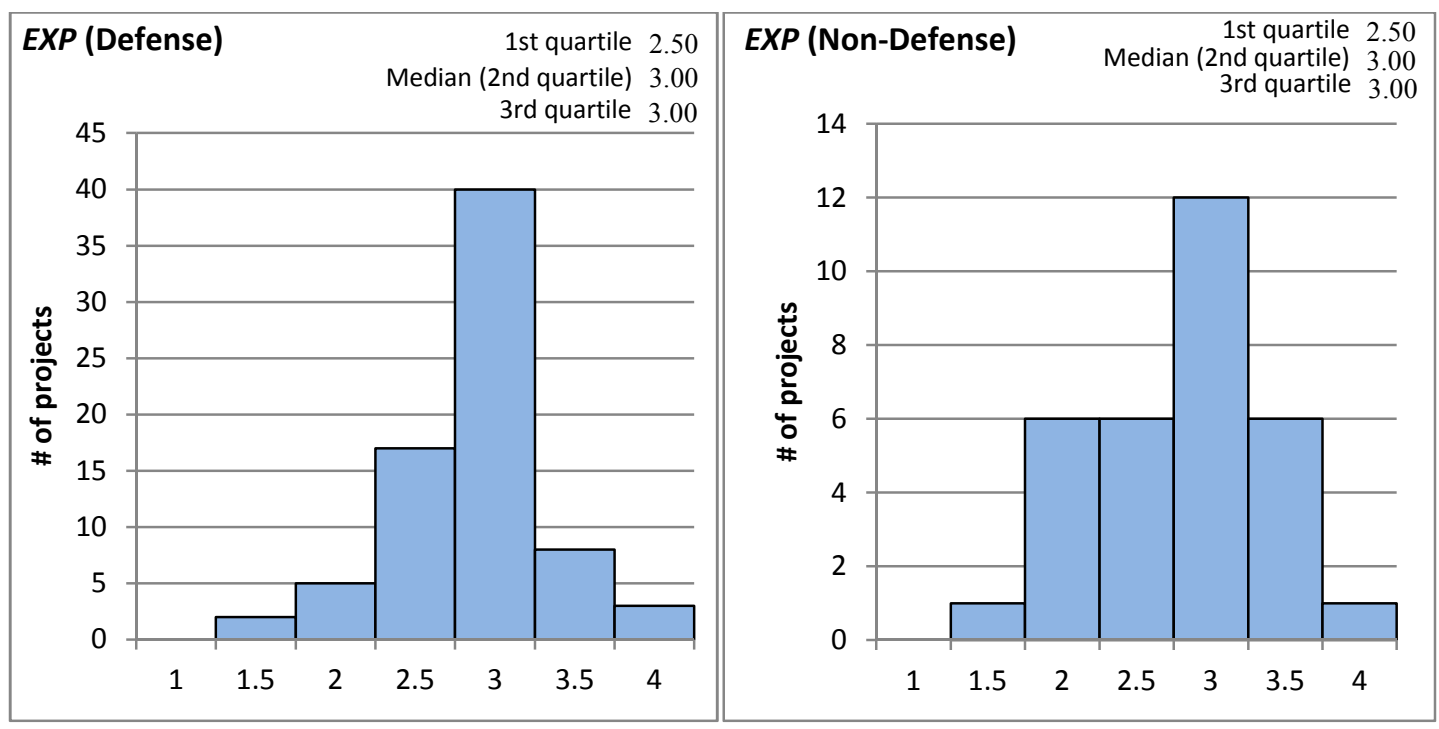

Figure 50: Experience Response Distribution

The mosaic charts of Figure 51 show the relationship between EXP and Perf for the defense and non-defense projects. Three categories - lower experience, middle experience, and higher experience - were established for EXP with breakpoints at 2.9 and 3.3 to create a nearly even distribution of projects across the three categories. These charts reveal a weak positive relationship (gamma $=0.09$ ) between EXP and Perf for the defense-domain projects, but a very strong positive 
relationship $($ gamma $=0.54$ ) for the non-defense projects. The difference in the magnitude of the relationship between defense and non-defense projects indicates that experience has a far greater impact on non-defense projects than it has on defense projects.

Perf vs. EXP (Defense)

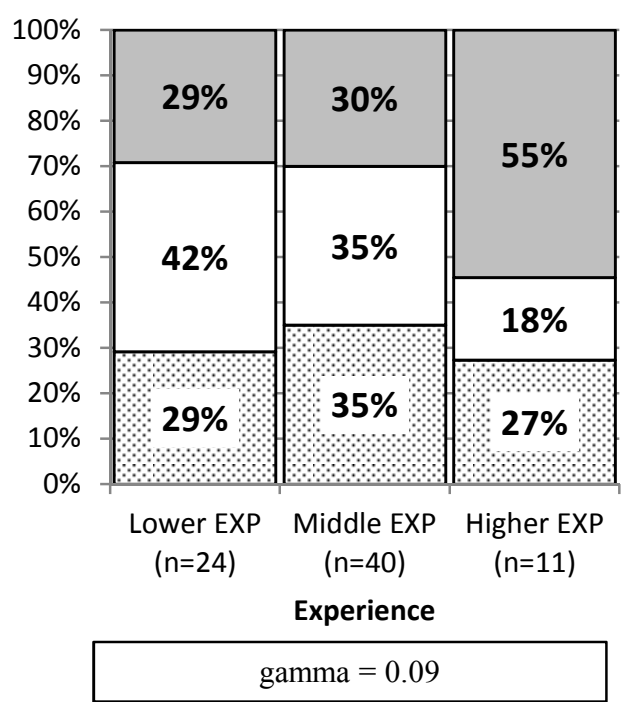

Perf vs. EXP (Non-Defense)

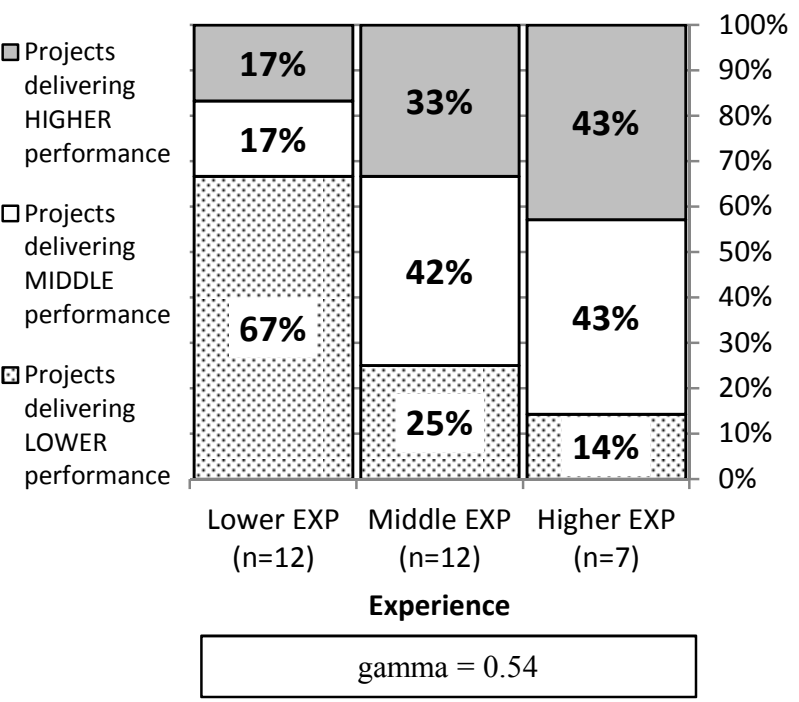

Figure 51: Performance vs. Experience 


\section{Summary and Conclusions}

\subsection{Summary}

The impetus for this survey was a desire to compare and contrast the application and impact of SE in two different domains - defense and non-defense - with the hope of identifying best practices in one domain that could be transferred to the other to further improve project performance. Our study found significant differences in both the deployment of these practices and the impact of these practices on project performance.

Our defense domain sample consisted of 116 project participants who self-identified as defense related. Of these defense projects, 75 were selected based on their PC score to create a sample reflecting degrees of project challenge equivalent to the sample of non-defense projects. Our nondefense sample consisted of 32 projects from sectors such as electronic equipment, communications, and health care.

We examined the performance of the projects, as measured on a scale of 1 (poor performance) to 5 (good performance) based on satisfaction of budget, schedule, and technical requirements. We found that performance against budget and technical requirements was essentially the same in both the defense and the non-defense domains. However, non-defense projects performed somewhat better against schedule than did defense projects. Table 2 and Figure 52 show the median values of the assessed performance measures.

Table 2: Project Performance Comparison

\begin{tabular}{|l|c|c|}
\hline \multirow{2}{*}{ Parameter } & \multicolumn{2}{|c|}{ Median Values } \\
\cline { 2 - 3 } & $\begin{array}{c}\text { Defense } \\
\text { Projects }\end{array}$ & $\begin{array}{c}\text { Non-Defense } \\
\text { Projects }\end{array}$ \\
\hline Total performance (Perf) & 3.51 & 3.59 \\
\hline Cost performance (PerfC) & 3.50 & 3.50 \\
\hline Schedule performance (PerfS) & 3.50 & 3.58 \\
\hline Technical performance (PerfT) & 3.67 & 3.67 \\
\hline
\end{tabular}




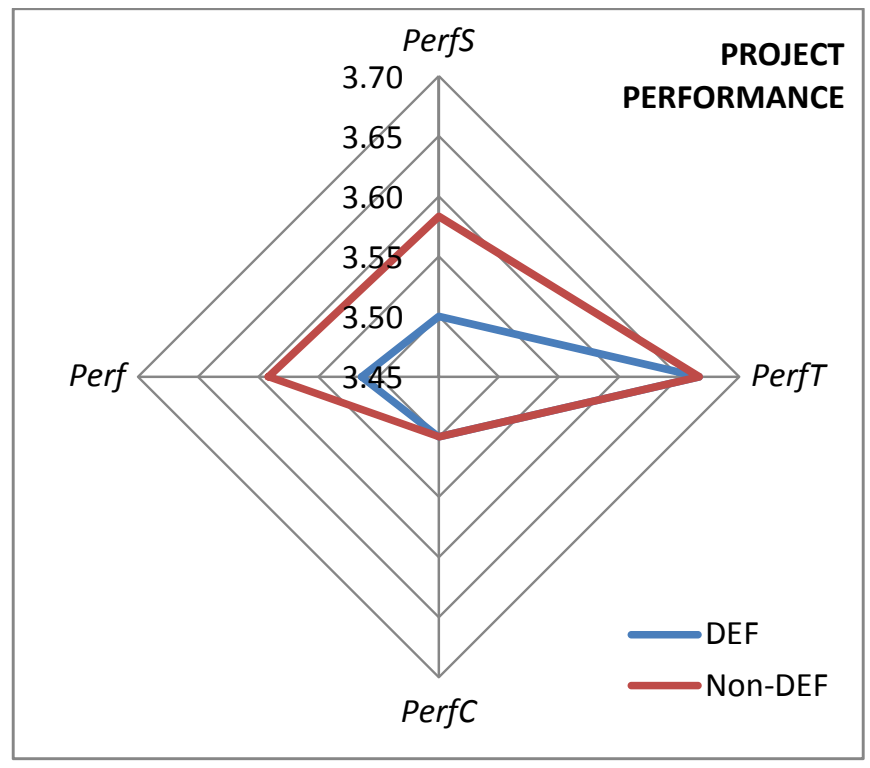

Figure 52: Project Performance Comparison

We examined the degree of challenge posed by the projects, measured on a scale of 1 (low challenge) to 4 (high challenge). Because we selected a subsample of defense projects to have the same median challenge as the non-defense projects, both groups exhibited a median value of 2.61 for $P C$.

Finally, we examined the deployment of SE practices in a number of SE process areas. The deployment was measured on a scale of 1 (little SE deployment) to 4 (much SE deployment). Here, we found some differences between the defense and the non-defense domain, as shown in Table 3 and Figure 53.

Table 3: SE Deployment Comparison

\begin{tabular}{|l|c|c|}
\hline \multirow{2}{*}{ Parameter } & \multicolumn{2}{|c|}{ Median Values } \\
\cline { 2 - 3 } & Defense Projects & Non-Defense Projects \\
\hline Total SE & 3.05 & 3.00 \\
\hline Early SE & 3.03 & 3.06 \\
\hline Project Planning & 2.96 & 2.87 \\
\hline Verification & 3.11 & 3.00 \\
\hline Monitoring and Control & 3.09 & 3.00 \\
\hline Requirements Dev't \& Mg't & 3.15 & 3.18 \\
\hline Trade Studies & 3.00 & 3.00 \\
\hline Validation & 3.00 & 3.00 \\
\hline Product Integration & 3.00 & 3.00 \\
\hline Configuration Management & 3.40 & 3.20 \\
\hline Product Architecture & 3.20 & 3.00 \\
\hline Integrated Product Teams & 3.00 & 3.00 \\
\hline Risk Management & 3.00 & 2.88 \\
\hline
\end{tabular}




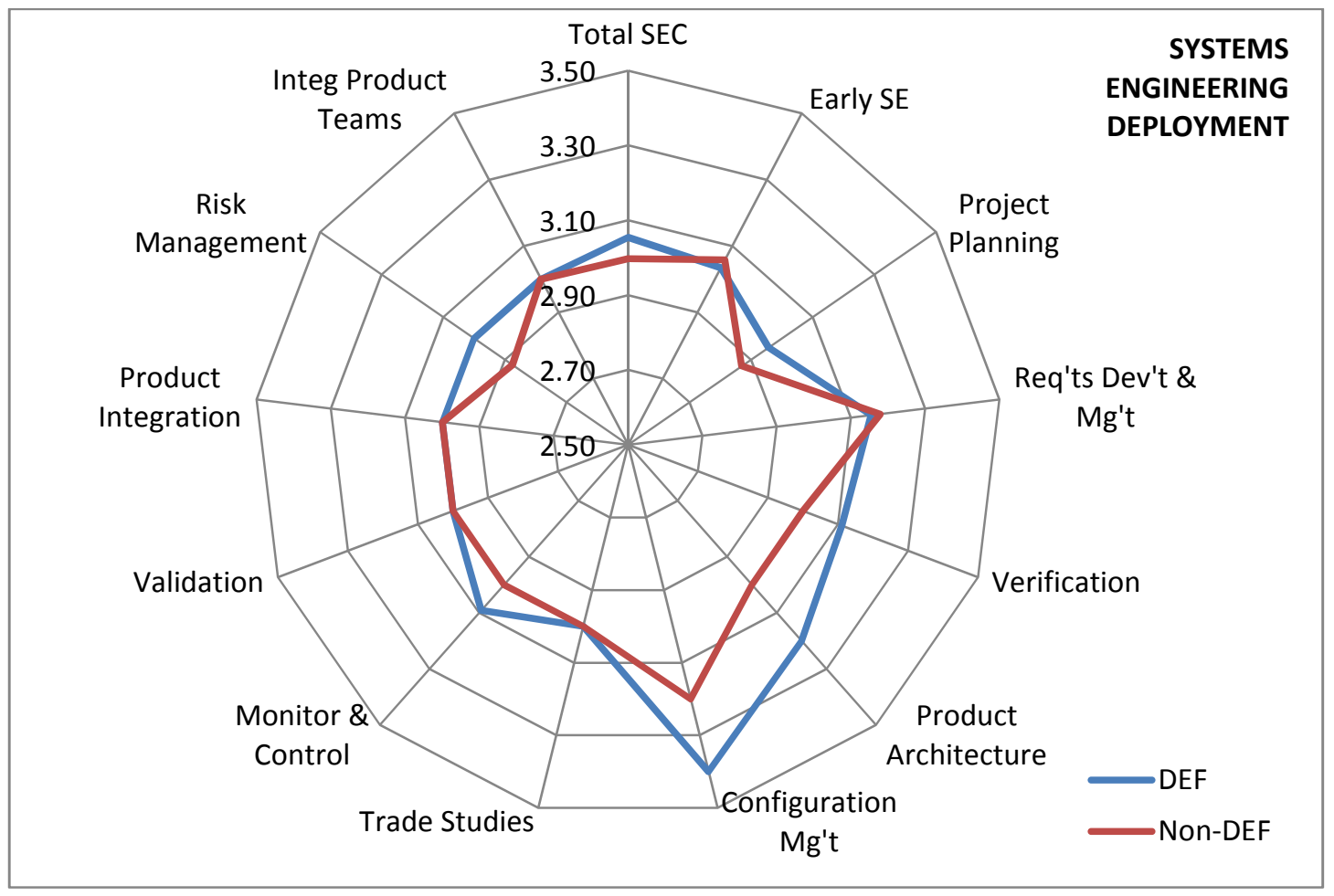

Figure 53: SE Deployment Comparison

In nearly all SE process areas except (1) Early SE and (2) Requirements Development and Management, the SE capabilities deployed by the defense projects were greater than or equal to that deployed by the non-defense projects. While most of the differences appear to be modest, the probability that 10 of the 13 would be greater for the non-defense projects by chance alone is unlikely ( $p<0.02$ using a simple sign test) [Kitchens 2002].

We then examined the relationships between the deployed SE activities and project performance, using Goodman and Kruskal's gamma to quantify the strength of the relationship. A gamma value near -1 indicates a very strong opposing relationship; a value near 0 indicates a weak or nonexistent relationship; and a value near +1 indicates a very strong supporting relationship. These relationships are summarized in Table 4 and Figure 54. 
Table 4: Perf vs. SEC Relationship Comparisons

\begin{tabular}{|l|c|c|}
\hline \multirow{2}{*}{ Parameter } & \multicolumn{2}{|c|}{ Gamma } \\
\cline { 2 - 3 } & Defense Projects & Non-Defense Projects \\
\hline Perf vs. Total SE & 0.57 & 0.66 \\
\hline Perf vs. Early SE & 0.61 & 0.62 \\
\hline Perf vs. Project Challenge & -0.08 & -0.24 \\
\hline Perf vs. Project Planning & 0.57 & 0.59 \\
\hline Perf vs. Verification & 0.55 & 0.64 \\
\hline Perf vs. Monitoring and Control & 0.48 & 0.38 \\
\hline Perf vs. Requirements Dev't \& Mg't & 0.46 & 0.60 \\
\hline Perf vs. Trade Studies & 0.45 & 0.30 \\
\hline Perf vs. Validation & 0.45 & 0.47 \\
\hline Perf vs. Product Integration & 0.45 & 0.52 \\
\hline Perf vs. Configuration Management & 0.42 & 0.47 \\
\hline Perf vs. Product Architecture & 0.38 & 0.54 \\
\hline Perf vs. Integrated Product Teams & 0.32 & 0.23 \\
\hline Perf vs. Risk Management & 0.28 & 0.40 \\
\hline
\end{tabular}

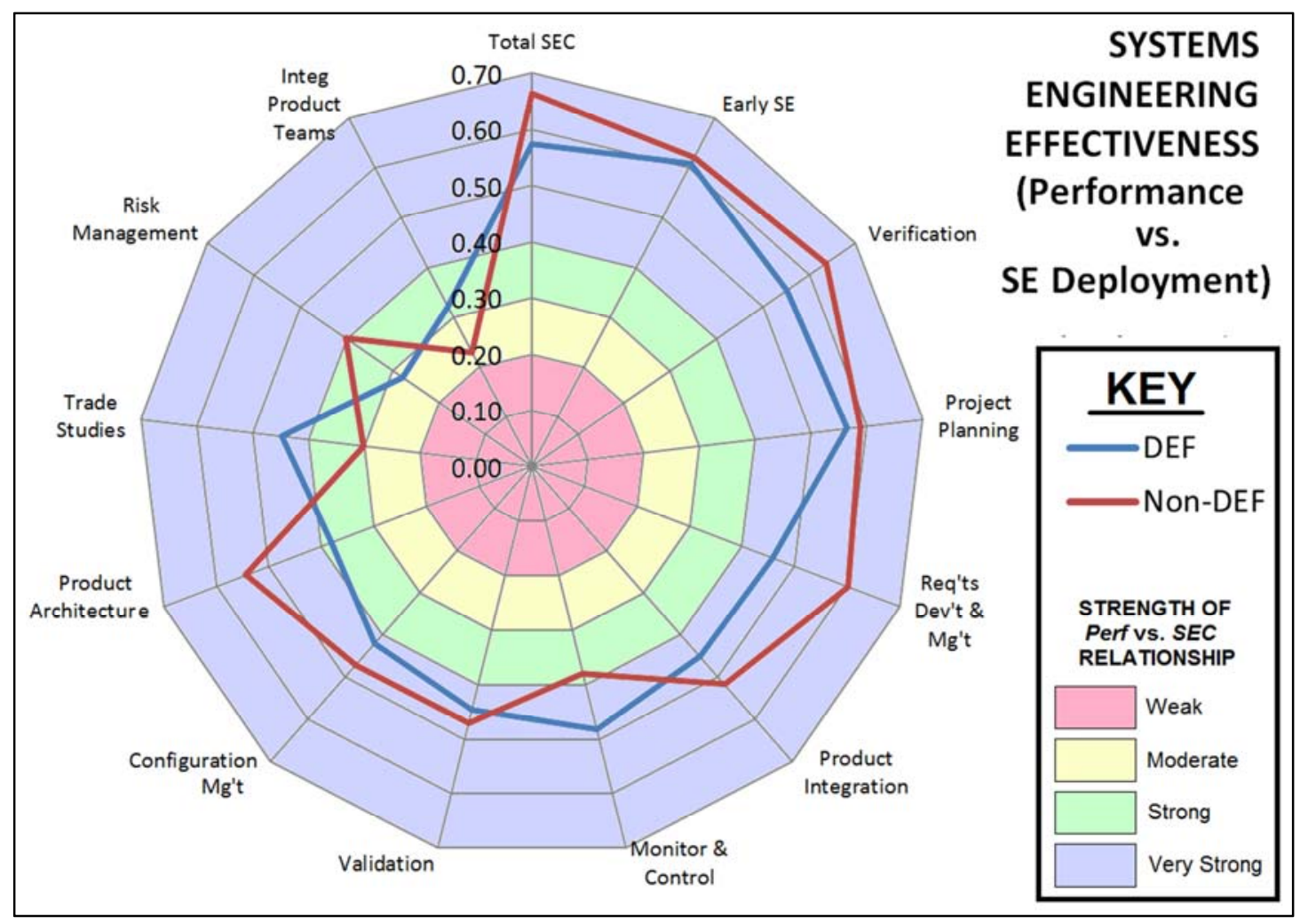

Figure 54: Perf vs. SEC Relationship Comparisons

In Figure 54 and Table 5, we see that 10 of the 13 relationships are stronger for non-defense projects than they are for defense projects. The probability that 10 of the 13 would be stronger for the defense projects by chance alone is, again, unlikely ( $p<0.02$ using a simple sign test). 
Table 5: Stronger SE Process Areas

\begin{tabular}{|l|l|}
\hline $\begin{array}{l}\text { Stronger Perf vs. SEC Relationships } \\
\text { for Defense Projects }\end{array}$ & $\begin{array}{l}\text { Stronger Perf vs. SEC Relationships } \\
\text { for Non-Defense Projects }\end{array}$ \\
\hline - Project Monitoring and Control & - Total SE \\
- Trade Studies & - Early SE \\
- Integrated Product Teams & - Verification \\
& - Project Planning \\
& - Requirements Development and Management \\
& - Product Integration \\
& - Validation \\
& - Configuration Management \\
& - Risk Management \\
\hline
\end{tabular}

\subsection{Conclusions}

Our data shows that non-defense projects deploy less SE than defense projects, yet achieve better performance. We also find that the relationship between SE deployment and project performance for most SE process areas is stronger for non-defense projects than it is for defense projects. Thus, even though the non-defense projects deploy less SE, they gain more benefit from it, contributing to better project performance.

Of particular significance are the SE process areas of Product Architecture, Requirements Development and Management, and Risk Management. These process areas show notably stronger relationships for non-defense projects than for defense projects, as shown in Table 6. Understanding these areas in non-defense projects and adopting methodologies and activities for defense projects could produce significant improvements in the performance of defense-domain projects.

Table 6: Notably Stronger Non-Defense Relationships

\begin{tabular}{|l|c|c|}
\hline Process Area & $\begin{array}{c}\text { Gamma } \\
\text { (Defense) }\end{array}$ & $\begin{array}{c}\text { Gamma } \\
\text { (Non-Defense) }\end{array}$ \\
\hline Product Architecture & 0.38 & 0.54 \\
\hline Requirements Development and Management & 0.46 & 0.60 \\
\hline Risk Management & 0.28 & 0.40 \\
\hline Prior Experience & 0.09 & 0.54 \\
\hline
\end{tabular}

We also note several areas where activities in defense-domain projects show stronger relationships to project performance:

1. Defense projects show a considerably stronger relationship between the performance of Trade Studies and project performance.

2. The performance of defense projects appears to be less affected by project challenge for defense-domain projects than non-defense projects.

Understanding the reasons behind these relationships in the defense domain and adopting them for non-defense projects could produce significant improvements in the performance of non-defense projects. 


\section{Next Steps}

Our data from the 2011 SE Effectiveness Survey identifies a number of SE process areas where SE activities in non-defense projects have impacts on project performance superior to those in defense-domain projects [Elm 2012b]. Likewise, it identifies several areas where SE activities in defense-domain projects have greater impacts on project performance than those in non-defense projects. Our data clearly shows these differences; unfortunately, it cannot explain why these differences exist.

We plan to perform additional research to answer the following questions:

1. What do non-defense projects do that makes their efforts addressing Product Architecture more effective than those of defense-domain projects?

2. What do non-defense projects do that makes their efforts addressing Requirements Development and Management more effective than those of defense-domain projects?

3. What do non-defense projects do that makes their efforts addressing Risk Management more effective than those of defense-domain projects?

4. Why does prior experience in non-defense projects have more impact than for defensedomain projects?

5. What do defense-domain projects do that makes their efforts addressing Trade Studies more effective than those of non-defense projects?

6. What do defense-domain projects do that makes their performance less sensitive to project challenge than that of non-defense projects?

The answers to these questions will enable the transplantation of best practices between the two domains to the benefit of both. 


\section{Appendix A Work Products Used to Assess SE Deployment}

- Alternative solutions

- Baseline archives

- Baseline audit records

- Change control board

- Commitment impacts

- Concept of operations

- Configuration baselines

- Configuration item list

- Cost and schedule baselines

- Customer requirements list

- Derived requirements list

- $\quad$ Earned Value Management System (EVMS) data

- $\quad$ EVMS updates

- $\quad$ EVMS variance thresholds

- Field problem assessments

- Field problem reports

- Integrated master plan

- Integrated master schedule

- Integrated product teams

- Interface control documents

- Interface descriptions

- Peer review plan

- Product architecture

- Product integration process

- Requirements acceptance criteria

- Requirements allocations
- Requirements approval process

- Requirements configuration records

- Requirements impact assessments

- Requirements management system

- Requirements provider criteria

- Review of action items

- Review of issues

- Review of selection criteria

- Review process

- Risk list

- Risk mitigation plans

- Risk mitigation status

- SE master plan

- SE master schedule

- SE processes

- $\quad$ SE tracking records

- Technical approach

- Trade study records

- Use cases

- Validation criteria

- Validation procedures

- Verification criteria

- Verification entry and exit criteria

- Verification procedures

- Work breakdown structure 


\section{Appendix B Acronyms and Abbreviations}

$\begin{array}{ll}\text { EVMS } & \text { Earned Value Management System } \\ \text { EXP } & \text { prior experience } \\ \text { FFRDC } & \text { federally funded research and development center } \\ \text { IEEE } & \text { Institute of Electrical and Electronic Engineers } \\ \text { INCOSE } & \text { International Council on Systems Engineering } \\ \text { NDIA } & \text { National Defense Industrial Association } \\ \text { PC } & \text { project challenge } \\ \text { Perf } & \text { project performance } \\ \text { PerfC } & \text { project cost performance } \\ \text { PerfS } & \text { project schedule performance } \\ \text { PerfT } & \text { project technical performance } \\ \text { SE } & \text { systems engineering } \\ \text { SEC } & \text { systems engineering capability } \\ \text { SEC-ARCH } & \text { Product Architecture systems engineering capability } \\ \text { SEC-CM } & \text { Configuration Management systems engineering capability } \\ \text { SEC-IPT } & \text { Integrated Product Teams systems engineering capability } \\ \text { SEC-PI } & \text { Product Integration systems engineering capability } \\ \text { SEC-PMC } & \text { Project Monitoring and Control systems engineering capability } \\ \text { SEC-PP } & \text { Project Planning systems engineering capability } \\ \text { SEC-REQ } & \text { Requirements Development and Management systems engineering capability } \\ \text { SEC-RSKM } & \text { Risk Management systems engineering capability } \\ \text { SEC-Total } & \text { total systems engineering capability applied to a project } \\ \text { SEC-TRD } & \text { Trade Study systems engineering capability } \\ \text { SEC-VAL } & \text { Validation systems engineering capability } \\ \text { SEC-VER } & \text { Verification systems engineering capability } \\ \text { SEI } & \text { Software Engineering Institute } \\ \text { SPI } & \text { EVMS Schedule Performance Index } \\ & \end{array}$




\section{References}

URLs are valid as of the publication date of this document.

\section{[EIm 2008]}

Elm, J.; Goldenson, D.; El Emam, K.; Donatelli, N.; \& Neisa, A. A Survey of Systems Engineering Effectiveness - Initial Results (CMU/SEI-2008-SR-034). Software Engineering Institute, Carnegie Mellon University, 2008. http://resources.sei.cmu.edu/library/asset-view.cfm?assetid=8493

\section{[Elm 2012a]}

Elm, J. The Business Case for Systems Engineering Study: Assessing Project Performance from Sparse Data (CMU/SEI-2012-SR-010). Software Engineering Institute, Carnegie Mellon University, 2012. http://resources.sei.cmu.edu/library/asset-view.cfm?assetid=34055

\section{[Elm 2012b]}

Elm, J. The Business Case for Systems Engineering Study: Results of the Systems Engineering Effectiveness Survey (CMU/SEI-2012-SR-009). Software Engineering Institute, Carnegie Mellon University, 2012. http://resources.sei.cmu.edu/library/asset-view.cfm?assetid=34061

\section{[EIm 2013]}

Elm, J. \& Goldenson, D. The Business Case for Systems Engineering Study: Detailed Response Data (CMU/SEI-2012-SR-011). Software Engineering Institute, Carnegie Mellon University, 2013. http://resources.sei.cmu.edu/library/asset-view.cfm?assetid=73582

\section{[Kitchens 2002]}

Kitchens, L. J. Basic Statistics and Data Analysis. Cengage Learning, 2002. 


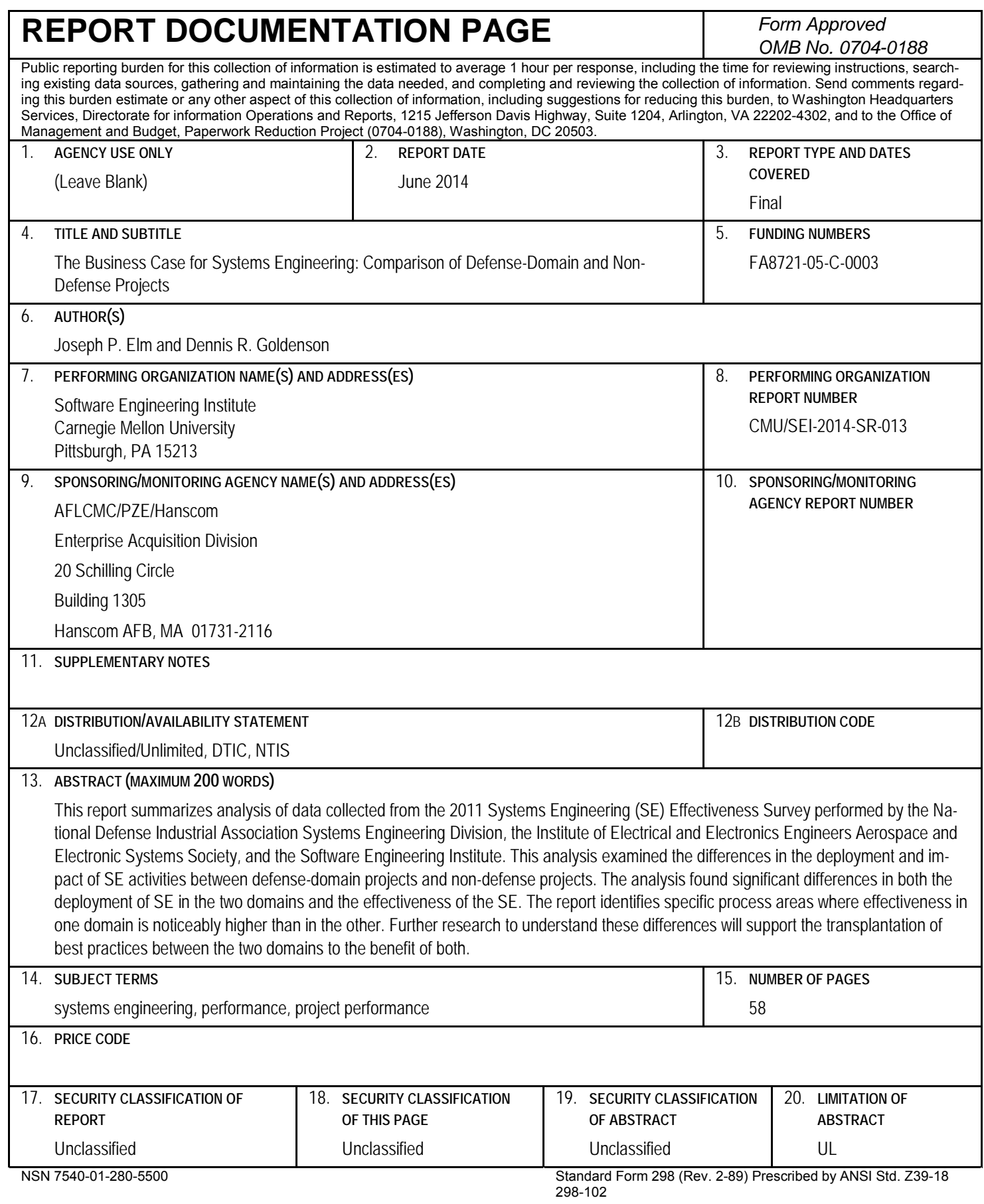

